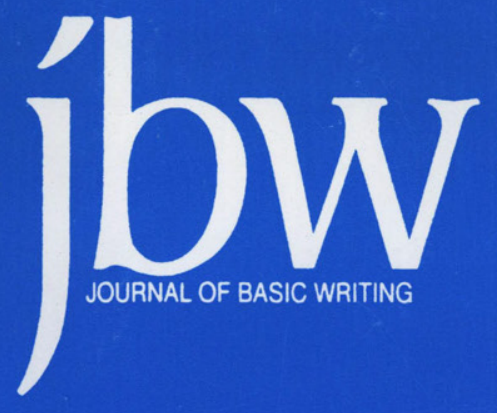

\title{
FALL 2003
}

VOLUME 22 NUMBER 2

Ventriloquism 001:

How to Throw Your Voice in the Academy

Hannah Ashley and Katy Lynn

Belief Spaces and the Resistant Writer: Queer Space in the Contact Zone Thomas Peele and Mary Ellen Ryder

Student Reflection and Critical Thinking: A Rhetorical Analysis of 88 Portfolio Cover Letters Laurel L. Bower

Basic Writing and Second Language Writers:

Toward an Inclusive Definition

Paul Kei Matsuda

Integrating Reading and Writing: A Response to the Basic Writing "Crisis" Sugie Goen and Helen Gillotte-Tropp 



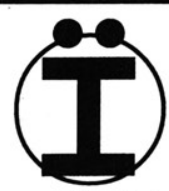

The paper used in this publication

meets the minimum requirements of the

American National Standard for Information Science -

Permanence of Paper for Printed Library Materials, ANSI Z39.48-1984.

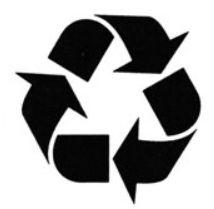

The text stock is also recycled.

\section{This publication is} available in microform from UMI.

Please send me information about the titles I've listed below:

Name

Title

Company/Institution

Address

City/State/Zip

Phone

\section{U.M.I}

A Bel I \& Howell Company 300 North Zeeb Road, Ann Arbor, M 48106 USA 800-521-0600 toll-free

313-761-4700 collect from Alaska and Michigan 800-343-5299 toll-free from Canada 



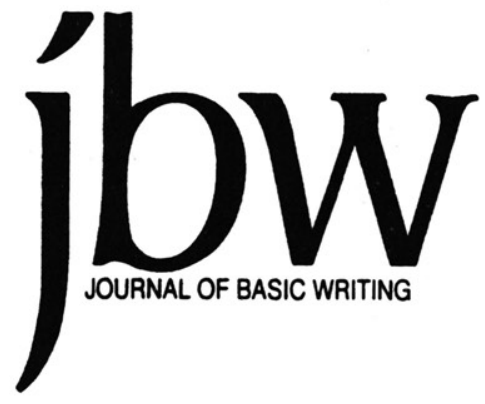

VOLUME 22 NUMBER 2

FALL 2003

The Journal of Basic Writing publishes articles of theory, research, and teaching practices related to basic writing. Articles are refereed by members of the Editorial Board (see overleaf) and the Editors.

\title{
Rebecca Mlynarczyk and Bonne August Editors \\ Johannah Rodgers and Karen Weingarten Editorial Assistants
}

The Journal of Basic Writing is published twice a year, in the spring and fall with support from the City University of New York, Office of Academic Affairs. We welcome unsolicited manuscripts and ask authors to consult the detailed "Call for Articles" in this issue. Subscriptions for individuals are $\$ 15.00$ for one year and $\$ 28.00$ for two years; subscriptions for institutions are $\$ 20.00$ for one year and $\$ 38.00$ for two years. Foreign postage is $\$ 10.00$ extra per year. For subscription inquiries or updates, contact:

\author{
Journal of Basic Writing \\ Boyd Printing Company, Inc. \\ Attn. Cathie Ryan \\ 49 Sheridan Ave. \\ Albany, NY 12210 \\ (800) $877-2693$ \\ (518) 436-9686 \\ www.boydprinting.com
}




\title{
JOURNAL OF BASIC WRITING
}

\author{
EDITORIAL BOARD
}

Linda Adler-Kassner

Eastern Michigan University

Chris M. Anson

North Carolina State University

David Bartholomae

University of Pittsburgh

Sarah Benesch

College of Staten Island, CUNY

Patricia Bizzell

College of the Holy Cross

Lynn Z. Bloom

University of Connecticut, Storrs

Gay Brookes

Borough of Manhattan Community

College, CUNY

Richard Courage

Westchester Community College, SUNY

Martha Clark Cummings

University of Aizu, Japan

Donald A. Daiker

Miami University

Suellynn Duffey

Georgia Southern University

Sarah Warshauer Freedman

University of California, Berkeley

Keith Gilyard

Pennsylvania State University

Gregory Glau

Arizona State University

Laura Gray-Rosendale

Northern Arizona University

Karen L. Greenberg

Hunter College, CUNY

Brenda M. Greene

Medgar Evers College, CUNY

Myra Kogen

Brooklyn College, CUNY

Patricia O. Laurence

City College, CUNY
Andrea A. Lunsford

Stanford University

Jane Maher

Nassau Community College, SUNY

Susan Miller

University of Utah

Sandra Murphy

University of California, Davis

Deborah Mutnick

Long Island University

Nathaniel Norment, Jr.

Temple University

\section{George Otte}

Graduate Center, CUNY

Hope Parisi

Kingsborough Community College, CUNY

Elizabeth Rorschach

City College, CUNY

Charles I. Schuster

University of Wisconsin, Milwaukee

Tony Silva

Purdue University

Trudy Smoke

Hunter College, CUNY

Ruth Spack

Bentley College

Lynn Quitman Troyka

Queensborough Community

College, CUNY, ret.

Karen S. Uehling

Boise State University

Evelyn E. Webb

Mississippi State Board for

Community and Junior Colleges

Harvey S. Wiener

Laguardia Community College,

Emeritus

Vivian Zamel

University of Massachusetts,

Boston 


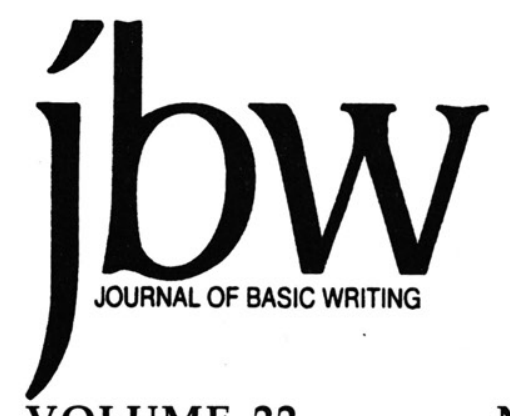

Ventriloquism 001:

How to Throw Your Voice in the Academy

Hannah Ashley and Katy Lynn

Belief Spaces and the Resistant Writer:

Queer Space in the Contact Zone

Thomas Peele and Mary Ellen Ryder

Student Reflection and Critical Thinking:

A Rhetorical Analysis of 88 Portfolio Cover Letters

Laurel L. Bower

Basic Writing and Second Language Writers:

Toward an Inclusive Definition

Paul Kei Matsuda

Integrating Reading and Writing:

A Response to the Basic Writing "Crisis"

Sugie Goen and Helen Gillotte-Tropp 


\section{CALL FOR ARTICLES}

We welcome manuscripts of 15-25 pages, double spaced, on topics related to basic and ESL writing, broadly interpreted. Submissions should follow current MLA guidelines. Manuscripts are refereed anonymously. To assure impartial review, include name(s), affiliation(s), mailing and e-mail addresses, and a short biographical note for publication on the cover page only. The second page should include the title but no author identification, an abstract of about 150 words, and a list of 4-5 key words. Endnotes should be kept to a minimum. It is the author's responsibility to obtain permission for including excerpts from student writing.

We prefer that contributions be submitted as Word document attachments via e-mail to: baugust@kbcc.cuny.edu. If electronic submission is not possible, mail five copies of the manuscript and abstract to:

\section{Professors Bonne August and Rebecca Mlynarczyk \\ Co-Editors, JBW \\ Department of English \\ Kingsborough Community College, CUNY \\ 2001 Oriental Blvd.}

Brooklyn, NY 11235

You will receive a confirmation of receipt; a report on the status of your submission will follow in about sixteen weeks.

All manuscripts must focus clearly on basic writing and must add substantively to the existing literature. We seek manuscripts that are original, stimulating, wellgrounded in theory, and clearly related to practice. Work that reiterates what is known or work previously published will not be considered.

We invite authors to write about such matters as classroom practices in relation to basic-writing or second-language theory; cognitive and rhetorical theories and their relation to basic writing; social, psychological, and cultural implications of literacy; discourse theory; grammar, spelling, and error analysis; linguistics; computers and new technologies in basic writing; assessment and evaluation; writing center practices; teaching logs and the development of new methodologies; and cross-disciplinary studies combining basic writing with psychology, anthropology, journalism, and art. We publish observational studies as well as theoretical discussions on relationships between basic writing and reading, or the study of literature, or speech, or listening. The term "basic writer" is used with wide diversity today, sometimes referring to a student from a highly oral tradition with little experience in writing academic discourse, and sometimes referring to a student whose academic writing is fluent but otherwise deficient. To help readers, therefore, authors should describe clearly the student population which they are discussing.

We particularly encourage a variety of manuscripts: speculative discussions which venture fresh interpretations; essays which draw heavily on student writing as supportive evidence for new observations; research reports, written in non-technical language, which offer observations previously unknown or unsubstantiated; and collaborative writings which provocatively debate more than one side of a central controversy. 


\section{EDITORS' COLUMN}

We are pleased with the ways in which the contributions to this issue describe fruitful applications of theory in the classroom and also consider the big picture - where the field of basic writing is at present and where it may be headed in the years to come. Several articles draw attention to the importance for students of effectively integrating a variety of "voices" in their essays. As basic writing teachers, we need to help students learn to include the ideas of others in ways that "dialogue with" and support their own views. Whether these outside perspectives originate in the larger community via service learning projects, in primary source documents such as position papers or song lyrics, or in traditional college reading assignments, the ability to orchestrate multiple voices is crucial to success in college writing. Helping basic writers to develop an awareness of and facility with the integration of different voices is extremely challenging and indirectly implies the responsibility to teach reading as well as writing, thus making our work in the BW classroom broader and more complex than it has often been viewed in the past. The final two articles point out the need for improved and expanded teacher education to help basic writing instructors deal with the new challenges they face.

The first three articles remind us of the great value of looking closely and critically at actual student writing. Using a variety of theoretical and rhetorical lenses, the authors of these articles provide fresh and intriguing perspectives on the discursive moves students need in order to succeed as college writers, suggest productive ways of responding to student texts, and question the rhetorical and cognitive processes revealed in the supposedly reflective documents known as portfolio cover letters.

In "Ventriloquism 001: How to Throw Your Voice in the Academy," Hannah Ashley and Katy Lynn apply Bakhtinian voicing theory to the analysis of student writing. The authors suggest that the manipulation of reported discourse is at the heart of successful academic writing, and they offer a taxonomy for analyzing the different voices that students invoke in their essays. Both this article and the one that follows describe practical classroom techniques for teaching students to use complex theoretical concepts in considering effective ways to revise their own writing and that of their peers.

"Belief Spaces and the Resistant Writer: Queer Space in the Contact Zone" resonates in fascinating ways with the previous article. Thomas Peele and Mary Ellen Ryder use the concept of belief spaces, adapted from the work of Gilles Fauconnier, as a way of hearing the various voices in student work. They illustrate their approach by looking at two essays written in response to a "contact zone" assignment 
that asked students to select and analyze a document for areas of cultural conflict. One of the students chose to analyze a song by the rap star Eminem. The resulting essay not only has homophobic overtones but, more to the point, ambiguous belief spaces. As editors, we realize that the rap lyrics quoted by this student may be shocking and offensive to some readers. Nevertheless, after consulting with several members of our Editorial Board, we decided that it was essential to quote freely from the student's essay and to include both drafts of his paper in the Appendix. The authors make it clear that they do not condone this student's implied meaning, but they explain how the belief spaces concept provided a way to talk with the student about revising his paper without silencing the expression of views with which the instructor disagreed.

In "Student Reflection and Critical Thinking: A Rhetorical Analysis of 88 Portfolio Cover Letters," Laurel Bower problematizes the issues raised by this relatively new genre of student writing. Surprisingly few of the cover letters she examined in her study showed evidence of genuine reflection about the student's writing process. She suggests that possible reasons for this may include the audience (usually the teacher), the length (in most cases, one page), and the point in time (the end of the semester, when students are busy with exams and projects for other courses). She concludes by recommending ways that teachers could actively encourage students to develop their metacognitive abilities through assignments that would lead to real reflection.

"Basic Writing and Second Language Writers: Toward an Inclusive Definition" by Paul Kei Matsuda is a historical account of the relationship between the fields of basic writing and English as a Second Language, often reflected in the pages of this journal. Matsuda suggests that because of demographic and institutional factors, the two fields frequently overlap, and non-native speakers of English are often enrolled in basic writing courses. This is particularly true for the growing number of so-called Generation 1.5 students, who were born in non-English-speaking countries but received at least part of their high school education in the United States. Matsuda argues for improved programs and teacher preparation so that basic writing instructors can better serve all the students enrolled in their courses, including the growing number of second-language writers.

"Integrating Reading and Writing: A Response to the Basic Writing 'Crisis'" by Sugie Goen and Helen Gillotte-Tropp illustrates how challenges sometimes become opportunities. Faced with an administrative mandate that students who did not complete remediation within one year would be "disenrolled," a team of faculty members at San Francisco State University developed a new fully integrated reading/ writing program in which students could complete remedial require- 
ments as well as first-year written composition within their first year of study. While this program is still in its early stages and the evaluation of its effectiveness continues, the initial results are extremely promising. Moreover, the collaborative process of curriculum development and pedagogical transformation described in the article provides a worthy model for others to emulate. As the journal was going to press, we learned that the Conference on Basic Writing has selected the SFSU program to share its 2004 Award for Innovation.

With this issue, we say farewell and thanks to three people who have served JBW well. Mary Carney, the journal's subscriptions manager for many years, has decided to step down. In the future, subscriptions will be handled by our publisher, Boyd Printing in Albany, NY. Our former editorial assistants, Mikhail Gershovich and Rhona Cohen, have accepted exciting new positions within the City University of New York. We welcome with pleasure their replacements, Johannah Rodgers and Karen Weingarten, both CUNY Ph.D. candidates in English.

Finally, we note with sadness the death of Marilyn S. Sternglass, professor emerita of English at City College of New York, CUNY. Many in the field of basic writing have benefited from Sternglass's work as a scholar and teacher. Her most recent book, Time to Know Them: A Longitudinal Study of Writing and Learning at the College Level, documents the struggles and ultimate success of a group of open-admissions students at City College who were followed during the six years of their studies. The book, which was the 1998 co-winner of the Mina Shaughnessy Prize of the Modern Language Association and won the 1999 Conference on College Composition and Communication Outstanding Book Award, argues powerfully that, given enough time, students who are initially placed in developmental courses can succeed.

- Rebecca Mlynarczyk and Bonne August 


\title{
Hannah Ashley and Katy Lynn
}

\section{Ventriloquism 001: How to Throw Your Voice in the Academy}

\begin{abstract}
This article sketches an operationalization of Bakhtinian voicing theory - a practical method of reading that we call "hearing voices." It also connects this method to service learning and other pedagogies that invite "private" voices into the classroom. Reported discourse is at the center of the technique, and we suggest that its significance relates to the types of speakers students are allowed to report and what they are reported as saying. Therefore, a taxonomy for categorizing reported discourse is offered-popular, scholarly and private reported voices. A reading of one student paper is presented, where focusing on reported discourse allows $u s$ to hear the different discourses around racism which emerge and the ways that the student gives voice to them and to herself in relation to them. We conclude by suggesting further ways to integrate "hearing voices" into the basic writing classroom.
\end{abstract}

\section{HEARING VOICES - A THEORETICAL OVERVIEW}

\section{Reading Basic Writers and Writing}

One way to describe basic writing is as a site of multiple pulls in seemingly opposite directions. It is, of course, a site of writing. Writing implies a reader, or at least an audience. Who is the reader in a basic writing classroom? In the most conventional of classrooms, the reader is the professor, and the professor represents the academy. She is the gatekeeper (or in some cases she is at least entrusted with the keys to a standardized test gate), and students must acquire enough convention to be read as "in" (or perform enough convention to be read as "bought in") to the academy. Even in less conventional classrooms, where workshopping, peer review, or outside publication is central, ultimately, the professor almost always holds the gate key of

Hannah Ashley is an assistant professor and currently serves as the Director of Basic Writing at West Chester University. She has published in Research in the Teaching of English, Reflections on Community-Based Writing Instruction and Pedagogy, and is the co-author of Eight Bullets: One Woman's Story of Surviving Anti-Gay Violence. She has ongoing scholarly interests in connections among class, race, and discourse; service learning; critical pedagogy; critical discourse analysis and Bakhtinian theory. Katy Lynn received her Master's in English from West Chester University in May 2003 and is currently an adjunct scholar at large in the greater Philadelphia area. She is teaching a diverse range of writing subjects, but her main interest remains basic writing and basic writers. This is her first major publication. 
the grade students must get to pass the course. So basic writing is a site of writing/being read in order to gain access to the academy.

But basic writing is also a site of writing/reading. Students in this formulation write in order to read. By definition, basic writing students' primary discourses are on the borders of the academy. Therefore, the views from within these discourses are sites from which to read academic and disciplinary conventions critically. As Gee notes, to critique a discursive convention is to critique the worldview which attends that convention. Basic writing can be conceived as a valuable location of critique, where the readers are the students, and what is read are the cultural texts of the university and the disciplines themselves.

We are not arguing here that instructors must choose either/or: what is read (student writing or the university and its disciplines), who reads (professors or students), and what the function of a basic writing course is (to provide access or to produce critique). In fact, we would argue that each of these dual pulls is vital to basic writers and writing. The trick is how, on the ground, to do both. Bakhtinian voicing theory, operationalized through an awareness and analysis of reported discourse, has the potential to enhance basic writing classrooms as sites for both access and critique. Reported discourse - the very mundane yet central conventions of quotation, citation, and paraphrase-helps to provide basic writing students with further access to the academy, but it can also be used by students in critical, resistant ways, to speak back to the academy, as we will demonstrate below.

Reported discourse is the nucleus of many of Pratt's literate arts of the contact zone - critique, parody, denunciation, vernacular expression, imaginary dialogue. Pratt describes the contact zone as a site of contested but unequal power relations and representations of self and other. These literate arts allow the less-empowered to re-present themselves, by appropriating and transforming the discourses of (the) power(ful). In a basic writing classroom, a further expansion of the uses of reported discourse is through the addition of private voices, not just scholarly ones, to those students can bring into play in their papers. Service learning is one way to bring focused, critical attention to private experiences. By service learning, we mean pedagogies which engage students in working with local community members and/or organizations in order to meet real community needs. Whether or not the community engagement projects themselves include writing, a crucial part of them - if they are to be effective as learning - is reflection, often in the form of writing. Students get to reflect on themselves, those they worked with, and they get to re-present those representations of self and other back to the gatekeepers in the academic context they are attempting to enter. 


\section{Voice and Voicing, Serving and Learning}

As teachers of composition and rhetoric, we are keenly aware that many of our actual practices on the ground do not match the theories that we bat around at conferences and in carpools. In particular, elegant ideas concerning discourse as performance, voice as multiple, and identity as shifting and conflicted are revolutionary, fascinating, valuable, and very difficult to integrate smoothly with the parts of our syllabi that we hope will help students to be read as "in."

It is easy to fall back on more comfortable conceptions of voice. In these conceptions, voice is a noun: writers have the power to position themselves, but they can only position themselves through one rhetorical voice at a time. Yes, writers can choose among many discourses, but they must choose, and the discourse basic writers need to be seen as allied with is that of the academy. Students must assimilate, at least on paper. If we believe these ideas, then with the best pedagogical intentions, we easily slip into planning an assimilationist basic writing course, or more subtly, executing assimilationist assignments, activities, conferences, written feedback, or grading rubrics.

A Bakhtinian framework helps to work against assimilationist tendencies by reconceiving voice as a verb. One does not "have" a "voice" - one voices, one is voicing. In this model, writers are authors with skilled awareness of heteroglossia. Heteroglossia is the perpetual state of language tension in which any utterance is suspended and to which every utterance contributes.

Philosophy of language, linguistics and stylistics... have all postulated a simple and unmediated relation of speaker to his unitary and singular "own" language, and have postulated as well a simple realization of this language in the monologic utterance of the individual. Such disciplines actually know only two poles in the life of language...: on the one hand, the system of a unitary language, and on the other the individual speaking in this language... [However] a unitary language is not something given but is always in essence posited - and at every moment of its linguistic life it is opposed to the realities of heteroglossia. (Bakhtin 269-70)

Bakhtin asserts that writers do not have to choose discourses. In fact, to do so is not really possible, in a Bakhtinian framework: heteroglossia means every utterance of every individual is a site of tension and dialogue, not stasis and closure. Every utterance represents multiple discourses operating. Writers do not have a powerful voice, they have the power to voice-to position themselves multiply 
through actively putting various discourses into play, to orchestrate multiple voices. If it is possible to see basic writers as always voicing, then basic writing is not a site of assimilation. It is not a site of identity loss, but identity negotiation, not discourse choosing, but discourse testing, and not the emergence of authentic voice but performance of multiple voices (Parks and Goldblatt; Lea and Street). The challenges are to apply this insight practically and to view basic writers as skilled enough to use all the linguistic resources at their disposal to those ends.

Bakhtin ${ }^{1}$ points the way toward negotiation, testing and performance of voices with his emphasis on reported discourse.

Heteroglossia...is another's speech in another's language, serving to express authorial intentions but in a refracted way. Such speech constitutes a special type of double-voiced discourse. It serves two speakers at the same time and expresses simultaneously two different intentions: the direct intention of the character who is speaking, and the refracted intention of the author...all the while these two voices are dialogically interrelated, they - as it were - know about each other... (324, emphasis added)

Reported discourse is the dressed-up term for the more pedestrian conventions of quotation, citation, and paraphrase. Bringing in "another's speech" / an Other's language allows the author to bring diverse discourses into contact by orchestrating various speakers giving voice to a range of utterances. These acts of reporting are doublevoiced because as writers - students, for example - play their own intentions off of another's, they must be in dialogue with that Other. There is no monologue, no simple expression of authentic, inner truths, when reported discourse is a central convention of a genre, as it is in the university.

In fact, one of the authors, Ashley, conducted a critical discourse analysis (CDA) in a university setting which suggested that reported discourse was the central convention of successful student writing in that context - that is, writing that yielded positive evaluations and good grades from instructors; in short, writing that provided access. It would be easy to take quotation, citation, and paraphrase as a matter of course in academic writing; it is so ubiquitous as to seem intrinsic. However, CDA takes as a central theoretical proposition that

a particular set of discourse practices and conventions may achieve a high degree of naturalization - they may come to be seen as simply "there" in a common-sense way, rather than socially put there. This is a measure of the extent to which 
powerful social forces and groups dominate a society or a particular institution. (Fairclough 9)

CDA's orientation of suspicion toward naturalized textual features helped Ashley to re-view reported discourse and attempt to explain the material and ideological effects of this particular textual convention.

It might also be easy to dismiss reported discourse as not useful in fostering positive resistance in students (Shor). When students are asked to respond to an author, and they use reported discourse to present their response, aren't they simply parroting, assimilating by impersonating the scholar they have read? How is dialogue or critique possible when basic writing students are often in the position of needing to mirror the ideas and language of academics? The home discourses of basic writing students may be eclipsed by the requisite summary or citation of "the reading." In actuality, every act of reporting another's utterance means changing that utterance. Even a complete recapitulation of something that was said-say, a newspaper reprinting the State of the Union address - shifts the meaning of that utterance because the context is new. A student purchasing a paper off an Internet service and turning it in shifts the meaning of that paper; the plagiarism makes the paper a parody, in addition to a representation of the ideas and ethos in the paper as originally written. These acute examples make the point that the more typical, incomplete acts of reporting that we see in academe - the excerpts, quotes, paraphrases, summaries, and citations that make up a great deal of academic discourse - these too, must be double-voiced. The intentions of the author are, as Bakhtin puts it, "refracted" through these instances of reported discourse, and simultaneously, the author must in some way be aware of the intentions of those reported. Both discourses are changed: the reported discourse and the "reporting context" (the student writer's discourse). As a result, discourses - and the "big D Discourses" which they are a part of (Gee) - have the opportunity to be tested against one another. Through reported discourse, writers, including basic writers, can give voice to a discourse without assimilating into it. This is the radical power of reported discourse. The examples we present below demonstrate some of this discourse testing.

While reported discourse can be used as a tool for testing discourses-literally or figuratively creating dialogues among speakers voicing various discourses and releasing them to critique each otherit is exactly this testing potential that also makes it key to the more conventional goal of basic writing, access. It is helpful to note that a focus on reported discourse operationalizes Bartholomae's insight that "the university... is the place where 'common' wisdom is only of negative values - it is something to work against" (156). Students can be 
seen capitalizing on this university value system quite concretely with generic opening lines of essays: "Many people think..." "Society believes..." These awkward introductory lines can be read as literally reporting the discourse of "people," "society." Successful students make the move that Bartholomae has spotlighted as valuable: they deride this popular discourse in favor of a more sophisticated, complex, disciplinary or at least sideways view of the issue. As students progress through the university, these ostensibly more intricate views are voiced through speakers inside particular disciplines, e.g., "Freud claims..." (Walvoord and McCarthy).

Students make their access-building alliances clear through the use of embedding phrases:

- Freud writes, ". . ."

- .... (Freud).

- What Freud is saying is. .

Students - as do we as academics, so much so that we take it for granted-embed ideas of authorities and experts in their own papers through the devices of quotation, citation, and paraphrase, and in so doing, ally themselves against lay ideas and with insiders, professionals, scholars. But even at the outset of their university careers, before choosing majors, even in basic writing classes, successful students position themselves as "in" by deriding the popular and allying themselves with the not-popular, which is often understood in the academy to be the province of the academic.

Thus, through reported discourse, students both perform alliance with scholarly discourses/worldviews and also engage in critical dialogue with those discourses/worldviews. One way to broaden the discourses available for reporting in the academy is service learning. Service learning adds private discourses to academic/disciplinary ones as an option against which to test the popular commonsense. When students are asked to take on vital tasks in the community and to reflect legitimately on those activities, the door to multiple discourse-testing is opened, rather than an austere, not-this-(commonsense)-but-that(academic sense) type of testing. This opportunity for multiplicity is particularly important for basic writers, who need to demonstrate access-gaining rhetorical moves but are often so far distant from academic/disciplinary discourses as to find them largely inaccessible, and 
possibly not very reflective of their worldviews nor useful in describing their experiences.

\section{Hearing Private Voices}

Concretely, private discourses are utterances voiced through speakers known intimately or at least personally by the author: "my uncle," "my neighbor," "the kids I worked with at the shelter," "my project partner," even "I" (the student author him/herself). Students bring in private discourses through detailed reporting of what occurred during their service encounters, including the things they themselves said, thought and did. This rich data collection provides students with additional "characters" to invoke (with their attendant discourses) in order to address the topics of their papers, voices other than the scholarly insiders they have read in the course. They can make the Bartholomae-access move of knocking down a popular commonsense, but the innovative view on the topic may not emerge from the academy. It may emerge in whole or part from a private/community discourse. Local/community/private discourses have standpoints to speak about the topic at hand that are often different from the mainstream discourse, as well as different from the leading scholarly discourse.

Another qualification is in order here. We are not claiming that service learning is the only way that students can effect both access and critique. Other pedagogies, such as those that emphasize narrative, memoir, ethnography, or cultural studies, can also open the door to discourse testing while not neglecting access-providing moves. For instance, the following example emerges from a course entitled "Investigating Experience," a general education course designed to follow the first-year composition course at our university and teach research writing skills while integrating memoir, interview, and observation into students' papers. One white woman in the course wrote her final paper about her own continued coping with anorexia. Her skilful paper included memoir, interview, and significant library research on the topic. Her draft was workshopped in class. After the paper was read aloud, there was a great deal of praise, yet several students asked questions such as "Why would it make you feel bad if your mother told you you had cellulite on your legs? Maybe she was just stating a fact." "How many calories is 1,000 ? Is that a lot or a little or what?" "What was so important about being a size zero? I just don't get it at all how you could starve yourself like that." Students may sound insensitive here, but in fact, Ashley, who was the course professor, noticed a pattern to the questions - or rather, the questioners. The women (the class was over three-quarters female) who "just 
didn't get it" all self-identified as African-American or Latina, while it was the white women (and men) who took for granted that the writer wanted to be tiny, that she knew how to track the number of calories she consumed, and that she had a mother who was critical of her weight.

The discourse of "fat as undesirable" played out as a white discourse in this class. The students of color brought their private community discourses into contact with that commonsense and called it into question. Ashley was able to point out the racial/ethnic divide in the understanding of weight and what it means by immediately "reporting" back to the students the dialogue as it had occurred moments before, but she overtly raced the speakers. One Latina student said, "Yeah, that is true, because I noticed that white guys want you to be small, and Latino guys want you to have a little butt but be big up top, and black guys like girls to be big all over." This set off a round of affirmative chattering. While reductive, the student's affirmation from her private experience still pushed the discussion further forward. Ashley asked the student whose paper was being workshopped whether the scholarship she used had labeled eating disorders as a race-based phenomenon. She replied that they had not, and said that she would be interested in returning to the literature to check into that idea.

Two types of discourse-testing occurred in this instance. It was an example of how bringing private discourses into the academic examination of a topic can help to push against a popular "universal" commonsense-in fact, relabeling that popular notion as a private and partial one, one attached to a (white) community, rather than a generic - "truth." Private discourses of the women of color in the class also pushed against the scholarly discourses brought in by the secondary research in the student paper, persuading the author to expand her investigation.

Practices that bring in the "I," like memoir and service learning, provide students with an opportunity to see how their own private/ community discourses are part of a particular set of popular/ commonsense notions which get called into question when they butt up against a different community discourse. This is why "private" is used throughout this article, rather than "personal." The label "personal" grants experiences asylum from critique - personal experiences are unique, individual, apolitical, one's "own." "Private" reminds us that perceptions, preferences, desires, even bodily sensations are not simply our own, but are shaped and constructed socially, in discourse (Bourdieu). If experiences are private, not personal, then the " $\mathrm{I}$ " that has them is also shaped in discourse. Instructors bearing this in mind can help students see themselves as Bakhtinian narrators with private positions, rather than Enlightenment authors with personal views.

By noticing and sometimes pointing out what students voice their 
"I" as saying, teachers can help students become narrator-characters in their own stories. Rather than needing to assume the distanced and neutral voice of a third-person author, they can reflect on their own discourses by treating their "I" as a speaker of reported discourses, too. Bakhtin suggests that just the existence of a narrator ups the heteroglossic ante:

All forms involving a narrator or a posited author signify to one degree or another by their presence the author's freedom from a unitary and singular language, a freedom connected with the relativity of literary and language systems; such forms open up the possibility of never having to define oneself in language; the possibility of translating one's own intentions from one linguistic system to another, of fusing "the language of truth" with "the language of the everyday," of saying "I am $\mathrm{me}^{\prime \prime}$ in someone else's language, and in my own language, "I am other." (314-15)

Where there is no completely removed, third-person author, all averrals take on the status of radical uncertainty. Caldas-Coulthard defines an averral as an assertion about a particular state of affairs in the world, and Tadros writes that "a basic assumption is that the writer avers the opinions and ideas of the text so long as $\mathrm{s} /$ he does not specifically detach him/herself from the embedded propositions expressed" (74). A narrator may provide detachment. Rather than a particular discourse taking on the status of truth, a narrator-author may begin to observe herself voicing a discourse, performing an identity to which she is not wedded. She may begin to hear herself as a distinctive echo and amalgam of previous voices, rather than expressing a single "real me."

Uniqueness and authenticity are not eliminated in a Bakhtinian framework; what is unique in a subject is that a particular set of discourses meet and find expression. A Bakhtinian narrator in academic writing does not have to be unified, unconflicted, and singular but instead can be "interanimated" with and by other voices. In fact,

The verbal dominant may shift to the reported speech....the reported speech begins to resolve, as it were, the reporting context, instead of the other way around. The authorial context loses the greater objectivity it normally commands in comparison with reported speech. It begins to perceive itself-and even recognizes itself - as subjective, "other person's speech." (Voloshinov 121)

Voices overlap, interrupt, double, and masquerade as each other in dialogue, never quite complete or finished, portraying worldviews that 
are never total because they are constantly interrupted by "another's language" and "another's voice." For this interruption to occur, there must be a rich well of diverse utterances from which to draw to discuss the topic at hand. It is therefore important that the practices that bring in the "I" - e.g., service learning-be integral to and integrated with the course work in some way, rather than a quick add-on, and that students have opportunities to gather rich linguistic/discursive "data" from their experiences and bring those data into their writing for the course.

\section{HEARING LINDSAY THROW HER VOICE(S)}

\section{Course Context}

The public university where we were teaching operates an Academic Development Program, through which students who would not normally be admitted to the university based on their SATs and grades are provisionally admitted; they are required to attend a six-week summer "academic boot camp," as many of them refer to it, and are provided with additional academic and social support throughout their first year. All of them take the university's basic writing course, either in the summer or the fall, and then they progress to the first-year composition course. Typically these courses are not different from mainstream developmental or first-year writing courses, except that they are usually slightly smaller and students are required to meet with a tutor on a weekly basis for additional support. Tutors and professors tend to have highly collaborative relationships, meeting throughout the semester to discuss student progress and issues.

At the point that the final paper which we examine in this section was written, Ashley and Lynn had been working together for two semesters, summer and fall, Ashley as the professor and Lynn as course tutor. Lindsay, who asked us to use her real name for this article, had been with another professor/tutor pair in the summer for her basic writing course, so we met Lindsay in the fall. Part of the Academic Development Program summer session includes collaborative work among all of the tutors, which includes math, speech, and reading as well as English. This was done both in the formal setting of weekly meetings held for the group of tutors and informal meetings between individual tutors. In this way the needs and concerns of students who were particularly resistant were discussed in terms of how to improve tutoring methods. During a number of these informal discussions throughout the summer session, Lindsay's summer English tutor spoke with Lynn regarding her concerns about Lindsay's passivity towards 
learning and her reluctance to explore new concepts. Lynn continued to work with Lindsay's summer tutor during the fall semester, so the dialogue was able to continue in a way that was beneficial to both Lynn and Lindsay in regard to addressing her resistance. Although Lynn did work closely with other students as part of the Academic Development Program, the opportunity to gain another's perspective on Lindsay and to closely observe her growth as a writer and a student over this period was in some ways unique due to the close interaction of the tutors involved with her in the sequenced courses.

In the fall semester, Ashley's first-year composition course design emphasized the use of voicing as a way to support a central claim. For example, the first paper asked students to interview one other student in the class about that student's experiences on September 11, 2001 (a project modeled after oral history example essays), and to write the narrative in a way that also supported a claim. Many students at first struggled with and then reveled in adopting the voice of their interviewee. However, some class discussions focused on questions about voicing such as, "What if my interviewee has views I don't share?" or "What if my interviewee cursed a lot?" This challenging assignment provided practice in the use of a voice other than one's own to support a thesis, growing a thesis "from the bottom up," and utilizing another's private voice as expert to describe and analyze a familiar situation. The second paper was a more traditional analysis of effective rhetorical strategies, but the reading assignments were bell hooks's "Killing Rage" and Gloria Steinem's "Ruth's Song," both strongly "personal" essays which explicitly recognize their public elements (i.e., racism and sexism, respectively).

The third and final major paper gave students the option to complete and write about a "community engagement project." Ashley prefers the term "community engagement" over "service learning." "Service" connotes a one-way, somewhat paternalistic charitable act, with the only benefit to students being a "learning experience." "Community engagement" conveys more of a two-way engagement in a shared community. However, we should note that many students were already familiar with service learning and used that term in reference to their projects. Students who took this option (many did) were encouraged to work in pairs and to write their final papers in pairs. Before, during, and after the project, they wrote guided journal entries, individually, which were focused on "re-viewing" their "selves" through the eyes of the community members, as well as re-viewing community members' actions and words. For example, the journaling prompt before students began asked questions like, "Am I eager or reluctant to begin this project, and why?" "What do I expect will happen or what do I hope to get out of it?" "What will I do if...?" "What images do I already have about...?" The three journal entries during the project 
asked students to "recount the experiences in your journal, so that a reader might experience the moment as intensely as you did. Sketch details, sensory impressions, emotional associations, and social allegiances that these moments contained for you." It also asked them to do "reflective and reflexive writing" after each "recounting." The three prompts for each successive entry were, "How do I perceive my self in this situation?" "How does this self perceive others who are involved in this situation?" "How do others who are involved in this situation perceive me?" Students followed these prompts and used them to reflect to quite varying degrees, but all of the students began to structure their reflections toward greater reflexivity.

The syllabus described this assignment as an opportunity to "create a focused essay with an explicit argument which uses scrutinized private experience as a central part of its evidence and argument." For many of the students, this was their first opportunity for self-examination in the context of a larger society, a task that often proved daunting at first. Many of the students' initial entries spoke of other people's actions in great detail, but when asked if those same people were reacting to something the student herself was doing, the question became harder to answer. One student, an African-American male, was having trouble fitting into the group where he was volunteering. When Lynn asked him what he thought the difficulty was, he immediately stated that the staff was racist. Lynn then asked him to examine his own behavior while volunteering. This was prompted by the fact that he had a history of skipping or showing up late to tutoring sessions. Although he was always perfectly friendly and even charismatic, he was also more often than not unprepared to do the work in the tutoring session and had little work prepared before the sessions began. Based on this history, Lynn was interested to know if he extended that behavior to his volunteer group and if the behavior might be part of the reason the staff was reacting in a negative way. This possibility had apparently never occurred to this student, and upon reflection he came to the conclusion that, although racism might be part of the problem, his tendency to show up late and need supervision to engage in tasks assigned to him might have an impact on people's reaction to him. This is one example of the ways in which the journal entries allowed the students to begin to see how their actions influenced the world around them and how their own private experiences had an impact on both the people around them and their interpretation of the experience they were having. 


\section{Voicing in Lindsay's Paper}

Below, we examine the use of voicing in Lindsay's paper. As noted above, Lindsay was a student with whom Lynn worked particularly closely over the course of the term. The topic which her paper addresses centrally and on which we focus our analysis is voicing around race and racism. (For clarity, in the examples of reported discourse below, embedding phrases will be in bold and the content of the averrals made will be underlined.)

When we first met Lindsay, she seemed somewhat complacent with her level of writing and academic ability and resistant to change. At one point she expressed directly to Lynn that she was not interested in having new ideas or changing her point of view. We asked Lindsay to review a draft of this article. After a few e-mailed comments back and forth, she wrote, "I want you to put in the paper whatever you saw of me. Maybe I was resistant to change. Katy [Lynn] would have been better to see that than I would have been able to. If that is what she saw, then by all means, put it in your paper. Freshman year is all about change, and by the time I had my time to spend with Katy I may have been all out of change at that point. It was just something that I found interesting of what other people thought of me. It made me realize that change is not always so bad and to watch how I act around people. I don't want them to get the wrong impression."

Lindsay grew up in central Pennsylvania, a predominantly white, rural, and working-class area. For her community engagement project, Lindsay volunteered at the Police Athletic League (PAL) ${ }^{2}$ Like many of the other students in Ashley's three similar classes, Lindsay chose PAL not because she was particularly compelled to work with this organization or its client population, but because it was the easiest choice, being close to campus and an organization that provided transportation to the site. Lindsay ended up working alone on her final paper. This was in part due to the schedule of the tutoring and the fact that Lindsay became a very strong student over the course of the semester. This meant that she was at PAL before everyone else and her experience was very different from the other students. The primary difference was with her relationship to the staff. As she was the only student there and was able to schedule her arrival at a time that was convenient to the staff, she received extensive individualized attention when she began her volunteer time at PAL.

As part of the preparation for visiting PAL, Lynn had Lindsay find the organization's mission statement. Lindsay and Lynn then did a brief textual analysis of that statement to help Lindsay better understand the culture of the organization she would be working with. They discussed what sorts of leadership traits and value systems a "recre- 
ational, societal and educational" organization run by the police might try to instill into a group of children and what impact that would have on the families who used PAL's services. By looking at the mission statement, Lindsay and Lynn were able to discuss PAL both in the context of the information she was receiving from the greater West Chester [Pennsylvania] community and in the ways the organization saw itself in relationship to the community.

Lindsay entered the project with several different discourses around the topic of race and racism. One that emerges in her paper and had shown itself earlier in the semester is the discourse that "whites are victims of racism at the hands of blacks." In one classroom discussion, for example, Lindsay talked honestly and animatedly about African-American students in the Academic Development Program (often cited by students and staff alike as modeled after a "family") as snubbing the white students; she used this as an example in a discussion about racism stemming from the bell hooks article. These comments were some of a number she made in class and tutoring sessions, which suggested that the discourse of "reverse racism" was a deep-rooted one for Lindsay.

This discourse establishes itself almost immediately in Lindsay's paper. She states: "The Greater West Chester chapter of the PAL organization is dominantly black and Hispanic." This could be read as a simple statement about numbers and a vocabulary problem (that is, she meant "predominantly"), but we read the use of "dominantly" differently for two reasons. One is the fact that Lindsay mentions here that the make-up of PAL is" "black and Hispanic," but she concentrates exclusively on African-Americans (as clients) in her paper, as well as in one-on-one discussions with Lynn and journal entries. Second, from another perspective, PAL is "dominantly" white-the staff is almost all white; it is the client population that is mostly of color. Lindsay makes a point of this later in her paper, as seen below. Yet Lindsay's description, in direct authorial discourse (not reported discourse, which would signal distancing and greater heteroglossia), portrays PAL as dominated by the people of color there.

But Lindsay immediately begins to contradict this discourse of "reverse racism." She notes early on: "Even though hearing from the surrounding community about racism being a prevalent issue within the organization, I have found my assumptions of racism to be totally misguided." Lindsay gives voice to the averral that "['reverse'] racism is a prevalent issue [at PAL]" through a popular "speaker" - "the surrounding community." She writes in terms of popular assumptions she had heard, but she is not specific about where she heard these assumptions (which would have made them private, in our system of analysis). She then gives her private narrator-self ("I...my...") alliance with these ideas but at the same time critiques them. These ideas 
are "misguided...assumptions." The popular commonplace and the private position reinforce, then immediately challenge one another. Lindsay begins to make Bartholomae's access move of critique.

It is interesting to consider how the narrator is being used here. For example, Lindsay could have written, "Even though I heard from the surrounding community about racism being a prevalent issue within the organization, the assumptions of racism are totally misguided." Why include a narrator who "has found" something? One explanation is that it sets up a narrator-character who can give voice to the heteroglossic views on race and racism that Lindsay was struggling with in the paper and the course. Notice that she guides us toward accepting her current views with the strong metapragmatic "found," which implies evidence and support for her refutation of the popular/private reverse-racism discourse.

Later in the paper, Lindsay more directly declares that she initially agreed with the popular discourse. She states, "Another assumption about PAL that I was sort of concluding to is that PAL parents and PAL kids could be racist." Again, she uses reported discourse to examine the commonplace as established by both the popular and her own private discourse. Note here that she distances herself from the statement by using the modalization "sort of." She restates her original belief in the idea that PAL families "could be racist [against whites]," while at the same time establishing this belief as a reflection of the popular discourse that she is critiquing in her paper.

Reported discourse serves Lindsay well in these access moves. However, Lindsay also uses reported discourse for a critique of the academic worldview about the nature of current and continuing racism. This worldview/discourse was represented by course readings and class discussions and was privately held by Ashley and Lynn (both of whom are white). We can briefly label this discourse as "active white racism," and summarize it in part as "racism of whites toward people of color is alive and well and predominant in our existing communities." We recognize that to label this worldview globally as "academic" is too simple; however, we represented the academy in this specific classroom context and the readings Ashley chose reinforced this set of ideas about the nature of racism.

As part of her work in PAL, Lindsay interacted with both the children and their parents/guardians. Through talking to one of the grandparents Lindsay entered into a conversation about racism in the local community. Lindsay reports this grandmother in the following way:

She was talking about how we have come a long way with in our West Chester community in the fight against racism. She was telling us a story of how she would go into stores and 

look at her to help her. She says that she has not seen that go on in a very long time.

Lindsay uses the private voice of the African-American grandmother as an expert authority. By paraphrasing this grandmother, Lindsay tests the scholarly discourse of "active white racism" with a private speaker voicing a discourse which says "racism did exist, but that was back in the day - we have come a long way since then." Lindsay subtly aligns herself with the speaker by voicing her in detail but by using somewhat neutral metapragmatics: the grandmother "tells stories" and "talks." The averrals themselves, though, are commanding: it has been a "very long time;" there is a "fight against racism," and " $w e$ " are engaged in that fight. The "we" here is ambiguous, but the addition of "our West Chester community" at least implies a united group of blacks and whites together.

This passage is key for two reasons. By aligning herself with the expert but private voice of the African-American grandmother, Lindsay again questions the popular (and her shared private) discourse of "blacks are racist against whites." She actually shows her narrator in a situation of potential contradiction - note that Lindsay calls her white narrator into this harmonious picture with her black interlocutor simply by including "us" in the passage, something she easily could have left out. A second reason why this passage is key is that she is beginning to create a position in the social world and therefore potentially for herself as an anti-racist white person. As she continues to reinforce this subjectivity, she takes greater risks in the way she examines popular and private discourses. This culminates in her ability to more clearly distinguish, discuss, and name the racial make-up of the PAL staff and the population that uses the PAL services. She states: "I see this as a mere coincidence that the blacks need the help and the whites are the helpers. This has NOTHING to do with the white race being superior to the black race." Here Lindsay creates a critical position which, while we could say it is privately advocated by both of us, was not a strong part of the academic discourse of this classroom. Lindsay voices her anti-racist white narrator as averring that the "help" received by African-Americans and provided by whites is not inherently about race (it is "a mere coincidence"); this dynamic is, particularly, not about racial "superiority." That is, if one reads between the lines, her narrator takes on and critiques racist biological discourses. Also, here, in contrast to other places, Lindsay's private narrator does indeed acknowledge that racism is alive and well, that there still are many whites around who believe that "the white race [is] superior to the black race." Some of these whites may very well be Lindsay's own private home community, as she implied in some tutoring sessions. The decision to type 
"NOTHING" in capital letters is an interesting choice and almost suggests a shout at those voices who might aver the opposite. And, finally, while Lindsay is not shouting at us, the representatives of the academy, she is speaking in a clearly critical way to our worldview which often emphasizes, too simplistically, more about culpability and guilt for whites than awareness, potential, and alliance.

In this paper, Lindsay is engaging in voice as a verb rather than voice as a noun, which allows the heteroglossic tension around broader cultural discourses of racism to emerge through reported private and popular voices. Scholarly discourses are addressed as a "dialogic backdrop," to use Bakhtin's label. Lindsay explores the tension she encountered in the lived experience of diversity and brings that tension back to the classroom to speak back to the academy. In this instance, she voices a changed narrator-self - not as a result of forced assimilation, but rather through the active dialogue and testing of multiple voices with each other, which allowed her to engage in identity negotiation rather than identity loss.

\section{CONCLUSIONS AND APPLICATIONS: USING REPORTED DIS- COURSE IN THE BASIC WRITING CLASSROOM}

In order to use reported discourse fruitfully, instructors need to be aware of it and its significance. This is the first challenge, since reported discourse is so ubiquitous in the academy as to seem completely inherent and natural. The following quotation was taken from the introduction to a popular writing textbook:

Every day, as you talk, write, and work, you use sources. Most of the knowledge and many of the ideas that you express to others originate outside yourself.... The best way to gain confidence and facility in writing from sources is to master each skill so thoroughly that it becomes automatic, like riding a bicycle or driving a car. (Spatt vii, $\mathrm{x}$, emphasis added)

By contrast, Voloshinov describes reported discourse not as automatic and natural but as a sketch of "social tendencies" within a particular context:

What we have in the forms of reported speech is precisely an objective document of [the] reception [of another's speech, which is the precursor to dialogue]. Once we have learned to decipher it, this document provides us with information, not about accidental and mercurial subjective psychological processes in the "soul" of the recipient, but about steadfast social tendencies...that have crystalized into language forms. (117) 
This "language form" which often blends into the rhetorical landscape is fairly easily recognized once one becomes interested in doing so. As we have noted, it is most directly signaled through embedding and embedded clauses together, where the averral about the state of affairs in the world-e.g., "The house is red" - can be attributed to someone other than the writer of the text-e.g., "Jane said, "The house is red'" (Tadros). ${ }^{3}$ Writers signal detachment from an averral by ascribing the proposition to someone else, through quotation, as above, citation, or paraphrase, as in: "Jane writes that the house is red," "Jane verified that the house was red," "Jane mistakenly described the house as red." When we begin to recognize reported discourse, we can start to ask critical questions about it as we read student writing. For instance, each reporting of "Jane's" discourse, above, signals a different relationship between the writer (let's say, John) and Jane. Here are further questions which may aid in re-viewing a writer's choices. Because this method of analysis is novel, we will elaborate using this highly straightforward example in order to make these suggestions for analysis more concrete:

- How is the writer using, or not using, the convention of reported discourse at this particular point in this particular piece of writing? That is, do I notice any pattern emerging?

Generally, has John Student voiced Jane Academic, or K. Scholar, or Jason Local, or himself? Where? How much?

- What purpose is served by having a "character" other than the author aver this particular proposition? Why does the author need to or choose to detach from the averral?

How would this read if John himself had stated this idea in direct authorial discourse? Where does John have "I" thinking, believing, stating ideas, and where does John frame averrals in direct authorial discourse, in the removed third person? How are the averrals different or similar, in terms of lexis, syntax, etc.?

- Who is the author allying himself with? Who is he not allying himself with? Who is he attempting to ally himself with and critique all at once?

E.g., "Jane said, "The house is red"" and "Jane writes that the house is red" tend to signal neutrality, perhaps a recognition of Jane's importance (to teacher/discipline) without too strongly affiliating with Jane; "Jane proved that the house was red" signals deference to Jane's authority, though perhaps some parody or duplicity because John uses and valorizes her exact words but leaves off quotation marks. "Jane was wrong when she described the house as red" signals authority taken up by John, acknowledging Jane's averral but denying its clout. ${ }^{4}$ 
- Of those who are voiced, are they voiced accurately? Are they quoted out of context, paraphrased sketchily or summarized thoroughly, are they dropped as a name?

Has John misrepresented/played with Jane's words? Has he simply commented that her words exist, as in "Jane writes about houses," without giving adequate representation of what Jane says about houses? Or do Jane's words pervade throughout John's paper?

- What sort of dialogue does the author and/or narrator seem to be having with those reported? Does the author sprinkle any key terms used by his reported speakers in his direct authorial discourse? Does he voice reported speakers, in paraphrase, with terms which are more likely to emerge from his own mouth? If private speakers other than the author/ narrator are voiced in the paper, how do they speak and on which topics?

Does Jane actually use the terms "red" and "house" or are these John's paraphrases? Perhaps Jane writes about "crimson quarters" or "a cherry apartment." Does Jane's term "red" invade John's direct authorial discourse or narratorial discourse on the topic of houses, without attributing the idea or language to Jane?

- What happens for us as readers when discourses and speakers appear mismatched from our vantage point?

Does John's paper include thoughtful ideas on the topic of houses and their redness, but voiced through private speakers, such as a parent, a community member, or the narrator? How might our assessment of the piece be changed if John ventriloquated Jane Academic's voice instead?

- Would expanding the repertoire of characters these students are allowed/encouraged to voice in their papers be beneficial to my students? How? How might it be beneficial to the university?

This method is not just an approach for instructors to use in reading student papers. Teaching students themselves to "hear voices" is also useful and possible. We have used attentiveness to reported discourse in peer review and as a tool to help "unpack" complex readings. In peer review of our students' essays on Gloria Steinem's "Ruth's Song" and bell hooks's "Killing Rage," instructions for reviewing drafts included asking peer responders to use a colored highlighter to mark every instance of reported discourse, i.e., every place where another "speaker" was "brought in to say something in the text." (The method had first been demonstrated in class.) On a direct visual level, this helped students to find a balance between simply recapitulating the readings (most of the paper is highlighted) and analysis (highlighted 
and non-highlighted portions alternate and mix). It also helped students to see when they were not supporting an analysis with evidence but simply stating an opinion (little or no highlighting, or highlighting is all clumped together, rather than signaling "dialogue"). Finally, it was a helpful tool to challenge students to move from fairly surface readings of the texts - "bell hooks is racist against white people" was a common response (of our white students) to "Killing Rage," for example - to more complex ones. Students attuned to reported discourse could make sense of our responses: "That's your voice. What does hooks actually say about white people? If you want to make that argument, you have to have a dialogue with her, which means listening to her voice, bringing it in, as well as responding." In fact, students in Ashley's courses have sometimes begun adopting the language of hearing voices, asking each other about their "voices" and the "voices" in their peers' papers.

Being taught to attend to reported discourse helps students to unpack complex assigned readings as well. Victor Villanueva's Bootstraps is a complex blend of voices itself. Ashley assigns parts of this book in her "Investigating Experience" course, mentioned above. While this is not a basic writing course, in a recent class, many of her basic writing students had followed her into the course, still as first-year students. Beginning with the first chapter, Bootstraps was challenging for them. They didn't have a sense of the previous debate that Villanueva is engaging. They couldn't recognize the "commonplace" / popular voices on the "topic" of "students of color and education" that Villanueva is attempting to challenge: "Students of color don't succeed educationally because..." Villanueva tells his story and then reports the discourse of scholars from Bereiter to Heath, charting the common wisdom from deficiency through difference theories, eventually arriving at the recent commonplace much of his book attempts to knock down: students of color can succeed academically if they conform to white, middle-class language conventions. His book is an example and an argument controverting this idea.

Rather than introducing the book to her students with a minilecture on the topic of schools and language diversity, Ashley opened with an exercise on reported discourse. A lecture would perhaps have helped students read this book, but it would not have helped them understand how to read other complex material, how to decipher other reported discourse for the work it does. She asked students to work in groups to pick out speakers in small sections of the text and label them as Villanueva's "squad" or "foe." (These labels were arrived at after a laugh at Ashley's expense, because she began with the term "posse" instead of "squad" and was told that "no one says that anymore.") Students were able to sense which speakers Villanueva is setting up an alliance with (who is his squad) and who he is voicing in order to dis- 
agree with (foes). They were able to be quite discriminating. For example, the mothers that lived on el bloque got labeled as "squad," even though what they voiced could be perceived as adversarial: "you, little Spanish boy...!" (2). By contrast, the class had a sense that "the guy at Thom McCann" whom Villanueva voices with the phrase "Puerto Rican fence climbers" was foe, even though they did not fully grasp the content of the racial slur (6). Similarly, students separated the more academic speakers and their discourses into squad and foe.

This exercise helped students to unpack Villanueva's support for his argument, both private and scholarly. The class eventually arrived at Villanueva's thesis from the bottom up, by looking at a pattern in what squad and foe speakers, as reported by Villanueva, were voiced as saying. After reviewing the list of Villanueva's foes and what they were saying about him and students like himself, one student said, "Those are all people who don't know ALL of him." The class went on to notice that those who were in the squad were people who understood multiple parts of Villanueva. Ashley had put the word "hybrid" on the board at the beginning of class, and students had defined it, primarily in relation to plants. After the squad and foe discussion, the class stated Villanueva's research question as, "How can you be a hybrid and succeed in school AND on the block?" This statement of his thesis and student's understanding of it seems more subtle and complex than a lecture would have allowed.

In the July 2003 issue of College English, Joseph Harris argues for demystifying the process of critical writing, making a case for focusing work in composition courses on close attention to revision. While he does not cite Bakhtinian theory, much of his article refers to reported discourse: "to write as a critic is to situate what one has to say about texts or issues in relation to what others have had to say about them..." (578). He talks about students who "are asked to ventriloquize our positions" and ideas "refracted by language" (582). He describes the success of a basic writing course which, in essence, centers on reported discourse. The course centered on "retellings" - "...competing versions of the same text: parodies, remakes, abridged or altered editions, adaptations, excerpts..." $(583,582)$. We conclude here with this report of Harris in order to point out the way that reported discourse is a constant, powerful but unacknowledged presence in academic writing. Raising our own awareness of it, examining it critically and learning how to interpret its uses in writing, student and otherwise, can ultimately help students to be read as "in." In addition, finding opportunities for students to "legitimately" report private discourses will help push the boundaries in composition courses and throughout the academy. Recognizing private discourses as worthy of report can help us and our students recognize that all utterances, even those that feel like "our own," are a ventriloquist act. 


\section{Notes}

1. That is, the Bakhtin circle-Bakhtin and others of his contemporaries, especially Voloshinov, for example, in Marxism and the Philosophy of Language.

2. "The basic mission of PAL is to offer young people a viable and constructive alternative to the temptations of 'street life' which can lead to a life of crime, alcoholism, drugs, vandalism, and delinquency. PAL provides the environment to keep boys and girls active, interested and busy through its supervised, multi-faceted recreational, societal and educational programs to develop leadership traits and build good citizens for tomorrow. PAL is dedicated to instilling in our youth a value system that recognizes the need to respect and protect the human and property rights of others and to uphold and obey the laws of our city, state and nation." (PAL Mission Statement, http:// www.phillypal.com/)

3. See Ashley and Wortham \& Locher for more detailed and complex schemas for identifying voicing.

4. The term for the feature we are exploring in this example is modalization, in the form of metapragmatic verbs (says, writes, believes, argues, denies, etc.) and type and extent of voicing. As a further example, our brief references to Bartholomae in this article signal a different sort of relationship than the extensive quotation of Bakhtin and different again from the simple citation of Lea and Street. How we voice them in metapragmatic verbs and nouns also signals relationship: Bakhtin has "frameworks" and he "points the way"; Bartholomae has "moves" and "insights."

5. See Ashley for further analysis of commenting in student papers.

\section{Works Cited}

Ashley, Hannah M. "Hearing Voices: Critical and Conventional Uses of Reported Discourse in a Service Learning and a Standard Composition Course." Diss. Temple U, 2002.

Bakhtin, Mikhail. M. "Discourse in the Novel." The Dialogic Imagination: Four Essays by Mikhail Bakhtin. Ed. Michael Holquist. Austin: University of Texas Press, 1981. 
Bartholomae, David. "Inventing the University." When a Writer Can't Write. Ed. Mike Rose. New York: Guilford, 1985. 134-65.

Bourdieu, Pierre. Distinction: A Social Critique of the Judgment of Taste. Trans. Richard Nice. Cambridge: Harvard UP, 1984.

Caldas-Coulthard, C. R. “On Reporting Reporting: The Representation of Speech in Factual and Factional Narratives." Advances in Written Text Analysis. Ed. M. Coulthard. London: Routledge, 1994. 295-308.

Fairclough, Norman. Critical Language Awareness. London: Longman, 1992.

Gee, James P. "Foreword: A Discourse Approach to Language and Literacy." Changing Literacies. Ed. Colin Lankshear et al. Philadelphia: Open University P, 1997. xiii-xix.

Harris, Joseph. "Opinion: Revision as a Critical Practice." College English 65.6 (2003): 577-92.

hooks, bell. "Killing Rage." Writing as Reflective Action. Ed. Duncan Carter \& Sherrie Gradin. New York: Longman, 2001.

Lea, M. R., \& Brian V. Street. "Student Writing and Staff Feedback in Higher Education: An Academic Literacies Approach." Student Writing in Higher Education. Ed. M. R. Lea \& B. Street. Buckingham, UK: Open University P, 2000. 32-46.

Parks, Stephen \& Eli Goldblatt. "Writing Beyond the Curriculum: Fostering New Collaborations in Literacy." College English, 62.5 (2000): 584-606.

Pratt, Mary L. "Arts of the Contact Zone." Profession 91 (1991): 33-40.

Shor, Ira. When Students Have Power: Negotiating Authority in a Critical Pedagogy. Chicago: University of Chicago P, 1996.

Spatt, Brenda. Writing from Sources. Boston: Bedford/St. Martin's, 1999. Steinem, Gloria. "Ruth's Song (Because She Could Not Sing It)." Writing as Reflective Action. Ed. Duncan Carter \& Sherrie Gradin. New York: Longman, 2001.

Tadros, A. "Predictive Categories in Expository Text." Advances in Written Text Analysis Ed. M. Coulthard. London: Routledge, 1994. 6982.

Villanueva, Victor. Bootstraps: From an American Academic of Color. Urbana, IL: NCTE, 1993.

Voloshinov, V. N. Marxism and the Philosophy of Language. Trans. L. Matejka \& I. R. Titunik. New York: Academic Press. 1973.

Walvoord, Barbara and Lucille McCarthy. Thinking and Writing in College: A Naturalistic Study of Students in Four Disciplines. Urbana, IL: NCTE, 1990.

Wortham, Stanton, \& M. Locher. "Voicing on the News: An Analytic Technique for Studying Media Bias." Text: An Interdisciplinary Journal for the Study of Discourse, 16.4 (1996): 557-85. 


\title{
Thomas Peele and Mary Ellen Ryder
}

\section{Belief Spaces and the Resistant Writer: Queer Space in the Contact Zone}

\begin{abstract}
In this essay we offer a method of textual analysis that we call the identification of belief spaces. The concept of belief spaces is adlapted from work in linguistics on mental spaces. Belief spaces are represented in a student's text by phrases such as "I think that" or "for many people today." In the first example, the belief space represented is the writer's; this is signaled by her inclusion of the pronoun "I." In the second example, the belief space represented is that of "many people"; whether the writer belongs to the belief space or not is unclear. We contend that one of the problems in student essays is ambiguity; the reader can't be sure what the writer is trying to convey. Further, we argue that one way to reduce ambiguity in student essays is to teach students how to identify the belief spaces in their texts. We use the concept of belief spaces to discuss an ambiguous essay written by a student on the subject of gay men. We also provide a copy of the assignment that we use to teach the concept of belief spaces to basic writing students so that they can use this method as a tool for revision.
\end{abstract}

\section{The Identification of Belief Spaces}

In this essay, we present a method of textual analysis, adapted from linguistics and stylistics, that we will call the identification of belief spaces (we define belief spaces and their context in linguistics in the following section). Using this method, we examine two essays that were written for a basic writing class. We describe how we taught this method, how students responded, and what the results were. We want to ruin the suspense: the student who we thought would most benefit from this strategy did not use it in his revision. However, we were able to use this approach to talk about this student's writing in ways that weren't directly confrontational. We found this useful since, in our opinion, the student was resisting our clearly left-leaning, liberal views on the subject of gay men. While we didn't agree with what we thought the student was saying, we also didn't want to force him to write a paper that we could approve of. Instead, we wanted to point out why it was hard to understand what he was getting at. In this way, we hoped to teach him, and, subsequently, other students, where, in his text,

Thomas Peele teaches basic writing, nonfiction writing, and graduate courses in composition and rhetoric at Boise State University. His areas of interest are basic writing pedagogy, cultural studies, and queer theory. Mary Ellen Ryder is an associate professor in the Department of English at Boise State University. She has a Ph.D. in linguistics from the University of California, San Diego. Her areas of research include historical English word formation and the stylistic analysis of popular fiction. 
meaning is obscured by his treatment of multiple belief spaces.

When we ask students to examine their belief spaces, we're not suggesting that this is a technique that will help them think through their ideas. Rather, what we're hoping to do is provide a means for textual analysis that allows students and teachers to talk about certain kinds of ambiguity and vagueness in student essays. We're suggesting that one cause of ambiguity, particularly in papers that are analytical rather than personal, is a disorganized proliferation of belief spaces. In other words, students put together a lot of sentences that include language such as "Some people think that" and "In society today." Over reliance on this kind of language-language that places the information in others' belief spaces - produces a text in which it is very difficult to know what the writer thinks. The "identification of belief spaces" exercise helps students identify why a reader might not know what the writer thinks; it's a way for the writer to identify when she might be stringing together what several other people think without ever specifically including her own opinion, or, as it is conceptualized in this exercise, her own belief space.

\section{What Is a Belief Space?}

Our use of belief spaces is adapted from a more extensive model: Gilles Fauconnier's work on mental spaces. Fauconnier is a linguist who became interested in accounting for the resolution of apparent contradictions in sentences like "In that picture, the green-eyed girl has brown eyes." (Note that without the opening phrase "in that picture," this sentence would be contradictory, while with the phrase, it is not.) Having shown that the explanations provided by theories in logic were insufficient to account for the data, Fauconnier created the notion of mental spaces which allow information to be assigned to different spaces while also permitting the description of something in one space to be used to refer to something in another. So, in the example given above, the writer is saying that the girl who has green eyes in reality (or at least in the belief space of the writer) is represented in the picture space as having brown eyes. Typical spaces include physical representations such as pictures, movies, and books, and cognitive representations such as dreams, beliefs, and memories.

The types of ambiguity resolution made possible by the mental spaces model struck us as particularly helpful in dealing with some ambiguities often found in student papers, so we adapted a small portion of the model, the part dealing with belief spaces, for use as a revision strategy. For the purpose of this essay, we define a belief space as a textual space created by a writer that marks the contents of that space as belonging to someone's set of beliefs. The belief spaces that the writers create can be (1) clearly attributed to the writer, (2) clearly attrib- 
uted to someone or something else, or (3) ambiguous as to whose beliefs they reflect. In the last two instances, the reader cannot determine whether or not the writer believes the information given in the space.

There are two basic ways to indicate belief spaces. One is to make an unqualified statement, such as "Tuition at this school is too high." By not attributing this belief to anyone in particular, the writer shows not only that she believes this statement to be true, but also that she expects all her readers to feel the same. In other words, she feels that the situation expressed in the statement is part of "reality," things accepted by everyone as unequivocally true. The second method is to overtly mark a statement as belonging to a particular person or group's belief space, as in "In my opinion, tuition at this school is too high" or "Students at this school believe that tuition here is too high." By attributing information to specific people's belief spaces, the writer is expressing some uncertainty as to whether the belief will be shared by readers who are not among the people described.

In limiting the people to whom a belief space is attributed, a writer also runs the risk of leaving her own stance unclear. Obviously, if a statement includes such phrases as "in my opinion" or "I believe that," the reader will know that the writer's beliefs are being expressed. However, if the belief space set up belongs to someone else, the writer's beliefs will not be nearly as clear. For example, if the belief space is assigned to a vaguely defined group, as in statements like "In today's society, people feel that moral values are no longer respected," the reader will not know whether or not the writer feels herself to be a member of this group. And even when the belief space is attributed to someone specific, as in "The president believes that the present policy is effective," the reader will not know whether or not the writer's belief space includes this information as well. Thus, unless the writer makes an unqualified statement, or a statement clearly marked as belonging to her belief space, the reader will not be able to determine the writer's beliefs.

There is another potential source for ambiguity in how belief spaces are expressed in an essay. A writer rarely marks a belief space more than once, even though the information belonging to the belief space may extend through a number of different sentences. Indeed, a repetition of the belief space involved would be considered redundant. Thus, in a text such as "In my opinion, tuition at this university is too high. Most students here are paying their own way and they shouldn't have to spend so much just to get an education, "readers would assume that the information in the second sentence is also a part of the writer's belief space, and would think that the addition of "I think" to the beginning of the second sentence was unnecessary. However, writers are not always consistent in maintaining the same space in these subsequent sentences. For example, in a text such as "Many people 
believe that university tuition is too high. This is stupid," it is likely that the second sentence belongs to the writer's belief space, even though it is not marked as such. In a text such as "In the view of society, this rock star is quite outrageous. He is really cool," it is hard to say whether the second sentence is in society's belief space, in the writer's belief space, or both.

Conceptualizing the student's essay as a series of competing belief spaces can help instructors and students identify specific phrases and clauses that leave the reader confused about the relationship between what the writer is thinking, the writer's expressed belief space, and other belief spaces in the text. We argue that composition instructors who teach students to examine and categorize their textual belief spaces will:

- identify multiple sites in the text from which to provide feedback to students on their essays; each of these sites will fit into the conceptual framework of a textual belief space, thereby allowing students the opportunity to perform the same type of analysis repeatedly;

- help students identify specific locations - textual evidence of belief spaces - where the meaning of their essays becomes ambiguous;

- provide students with specific, belief-space related reasons for that ambiguity;

- suggest to students two rhetorical constructions that will help diminish the ambiguity of their essays: the first person singular and the unqualified claim; and

- demonstrate to students how through analysis of textual belief spaces they can move from producing ambiguous, "academicsounding" essays to essays in which their views are clear.

\section{Teaching Belief Spaces}

We teach students to locate belief spaces using the exercise attached as Appendix A. Appendix B is a chart demonstrating that most of the students understood the strategy after two thirty-minute sessions presented over the course of two weeks. To present this strategy, we ask students to look for particular phrases and clauses in samples that we've provided. In this case, we worked with sentences from Kerry's essay (both students whose work is quoted in this article signed forms giving us permission to use their writing anonymously for research designed to "contribute to our general knowledge of the composing process of college students"; the names "Kerry" and "Jan" are pseudonyms). We developed and used this strategy for the first time in the fall of 2002, and we offered it as we would offer other tools of textual analysis - as an exercise to perform on student essays in order to test for clarity. Students were not required to use the strategy al- 
though we did discuss the results with them after the initial training session. There was no test later in the term to determine whether or not they recalled this strategy.

\section{The Contact Zone Essay}

We asked students to write in response to Mary Louise Pratt's "Arts of the Contact Zone." As Pratt writes, the term "contact zone" refers to "social spaces where cultures meet, clash, and grapple with each other, often in contexts of highly asymmetrical relations of power, such as colonialism, slavery, or their aftermaths as they are lived out in many parts of the world today" (607). In our classroom, we use a skit from Nelly's popular CD Nellyville to demonstrate an example of a social space where cultures meet. In this skit, a black man goes into a music store to buy Nellyville (the CD on which the skit is recorded; a postmodern moment if there ever was one). He must deal with a white clerk. We listen to the clip, then talk about how the various cultures are represented by means of language and attitude:

[Cedric:] Yo yo yo yo, my man, yo

[Clerk:] Yea, what can I help you with?

[Cedric:] Hey c'mon man you gotta say you got me on dis one, Look. . .

[Clerk:] What do ya need, what do ya need?

[Cedric:] You got da new Nelly? You got dat in? The Nellyville, you got dat right?

[Clerk:] What is that rap or something?

[Cedric:] Wha?

[Clerk:] I think we jus sold out of it man.

[Cedric:] SOLD OUT?! C'mon bro dis da fourth, fifth, store I've been to today, they all sold out!

[Clerk:] We're all sold out bro.

[Cedric:] C'mon man you gotta help a brotha out, man I'm in a [Clerk interrupts: (Hey man!)] desperate sitiation herre playa!

[Clerk:] I'd love to help you my brotha!

[Cedric:] I got a nice lil sexy lil thing waitin on me at da crib, and all she wanna hear is Nelly, I'm tryin to get it through your smell.

[Clerk:] I hear ya, [Cedric interrupts: (wha?)] I hear ya, you gotta get the mood goin, ya know...?

[Cedric: (laughin)] Yea, dats what I'm tryin to do pimp juice!

[Clerk:] PIMP JUICE?!

[Cedric:] Look man, let me ..., can you download it for me? sumthin?

[Clerk:] No man, we can't do that here, sorry! 
[Cedric:] Mp3? You can't... ?

[Clerk:] No, we can't, we can't Mp3, sorry!

[Cedric:] Let me take one of your listenin machines or sumthin, and I'll bring it back to you tomorrow.

[Clerk:] Ya fuckin crazy? My boss would kill me man!

[Cedric:] Look man, jus check in da back, do whateva you gotta do.

[Clerk:] Hold on, let me see what I can do for ya bro. Let me see...

[Clerk:] Man this is the last one I got.

[Cedric:] For real? Aight! Cool wait...

[Clerk:] It's the clèan version, that's all I got, I found the clean version for ya!

[Cedric:] It's da clean version?

[Clerk:] Nelly, ya know the new one, Nellyville.

[Cedric:] It said there's NO cussin on it? NONE?

[Clerk:] Ya want it?

[Cedric:] Dat's all you got?

[Clerk:] It's hip-hop!

[Cedric: (sigh)] Damn aight, aight give me dat man. I jus got ta make it happen right now, I jus gotta ...

[Clerk:] Alright, Alright but hurry up we got people waitin in line here, they've been waitin for a long time.

[Cedric:] Yea, go ahead and giva it to me.

[Clerk:] Good luck dawg!

Most students enjoy this demonstration because even though it's funny, it presents a culture clash that many of them have experienced themselves - coming into contact with another cultural group and finding it difficult to understand and make oneself understood. A student who chose this text to analyze for their "Contact Zone" paper might focus on the way the representative of the dominant, white culture appropriates the language of the subordinate, black culture without having any grasp of that language.

The assignment included in Ways of Reading (Bartholomae \& Petrosky) asks students to conduct their "own local inventory of writing from the contact zone.... Once you have completed your inventory, choose a document you would like to work with and present it carefully and in detail" (620-21). A student might choose to discuss a document such as the one presented above, or they might choose to present a document in which a subordinate culture either represents itself to or is represented by the dominant culture. For example, the subject of the other paper that we discuss in this essay is the lobbying document written by PFLAG-Parents and Friends of Lesbians and Gays. This is a good example of a document from a contact zone be- 
cause it specifically talks about how a subordinate group should represent itself to a dominant group. In addition, this assignment provides a context in which students will have to demonstrate their own belief spaces as well as those represented in the texts that they analyze. If students fail to clearly delineate between what they believe and what others believe, they run the risk of being unclear. In fact, although almost any text will show some use of belief spaces, an assignment such as this one is sure to elicit at least two and probably more belief spaces, making a belief space analysis especially useful to students and their professors during the revision process.

The assignment successfully provoked students to write about many significant areas of cultural conflict. The eighteen students who completed it wrote about a number of different conflicts - for example, the conflict between black and white cultures in America, homelessness, anti-Semitism, and the Arab-Jewish conflict. Other students in the class wrote about the conflict between environmentalists and ranchers, between American Indians and whites, between independent cowboys and corporate ranching, and between straight and gay culture. In choosing to write about these areas of cultural conflict, students were demonstrating some of the critical thinking that we hoped to see. By choosing textual representations produced either by the marginalized group itself or by a mainstream group representing a marginalized group, students had identified rhetorical features of a text that were significant to them. Students engaged in a subject that interested them, chose a document that was relevant to them in ways that an instructor could not anticipate, and clearly presented a number of belief spaces before providing their analysis.

Four of the eighteen students who completed this assignment wrote about the contact zone that exists between lesbian/gay and straight culture. ${ }^{1}$ We find this significant for two reasons. First, this strikes us as an inordinately high percentage of student papers on this subject. In teaching this class using more or less the same curriculum for the past ten years, Tom has previously seen only one or two papers on this subject. While the reasons for the number of papers on this subject remain obscure, we want to focus on the second point of significance, which is that, with one exception, these essays were the most ambiguous with respect to the belief spaces that they represent. In other words, the writers of these essays, who addressed one of the most socially charged subjects in the class, were also the writers who had the most difficulty delineating between their belief spaces and the belief spaces of others. ${ }^{2}$ Our theory about the reason for this is that students who choose to write about an area of cultural transition, in this case the relative acceptability of lesbian and gay cultures to mainstream society, are in a very difficult rhetorical position. ${ }^{3}$ The students in this study wanted, they claimed in conversation, to be pro-tolerance. The 
essays themselves, however, reveal an at-best ambiguous stance with regard to tolerance. This ambiguity can be identified for students by pointing out their belief spaces. Through analysis of two of the essaysthe one unambiguously antiheteronormative text and one of the most ambiguous heteronormative texts - we will demonstrate how, through the identification and analysis of belief spaces, we were able to determine a way to begin talking to students about these essays. We use the term "heteronormative" to indicate a belief system in which heterosexuality is not only a statistical norm (which it is) but also a cultural norm, the transparent form of sexuality against which all other forms of sexuality are implicitly and explicitly measured. "Antiheteronormative" suggests resistance to this belief system without suggesting a new hierarchy. (For a more complete discussion, see Warner.)

\section{Jan's Essay}

Jan's essay, the full text of which is included as Appendix C, is unambiguously antiheteronormative. The belief spaces she describeshers and others' - are clearly marked and present a consistent perception of the issues. Jan's essay begins as follows:

The year 2002 has been a year of politics and campaigns with each candidate, regardless of party affiliation, invoking the family values mantra. The candidates use this to appeal to the common concerns of the common voter.

This language clearly represents the writer's belief space. With these unqualified claims, Jan is merely reporting recent events. She does not write, for example, that "Some people think the candidates use this appeal to appeal to ... the common voter." Had she used that language, she would be presenting the belief space of "some people." In contrast, in the next sentence, for example, Jan introduces another belief space. She writes:

On the surface this seems to be an apolitical issue but the reality is that it is a powder keg of explosive issues rolled into one catch phrase.

With the phrase "on the surface," Jan indicates the existence of another belief space, a space in which others, but clearly not she, believe that the phrase "family values" is innocuous. Then, with the phrase "but the reality," Jan returns us to her belief space, to what she thinks, and expects others to think, is true.

Partly as the result of her clear delineation of these belief spaces, 
Jan is able to demonstrate critical thinking later in her essay. She pits her beliefs against those of various others, then situates her examination of the language of a particular text (the PFLAG Tool Kit for a Family Lobby Day) within the space created by the conflict between these two belief spaces. Jan interprets the language of the PFLAG document, then provides evidence of critical thinking, writing that

The statistics in the Tool Kit help put the reality of family composition into perspective. Debunking the misconceptions about these families is the primary method of communication advocated for the lobbyist interested in affecting change at the legislative level.... The message that all families deserve respect and representation is the driving force behind the Tool Kit.

Having described the ways that these two cultures come into conflict with one another, Jan then interprets the language of the Tool Kit and tells us her understanding of how that language operates. Throughout the essay, Jan systematically contrasts her belief space with others' belief spaces in order to draw conclusions about how, in her view, the term "family values" is used by others to misrepresent reality as she sees it. Such clear analysis should be one of the main goals of the basic writing classroom.

\section{Kerry's Essay}

\section{“Faggot! Talking about I fabricated my past he's just mad I won't ejaculate in his ass."}

This epigraph, a line from Eminem's song "Marshall Mathers" on the Marshall Mathers LP, was used by Kerry to open both drafts of his essay, which are included in Appendix D. The drama of the already highly offensive line was heightened by the way the essay was delivered: electronically. This means that when Tom opened the student's essay, this line, in bold face, 14 point font, seemed not to be so much announcing the title of the paper as addressing him directly-for a moment, he thought he was receiving hate mail from the student. Eminem's rap lyrics, this student claims, qualify as written artifacts from the contact zone because they are manifestations of the efforts of marginalized people (rappers) to represent themselves to mainstream culture.

The student's assessment of the lyrics to this particular song as representative of writing from the contact zone is questionable; the song is mainly a rant against a variety of people and entities who irritate Eminem - his mother, N'Snyc, the Backstreet Boys, Britney Spears, the Insane Clown Posse, and various unnamed relatives. Furthermore, the student's essay, a putative inquiry into whether or not Eminem (or 
Slim, as the writer refers to him) is "sending the right message to society, " doesn't respond to the assignment. From the outset, the student's conceptualization of the communities he wishes to discuss - is it rappers or is it gay men and lesbians? - is unclear.

In this context, the difficulty that Kerry will have in presenting his opinion on the subject is clear. First, the subject of his essay is fuzzy; and second, the belief spaces he constructs in his text not only almost entirely bypass his own views but also are disorganized. An analysis of the belief spaces in this text makes it clear why his essay is at best ambiguous with regard to its heteronormative stance: he rarely presents his own belief space. When he does, that belief space is generally heteronormative rather than antiheteronormative. For example, while the quotes around the text of the epigraph clearly place the text outside Kerry's belief space, the placement of text and the fact that it was in bold face and in large font both suggest an endorsement of Eminem's lyric rather than a disagreement with it. Kerry's essay, like Jan's, begins with an unqualified claim: "These are just a few words from the notorious rap artist Eminem's, song title 'Marshall Mathers,' whose recent album went triple platinum." In this sentence, Kerry provides a statement of fact, a part of "reality" that exists within his belief spaceKerry clearly believes this sentence is going to be uncontroversial. In the next sentence, however, Kerry presents another's belief space: "But in the eyes of the public, Slim Shady's vicious metaphors and descriptive lyrics are none the least offensive to the gay community." In this sentence, the belief space clearly belongs not to Kerry but the public, and the offensiveness, even in the public's view, is only to the gay community. Though Kerry may very well be a part of one of these groups, in these sentences he stands outside these belief spaces. It's impossible to tell how he himself feels about Eminem's lyrics. Then, Kerry refers us to other belief spaces: "Several songs have created lots of controversy within the hip-hop nation and society." In this sentence, again, the controversy lies elsewhere, and again we cannot unambiguously place Kerry in either of these belief spaces. Kerry's lack of awareness of the belief spaces he is describing results in a chaotic arrangement of his evidence.

In the next sentence, however, Kerry performs the move that Jan demonstrated above, moving us from his belief space into another's belief space: "In many ways this rising star has blessed us with his many talents, providing us with his [breathtaking] lyrics, but is Slim sending the right message to society?" In this sentence, the initial clause and the participial phrase, being unqualified, both almost certainly refer to Kerry's belief space. Here, based on the evidence of how he situates himself in his belief space, Kerry clearly feels as though he, as a part of "us," has been blessed with Eminem's many talents, and that he, Kerry, has been provided with breathtaking lyrics. Kerry's position in this 
belief space demonstrates a kind of happiness about Eminem's influence, a happiness that conflicts with his stated intentions for this essay. After the conjunction, however, Kerry moves us into another belief space: society. In this clause, Kerry effectively removes himself from the critique; his concern is with whether or not Eminem is sending the right message to society. Because it's unclear whether or not Kerry includes himself in society, the reader is left with the impression that Kerry does not worry about whether or not he is receiving the right message. This is not to argue, of course, that phrases such as "to society" should be banned. Clearly, it's necessary for students to provide a number of belief spaces if they plan to analyze texts and incorporate that analysis into their own essays. What Kerry has done, however, is to consistently assign the problems of offense and concern to other belief spaces, which suggests to the reader that Kerry is not troubled by Eminem's lyrics. The remainder of Kerry's essay continues in the same way - Kerry rarely commits himself to any particular belief space, and when he does, he places himself in a heteronormative belief space, a belief space that conflicts with the belief space he claimed in conversation to inhabit.

The revised version of Kerry's essay contains another striking example of his heteronormative belief space. In this draft, he writes that Eminem's recent album "has two skits with a man named 'Ken Kaniff' who really is Eminem in disguise. 'Hey [there] cock boy? Who is this Chris? No it's Ken Kaniff from Connecticut, you want me to melt in your ass not in your hand Eminem. Yo Chris fuck you flaming [faggot]. These skits were very offensive to a lot of people." Again, Kerry provides us with no information about where he stands in relation to this lyric, but instead assigns the offensiveness to the belief space of "a lot of people." Furthermore, Kerry fails to end the quote; Eminem's language bleeds directly into his own, suggesting not only error but also confusion about his own belief space.

Kerry's motivations are a mystery to us. He appears, though, to be using ambiguously marked belief spaces in order to defuse a controversial subject. What he thinks we may never know. We believe, however, that this essay and others like it - those in which the writer claims to be advocating for a particular progressive cause but actually seems to be working against it--might be an example of one of the ways that students resist us. If Kerry opposes gay rights, his rhetorical situation makes it very difficult for him to say so. Rather, Kerry seems to be invoking academic language to make it appear as though he supports gay rights when in fact he never makes his own views clear. In this way, he might still be able to keep a clear conscience without taking a confrontational stance with his teacher. This kind of resistance, if it is indeed resistance, is worthy of attention. If it is resistance, Kerry is attempting a particularly complex rhetorical task, an attempt that 
should be respected. If nothing else, he's trying to use writing to resist what seems to him to be an oppressive regime - in this case, his composition teacher. As in the contact zone described in the assignment, Kerry is appropriating the language of the oppressor to undermine the oppressor: telling him what he wants to hear while keeping what he thinks obscure.

Confronting this student provoked denial; he claimed that he meant the essay to be pro-gay, and there was nothing else to say. While this may well be true, the text suggests otherwise. We explained to Kerry in conference the difficulties with his text, and we used the text to demonstrate the strategy of identifying belief spaces. Kerry failed to clarify the belief spaces in his revised essay. Instead, he added about a page of new text, including the excerpt discussed above. Kerry ends his second draft with an anecdote about Eminem performing alongside Elton John, who praised the rap star as "a wonderful artist." The essay concludes: "So not all people are offended by Eminem music because they understand that's exactly what it is, as far as his lyrics what he's rapping about discriminating against the gay community I believe its wrong but so are a lot of things in this country that we deal with." Thus, even in the revision, Kerry continues to present conflicting belief spaces. Even the claim "I believe it's wrong" is undermined by "but so are a lot of things." Kerry seems to be determined to oppose the instructor without ever confronting him.

The identification of belief spaces has some obvious drawbacks. In particular, students and instructors might have difficulty in understanding the belief spaces represented in a well-written essay such as the one provided by Jan. However, this pedagogical approach is designed to be used when the essay looks like Kerry's - when the writer's belief space is under-represented. In such cases, the essay is frequently academic in tone, but fails to say anything meaningful. As the table in Appendix B illustrates, students can use this strategy to identify the problem; students can point to specific areas of the text where the writer might think about revising his essay. In this way, students develop confidence as editors and as writers. In addition, they have access to one more revision strategy.

Instructors can use the identification of belief spaces as an exercise when they are confronted with problematic papers such as Kerry's. Composition teachers frequently think and talk about the relationship between language and power; we urge our students to learn to write well so that they can, among other things, resist oppression. If we are following Foucault, we say that discourse constructs reality to a greater or lesser degree, and that discourse can be used to resist and possibly change racist, sexist, heteronormative, and other epistemologies. But what do we do when students resist us? When they view us as members of an oppressive regime? Helping students to identify their belief 
spaces allows us to talk about controversial view points with which we might strongly disagree without silencing the student; it allows us to examine language from an apparently neutral position. With this approach, we might be able to avoid shutting down students who express opinions with which we disagree. If students are prevented from expressing views that instructors find offensive, we run the risk of never learning what they think and of teaching them to write only what they know we want to hear.

\section{Notes}

1. We use the term "lesbian/gay" even though in most of these student essays the default term is "gay." The term "gay" appeared most prominently, even when the writers were implicitly discussing, in addition to gay men, lesbians, transvestites, and transsexuals (one writer confused transsexuals and transvestites). In these texts, "gay" appears to take the role of the universal signifier "him" and suggests the need for further discussion in composition classes of the ways that male-identified language comes to represent entire groups of diversely gendered people.

2. In our academic setting, the majority of students in the basic writing classroom share an Anglo-Saxon heritage. Issues of race tend to be less charged than issues of sexual orientation; many students believe that there is no racial hierarchy in Idaho.

3. The writers are grateful to Gail Shuck for pointing out the relationship between a high level of controversy and a high level of belief space ambiguity.

\section{Works Cited}

Bartholomae, David, and Anthony Petrosky. "Assignments for Writing." Ways of Reading. $6^{\text {th }}$ ed. Boston: Bedford, 2002. 620-23.

Eminem. "Marshall Mathers." The Marshall Mathers LP. Interscope, 2000. Fauconnier, Gilles. Mental Spaces: Aspects of Meaning Construction in

Natural Language. Cambridge, UK: Cambridge UP, 1994.

Nelly. Nellyville. Universal, 2002.

Pratt, Mary Louise. "Arts of the Contact Zone." Ways of Reading. $6^{\text {th }}$ ed.

Ed. David Bartholomae and Anthony Petrosky. Boston: Bedford, 2002. 604-23.

Warner, Michael. Fear of a Queer Planet: Queer Politics and Social Theory. Minneapolis: U of Minnesota P, 1994.

Werth, Paul. Text Worlds: Representing Conceptual Space in Discourse. New York: Longman, 1999. 


\section{APPENDIX A}

\section{Belief Spaces Revisited}

Now that you've had an opportunity to play around with the concept of belief spaces, I'd like for you to try the exercise again. Here are some more instructions for how to find belief spaces:

The Writer's Belief Space is marked in two ways:

- The first, most obvious way is if I say something specific in my sentence:

"I believe there are twenty people in this class."

- The second, less obvious way is if I use an unqualified claim or a declarative sentence. An example of this would be the sentence "There are twenty students in this class." This is in my belief space because I haven't assigned it to someone else's belief space.

Another's Belief Space is marked by specific language.

- So, if I revised the example above to "Some people think that there are twenty students in this class," then I've successfully assigned this idea to a belief space that belongs to "some people."

- Or, if I write the sentence "That there are twenty students in this class is of concern to some people," I have again successfully assigned this idea to the belief space of "some people."

\section{My Belief Space and Another's Belief Space}

Of course, it's also possible to provide two or more belief spaces in one sentence. In the sentence, "I think that twenty people in a class is too many, but some people think it's not enough," I have provided my belief space" "I think" and another's belief space, "some people."

\section{Coding System}

I'd like for you to try the exercise again, using the same coding system. At the beginning of the sentence:

- Put the number $\mathbf{1}$ if you think that the sentence reflects the writer's belief.

- Put the number 2 if you think that the sentence reflects someone else's belief that the writer is merely reporting.

- Put the number 3 if you can't tell whose belief is given in the sentence.

- If more than one belief space is given in the sentence, put the appropriate number near the place that the belief space changes. 


\section{APPENDIX B}

\section{Students Grasp This Strategy Easily}

Using the instructions reproduced in Appendix A, students were asked to identify the belief spaces in Kerry's text. As you might expect, there was some discrepancy in the coding. However, as the following table illustrates, the vast majority of the twenty students surveyed were able to identify the belief spaces represented in the text, and, more importantly, were able to correctly assess the difficulty: that Kerry had not sufficiently presented his own views. His failure to present his own opinions rendered the essay unsatisfactorily vague. (When more than half the students agreed on the designated belief space, the percentage is printed in bold type.)

\begin{tabular}{|l|l|l|l|}
\hline Sentence & $\begin{array}{l}\text { Writer's } \\
\text { Belief } \\
\text { Space }\end{array}$ & $\begin{array}{l}\text { Other's } \\
\text { Belief } \\
\text { Space }\end{array}$ & $\begin{array}{l}\text { Ambiguous } \\
\text { Belief } \\
\text { Space }\end{array}$ \\
\hline $\begin{array}{l}\text { Eminem has not only offended the gay community, but has tampered } \\
\text { along the lines with religion. }\end{array}$ & $10 \%$ & $\mathbf{9 0 \%}$ & \\
\hline $\begin{array}{l}\text { In recent [S]ource magazines there have been several complaints about } \\
\text { him abusing his freedom of speech. }\end{array}$ & & $\mathbf{1 0 0 \%}$ & \\
\hline $\begin{array}{l}\text { There also has been lots of controversy that has build up in the hip-hop } \\
\text { nation because of his lyrics. }\end{array}$ & & $\mathbf{9 5 \%}$ & $5 \%$ \\
\hline $\begin{array}{l}\text { He purposely talks about other rap artist[s] to enlighten his music. } \\
\text { Those that even speak out against him are targets to be talked about. }\end{array}$ & $\mathbf{1 0 0 \%}$ & $\mathbf{7 0 \%}$ & $25 \%$ \\
\hline $\begin{array}{l}\text { Many often wonder does he rap in such a manner because that's what } \\
\text { [sells] or is he really displaying his feeling for others around him. }\end{array}$ & $10 \%$ & $\mathbf{9 0 \%}$ & $5 \%$ \\
\hline $\begin{array}{l}\text { In many people[']s eyes Eminem is doing nothing wrong by exercising } \\
\text { his right to produce music in which he feels is suitable to his audience, } \\
\text { if people are not mature enough to realize that its just music they } \\
\text { shouldn't be [allowed] to purchase it. }\end{array}$ & & $45 \%$ & $\mathbf{5 5 \% *}$ \\
\hline $\begin{array}{l}\text { Since [our] technology is so good in this day [and] age a lot of his } \\
\text { music isn't purchased inside music stores, but downloaded off the } \\
\text { internet. }\end{array}$ & $\mathbf{7 5 \%}$ & $10 \%$ & $15 \%$ \\
\hline $\begin{array}{l}\text { This makes a lot of rap artist aggravated because it not only takes away } \\
\text { from their profits, but also rids the music of its purity. }\end{array}$ & $10 \%$ & $\mathbf{9 0 \%}$ & \\
\hline
\end{tabular}

"Ten of the eleven students who coded this sentence "ambiguous" correctly identified this sentence as runon and coded both sentences correctly. 


\section{APPENDIX C}

\section{Jan's Essay: Second Draft}

\section{FAMILY VALUES}

The year 2002 has been a year of politics and campaigns with each candidate, regardless of party affiliation, invoking the "family values" mantra. The candidates use this to appeal to the common concerns of the common voter. On the surface this seems to be an apolitical issue but the reality is that it is a powder keg of explosive issues rolled into one catch phrase. Defining" "family values" is even a challenge to most but legislators are constantly trying to convince the American public that they know what's best for the preservation of these nebulous standards. There is one group that seems to be caught in the cross fire about who and what constitutes a family. This group is gay and lesbian parents and their children.

There is a huge, commonly held misconception that all families fit into the idealized form of Mother, Father and the children and that families that do not fit into this model are in some way inferior or defective in their composition. Children from these families must live in a culture that tells them that their families are "wrong". The children can't help but infer that they must be "wrong" as well. They are the victims in the struggle between the mainstream heterosexual culture and the not so mainstream homosexual culture. This is a contact zone that is filled with strong emotion and self-righteousness from both sides.

With each side fighting the other for existence, the families with children are caught in the middle of the fight and for the most part forgotten. These families represent both sides of the contact zone simultaneously, one side as gay citizens fighting for recognition and respect, and the other side as parents fighting for the health and happiness of their families. There are numerous organizations that are dedicated to the cause of the family and the preservation of its integrity. There are however, very few dedicated to preserving the rights of the alternative family, specifically families that include gay or lesbian parents. Three organizations have joined forces to create a handbook on how to lobby for these families.

A Tool Kit for a Family Lobby Day is sponsored by Parents, Families and Friends of Lesbian and Gays (PFLAG), Children of Lesbian and Gays Everywhere (COLAGE) and the Family Pride Coalition. It outlines step by step ways to present relevant issues to mainstream legislators. These organizations feel that it is "imperative that our families communicate honestly and more frequently with our elected representatives. No matter where a policy maker stands on issues that affect our lives, our families and our loved ones, we can and must build relationships with those officials to give our issues real names and faces. 
We need to do it for ourselves and for the larger GLBT movement."

The "Tool Kit" provides statistical data to remedy the misconceptions that plague the GLBT community in regards to family structure. The facts contained in the "Tool Kit" help change the commonly held assumption that all families look a certain way. Single parents, racial minority parents and adoptive parents combined with GLBT parents are a growing and important group that gets ignored when the politicians speak of "family values". The statistics help put the reality of family composition into perspective. Debunking the misconceptions about these families is the primary method of communication advocated for the lobbyist interested in affecting change at the legislative level.

The message that all families deserve respect and representation is the driving force behind the "Tool Kit". The fact that one in five gay or lesbian households has at least one child in residence and that there are 3.9 million estimated sons and daughters, under the age of nineteen, with gay or lesbian parents is a sobering statistic that is brought into focus by the "Tool Kit". These facts bring to the forefront the reality that not all families are in the "ideal" form but yet should enjoy the same reverence given to the more traditional model. This "Tool Kit" provides all the ammunition necessary to combat the ignorance that is so pervasive in the political arena. It gives the who, what, when, where and how in the cause of promoting equality in the area of Family Rights as they relate to the GLBT community. It is a thorough and detailed account of issues and solutions that should and could be addressed. Great importance is placed in the furtherance of education for the mainstream to rid it of the negative stereotypes and mythological assumptions that hinder the progress of Family Rights everywhere.

The commonalities parents face are the issues that all legislators can relate to. The safety of our schools and workplaces and the rights of children to grow up free of discrimination are concerns that are common to all. The "Tool Kit" shows the lobbyist for the GLBT community how to merge these commonalities with the Gay Rights agenda to create the most effect. This could be a powerful tool in the struggle against discrimination when presented in a calm, rational and organized manner. 


\section{APPENDIX D}

\section{Kerry's Essay: First Draft}

\section{Contact Zone \\ "Faggot! Talking about I fabricated my past he's just mad I won't ejaculate in his ass."}

These are just a few words from the notorious rap artist Eminem, song titled Marshall Mathers whose recent album went triple platinum. But in the eyes of the public, Slim Shady vicious metaphors and descriptive lyrics are none the least offensive to the gay community. Several songs have created lots of controversy within the hip-hop nation and in society. In many ways this rising star has blessed us with his many talents, providing us with his breathe taking lyrics, but is Slim sending the right message to society.

Eminem is a role model for many young teenagers in today society. A lot of people are concerned with the fact that America praises Slim Shady for discriminating against the homosexual community. Teenagers worship Slim Shady so much that they sometimes make the mistake of confusing his lyrics with reality. Trying to imitate his lifestyle and feel closer to Slim some go out and commit antigay hate crimes towards others. In result the homosexual community has rallied outside of records stores releasing his albums trying to convince others not to purchase his music.

Eminem has not only offended the gay community, but has tampered along the lines with religion. In recent source magazines there have been several complaints about him abusing his freedom of speech. There also has been lots of controversy that has build up in the hiphop nation because of his lyrics. He purposely talks about other rap artist to enlighten his music. Those that even speak out against him are targets to be talked about. Many often wonder does he rap in such a manner because that's what sales or is he really displaying his feeling for others around him.

In many peoples eyes Eminem is doing nothing wrong by exercising his right to produce music in which he feels is suitable to his audience, if people are not mature enough to realize that its just music they shouldn't be aloud to purchase it. Since are technology is so good in this day in age a lot of his music isn't purchased inside music stores, but downloaded off the internet. This makes a lot of rap artist aggravated because it not only takes away from their profits, but also rids the music of its purity. 


\section{Kerry's Essay: Second Draft}

\section{Contact Zone}

\section{"Faggot! Talking about I fabricated my past he's just mad I won't ejaculate in his ass."}

These are just a few words from the notorious rap artist Eminem, song titled "Marshall Mathers" whose recent album went triple platinum. But in the eyes of the public, Slim Shady vicious metaphors and descriptive lyrics are none the least offensive to the gay community. Several songs have created lots of controversy within the hip-hop nation and in society. In many ways this rising star has blessed us with his many talents, providing us with his breathe taking lyrics, but is Slim sending the right message to society?

Eminem is a role model for many young teenagers in today society. A lot of people are concerned with the fact that America praises Slim Shady for discriminating against the homosexual community. Teenagers worship Slim Shady so much that they sometimes make the mistake of confusing his lyrics with reality. Trying to imitate his lifestyle and feel closer to Slim some go out and commit antigay hate crimes towards others. In result the homosexual community has rallied outside of records stores releasing his albums trying to convince others not to purchase his music.

Eminem has not only offended the gay community, but has tampered along the lines with religion. In recent source magazines there have been several complaints about him abusing his freedom of speech. There also has been lots of controversy that has build up in the hiphop nation because of his lyrics. He purposely talks about other rap artist to enlighten his music. Those that even speak out against him are targets to be talked about. Many often wonder does he rap in such a manner because that's what sales or is he really displaying his feeling for others around him.

In many peoples eyes Eminem is doing nothing wrong by exercising his right to produce music in which he feels is suitable to his audience, if people are not mature enough to realize that its just music they shouldn't be aloud to purchase it. Since are technology is so good in this day in age a lot of his music isn't purchased inside music stores, but downloaded off the internet. Slim Shady has several songs in which he talks about the homosexual community, on his recent album he has two skits with a man named "Ken Kaniff" who really is Eminem in disguise. "Hey their cock boy? Who is this Chris? No it's Ken Kaniff from Connecticut, you want me to melt in your ass not in your hand Eminem. Yo Chris fuck you flaming fagot" ${ }^{\prime \prime}$. These skits were very offensive to a lot of people because their was no signifigence to the al- 
bum, they were just installed to humor his audience and make fun of the gay community. Eminem also has a skit with Ken Kaniff were he's giving this guy a blowjob, making all kinds of vulgar sounds which wasn't pleasant. People often wonder what Eminem has against the homosexual community, when confronted about in interviews he's says "Its just music, you don't like don't buy the shit dummies".

Not to long ago at the MTV music source awards Eminem performed one of his hit songs with Elton John who is gay and at the end of their performance Elton John gave Eminem a hug and their was this big situation about Slim involved with Elton. They also interviewed Elton after the awards and he had nothing but, positive feed back. "Eminem is a wonderful artist and I love his music, keep the good work up". So not all people are offended by Eminem music because they understand that's exactly what it is, as far as his lyrics what he's rapping about discriminating against the gay community I believe its wrong but so are a lot of things in this country that we deal with. 


\title{
Student Reflection and Critical Thinking: A Rhetorical Analysis of 88 Portfolio Cover Letters
}

\begin{abstract}
This research is an analysis of 88 first-year portfolio cover letters from the Spring 2000 English 102 Program Assessment at the University of Nevada, Reno. This analysis focuses on what these students viewed as the rhetorical purposes of cover letters. The goal of this study was to apply the theories of Aristotle, Toulmin, and Burke to these letters to analyze their appellate, argumentative, and performative nature. The results of the study suggest that, while a majority of the student writers reviewed what they had learned, offered support for portfolio choices, and supplied information about learning, they did not often reach a level that demonstrated metacognitive ability by examining assumptions about writing and thinking. It is possible that the genre of the portfolio cover letter and its role in reflection need to be reexamined and redefined.
\end{abstract}

As a basic writing and first-year composition teacher, as well as a former basic writing program coordinator, I have found that students often use the term "critical thinking" as a sort of linguistic buzz word, having little idea how to accomplish this "critical" skill. Students often find critical thinking to be a foreign and difficult task, perhaps because it differs educationally from finding a single right answer. As one student puts it, "critical thinking doesn't seem to get me anywhere." Such students can find this kind of analysis time-consuming and confusing, especially when there are several options or avenues from which to choose.

Because our society encourages forward progress and quick fixes and because critical thinking requires stepping back self-critically from the task itself to determine the best course of action, students may struggle with thinking critically. Critical thinking requires students to stretch themselves intellectually and psychologically, possibly taking two steps back before taking one forward. It requires students to dig and take apart their decision-making and justify their actions. According to composition research, one of the ways to encourage this type of cognitive digging is to have students participate in reflective writing. Reflective thinking and writing, as Kathleen Blake Yancey has postulated, can contribute to a student's understanding of accomplishment

Laurel L. Bower received her doctorate in rhetoric/composition from the University of Nevada, Reno, in May 2003. She is based in Boise, Idaho, and is presently writing full-time. She hopes to obtain a teaching position in Idaho in the future. 
because he/she must articulate that accomplishment (Reflection 6). In addition to articulating accomplishment, critical reflective thinking also focuses on how the process itself has progressed, mechanically and intellectually. For the present, this dualistic definition of reflection will be appropriated, although, as a result of my study, I hope to further complicate it.

In my own classes, I have incorporated reflective exercises, but the results have not been satisfying. Often students seem able and willing to step back and review their work but have difficulty weighing alternatives or formulating multiple analytical interpretations. How can teachers encourage students to be independent decision-makers and deeper thinkers, especially with regard to their writing? What kinds of reflective strategies do students exhibit in supposedly reflective documents, such as portfolio cover letters and how can these strategies be expanded?

\section{RESEARCH ON REFLECTIVE WRITING}

I sought answers to these questions through exploring research on reflective writing. Reflective writing seems to be an accepted disciplinary way of encouraging critical thinking in basic writers and indeed in all first-year composition students. If students look back on their work reflectively and attempt to see what they have learned from the writing process, this information can be vital to improving their skills as writers and thinkers. "Becoming aware of your thought processes," according to Swartz and Perkins, is the first step toward achieving metacognition or thinking about thinking (quoted in Barell 258). Reflective writing also encourages students to highlight the reasons behind their choices and to describe how those choices affected their writing.

As Donna Qualley asserts, the treating of self as other, or being reflexive, encourages learners to see themselves through new, self-critical eyes. In Qualley's view, one's self is the object of reflective consciousness in reflexivity, with an accompanying awareness of the self's role as agent in knowledge production (14). To develop this agency, according to Jerome Bruner, students create an "autobiography" in a reflective document that fosters a dialogue with a sense of self. According to Bruner, this dialogue has the potential for "discovery" with the following long-range benefits: ing],

1) an increase in intellectual potency [exercising critical think-

2) the shift from extrinsic to intrinsic rewards [establishing selfdetermination],

3) the learning of the heuristics of discovery [developing a willingness to take risks], and 
4) a way to conserve memory [building experience upon experience] (83).

This is how individual meaning is created. A true dialogue will ask hard questions that demand an answer, and by viewing one's self as other, the individual must reexamine previously held beliefs and decide if those beliefs are beneficial or inhibiting or something in-between. This is the same kind of critical thinking asked of many basic writers in first-year writing assignments when they are asked to reflect upon why they wrote about their topic. Thus, reflective activity that recalls information can foster metacognition, or the analysis of one's thinking, as a way to enhance reasoning skills. In turn, this new information can result in a more satisfying written product and a better understanding for the student of his/her cognitive and linguistic processes.

The next step after recalling information is to contemplate how that information affects why and how one has done what one has and to consider what effect this new analysis might have on future acts. In this way, one begins to achieve control of one's thinking, the second significant part of achieving metacognition. According to Hacker, Dunlosky, and Graesser, the success of this control is realized through knowledge of 1) the task itself, 2) the demands posed by the task, 3) people's knowledge of the task, and 4) the kinds of cognitive strategies people can bring to the task (10). The first two items in this list can be achieved through a heightened awareness of what one has done (a review), but the latter two items must be gained from assessing one's thinking.

When teachers choose to develop their students' reflective and reflexive abilities and help them change their individual cognitive orientations, Kenneth Dowst calls this an "epistemic" approach to teaching, seeing language as a mediator between a self and objective reality (68). In other words, we can not know the world directly; instead we compose our knowledge of the world when we compose with language. Dowst further submits that what we know will affect how we act, and that experimenting with language is analogous to experimenting with knowing, which can result in changed behavior (70). To the epistemic teacher, knowledge, behavior, and language are all inextricably linked, meaning that students are presented with a type of writing activity that they can manage reasonably well, followed by questions that explore the importance of what they, as writers, have just done. Dewey calls this kind of education "progressive," where experience is combined with a review of that experience that yields "capital" for future experiences (87). True learning, Dowst adds, is always a reconstruction of previous learning and experience (73), a reflective building of experience upon experience, and such reconstructions can foster mental adaptation. Berthoff further stipulates that reclaiming the imagina- 
tion is a way of bringing creative mental processes out in the open (4). When students "re-create" what happened in a piece of writing, remembering what they did and why, they are tapping into those mental processes.

In understanding how written reflection influences epistemological development, part of James Britton's theory of how language functions in the writing process is useful in connecting linguistic ability and experiential learning. Britton ("The Composing Process") posits that the writing act can encourage students to assume different roles, because first, they become participants in their writing when they compose a draft of a writing assignment. Such an assignment creates an opportunity for them to experience a linguistic "transaction" between their ideas and an audience, a transaction that is expressive in nature, because, if the topic is self-selected and meaningful to students, it will have purpose for them (16). When students reflexively detach themselves from their writing selves and step back to reflect upon their pieces of writing and see them through a reader's eyes, they become spectators of that writing experience, increasing their understanding of the symbolic and evaluative nature of their work, a cognitive function. Then students might go back and revise their writing, becoming participants again, to perhaps reflect upon the writing at the end, becoming spectators again. Britton adds that while students are participants in their writing evaluations as shapers of the work, they operate under the "constraints of self-interest, in the light of ... [their] hopes and fears regarding the outcome" (17). But when students stand back and become spectators of their work, they will "not lose or gain by the outcome," because they do not see the written product as a part of their sense of self, their ego, at that moment (17).

To further explain how this process works, Britton ("Language") adds that all human behavior is experimental. The way we learn or grow from anything is to form a hypothesis from previous experience (reviewing what we have done) that will be applicable to the present situation. Then we test that hypothesis in light of what actually happens in the present (196-97). Next, we evaluate what this conjunction of past and present has taught and perhaps revise the hypothesis, an act that can reveal not only growth and experiential learning, but can also inform our future acts.

How does self-assessment through reflective thinking lead to changes in thinking and ultimately in behavior? According to Geoffrey Hewitt, it allows an individual to "discriminate between his or her current level of behavior and some significant social or individual standard" (5). Self-assessment, Hewitt adds, can disrupt stereotypical behavior and lead to an understanding of why some behaviors are rewarded in a culture and others punished (5). This is significant for basic writers, who often have developed detrimental behavioral patterns 
in school writing or who may become blocked, feeling that they don't know what is expected. A monitoring of self through reflection helps a learner determine the value system of a particular community and integrate his/her own abilities into the existing system. In academia, Yancey asserts, self-knowledge through assessment can affect what one believes it takes to be a college writer ("Dialogue" 99).

Assessment through reflection or a "rhetoric of reason," as James Crosswhite adds, creates a "dialectic" that allows students to reconcile their previous experience in school and in life with what they are presently learning in college, creating a new learning identity for themselves (285). Some basic writers need to develop new positive writing identities in order to reconstruct or reconcile their present learning with previous beliefs about themselves as writers or about a writing class. David Bartholomae (1985) calls this reconciliation a "compromise" between a student's personal history and the requirements of a particular convention (135). If the student is to be successful in communication, this reconciliation often involves change, a change in how the student approaches and thinks about writing. If it appears that a previous experience or behavior does not fit into or work with the current learning schema, a conflict is created. To resolve this conflict, students must assess their previous beliefs in light of the new material that they have learned. So how do students assess their previous beliefs in reflective documents such as portfolio cover letters?

In reviewing research that contained actual portfolio cover letters as exemplars of reflective thinking, I was surprised to discover that little work had been done regarding what kinds of rhetorical strategies students enact in end-of-semester reflections. While a great deal of theory proposes what reflection is and how it is accomplished, there is little evidence of what students actually do in such purportedly reflective documents. An exception was a study by Edward Wolfe of high school portfolio cover letters; unfortunately, Wolfe's discussion was difficult to follow because of a lack of explanation regarding categorical decisions and conclusions.

Detailed information about the kinds of rhetoric in students' reflective writings might help teachers determine what students can accomplish reflectively and what is missing in their metacognition. What kinds of reflection do students accomplish in cover letters? Do portfolio cover letters appear to be a useful means for reflective activity? Answers to these kinds of questions may provide teachers with insight into students' reflective processes and the rhetoric of the portfolio cover letter. 


\section{RESEARCH DESIGN}

To provide insight into students' reflective rhetoric, I used 88 cover letters from 30 different sections of English 102 (second-semester composition) provided by the Spring 2000 Core Writing Program Assessment conducted at the University of Nevada, Reno, for which I obtained human subject approval. Of the 200 portfolios used for the assessment, 88 had both cover letters and student consent forms. I was privy only to the actual letters themselves, not the cover letter assignments, the teachers' philosophies, or the portfolios, so this study is limited to a rhetorical analysis of the letters only. Future research should delve deeper into the external context of these documents to better understand what can and can not be accomplished through reflection. Case-oriented and longitudinal studies should endeavor to describe what students and teachers actually accomplish through reflection and its long-term effects. Ideally, such studies would include more types of methodologies and would analyze more contextual factors of individual classes such as the reflective assignments themselves, the context of the classes and their curricula, and the personalities of students and teachers.

Portfolios in this assessment were comprised of one best essay, a series of essays, or a multi-genre presentation of written work offered at semester end. Thus, the cover letter, by extension, was the reflective culmination of a grading period, after the portfolio had been compiled and polished, giving students the opportunity to look back at what they had done. The primary reader and grader for these portfolios was the student's classroom teacher. Students knew that five portfolios from each class would be selected for an outside assessment, but they also knew that the outside reader would not influence the teacher's evaluation or grade in any way.

Since there was very little foundational research in cover letter analysis upon which to build, I sought a new methodological approach that addresses what I see as a tripartite set of rhetorical purposes and strategies for the portfolio cover letter.

1. A portfolio cover letter seeks to appeal to a teacher and convince that teacher of epistemological growth in the areas of writing and learning. As an epistemological tool, the portfolio cover letter suggests to an outside audience what students know and how they know it. Because one of the rhetorical purposes of the cover letter, according to McNeill and Bellamy (preface), is not only to give evidence of what was done, but also to convince the teacher that something valuable was learned, the cover letter is a persuasive document. Through the cover letter, students seek to convince teachers that portfolios have been valuable learning tools, and sometimes they justify their grades based upon class criteria. These kinds of appeals can be 
defined by applying Aristotle's theory in which rhetoric seeks to find the "best" means for persuasion (quoted in Bizzell \& Herzberg 153), possibly leading to an understanding of how certain persuasive rhetoric functions (Aristotle, Book II, Chapter 9). Thus, the use of Aristotle's theory of appeals, using ethos, nomos, pathos, and logos, is informative with regard to where students concentrate their persuasive strategies and how they seek to appeal to the teacher.

2. A cover letter allows students to construct arguments to support their writing growth. The cover letter is rhetoric that exhibits argumentative strategies. Students must be able to justify the choices of certain pieces of writing for their portfolios and argue for what and how they have learned. Stephen Toulmin's theory, therefore, about how arguments are structured and supported is helpful in understanding not only how students' arguments are designed and supported with data, but also how the warrants for these arguments work, revealing possible intentions and justifications for the assertions.

3. A cover letter exhibits a public performance of a sense of self that demonstrates learning, shared classroom goals, and valuable classroom experiences. Students can use the opportunity of writing a portfolio cover letter to analyze and critique themselves, participating in reflexive and metacognitive activity. Such an analysis is intended as a performative document that demonstrates individual writing development and describes the circumstances behind that development to the teacher and other readers. Thus, Kenneth Burke's theory about performative acts is useful in analyzing how a self is constructed and presented. This construction includes students' understanding of their writing, their portfolios, and the conditions under which that writing was constructed. Burke's explication of context is valuable in piecing together the rhetorical purposes of students, portfolios, and classrooms, using only the students' rhetoric and the values associated with each. Such a contextual analysis, open to other interpretations of course, will help the reader understand the reasons behind students' selections of assertions and appeals.

\section{THEORETICAL LENSES FOR ANALYZING COVER LETTERS}

\section{Aristotle}

Aristotle believed that argumentative appeals encompass three areas - ethos, pathos, and logos, with a possible fourth being nomos. Categorical definitions follow, with the understanding that sometimes appellate statements can be cross-listed. In most cases, I made a decision about the primary thrust of a statement.

1. Ethos. Appeals to ethos focus on how one establishes authority. This classification is used when a statement seeks primarily to 
assert student or writer authority. An example of a representative student comment is: "I researched this topic extensively, finding everything I could about AIDS" (Letter \#81). This student authenticates writer authority through the thoroughness of the research, establishing the level of effort put forth. In a second example, "I have improved as a writer and have become more aware of my diction, sentence structure and organizational techniques" (\#86), the student shows another way to establish ethos, by stressing important values exhibited by the student's writing and learning.

2. Nomos. Appeals to nomos center on commonly held sets of values, established, in this case, by the students, the teacher, and the classroom culture. An appeal is classified as nomotic when it primarily focuses on the value system of that particular classroom, i.e., the assignments, teacher, or curricular priorities. Examples include "Revision is a very powerful key" (\#6), and "I know I must convey my opinion in a very persuasive manner" (\#2). The latter comment also contains an ethical appeal as the student is establishing authority through reiterating the classroom precept of effective persuasion in writing. An appeal was determined to be nomotic when the verbiage reflected terms often used in an English class.

3. Pathos. Appeals to pathos are designed to evoke or express an emotion, either positive or negative. Pathetic appeals in these letters focus on three areas - students' writing hardships in particular classrooms, pride in what they have accomplished, and the evocation of an emotional reaction from the teacher through the discussion of a particular emotional reaction to an assignment or the offer of a compliment. An example of a hardship comes from Letter \#3: “. . . I tried to think how to change it [the essay]. I was so frustrated I cried for a few minutes and then I gave up." This student later expresses how she/he "hung in there" and went back to writing, having, all in all, a positive learning experience, a comment that accents the draining yet rewarding nature of writing.

Many students express pride in their portfolios and want the teacher to share their feelings. They also seek to evoke sympathy when their performance in the classroom is less than might be expected. An example is "As you know, I had a really bad semester, and some really tough stuff happened ... and my writing suffered" (\#61). Students often compliment their teachers, for example, "I love your down-toearth attitude..." (\#10), possibly to evoke a positive reaction from the teacher and to express appreciation for his/her efforts.

4. Logos. Logical appeals present a rationale or supportive reasoning for certain decisions, in this case, generally signaled by "because." While it can be argued that entire letters, in some cases, are logical appeals, spending their length justifying the choices made and the reasons behind those choices, I limited my analysis to sentences 
and paragraphs. Statements are logical appeals if they primarily present evidence for particular choices or provide rationales. For example, "I chose the pieces for this portfolio, because I can more adequately assert my positions and then support those opinions with analysis ... than in my other writings ..." (\#21).

Students in this group of 88 are least likely to see logical appeals as crucial to persuasion (see Figure 1), except with writerly decisions or reasons for a particular positive evaluation. Logical appeals are used to explain deductive or inductive reasoning for decisions made either in the writing itself, the portfolio as a whole, or a particular method of evaluation. Examples of logical appeals, the first of which also reveals classroom values, are "I chose Essay \#3 and Essay \#4 as my showcase papers because they are the two essay[s] that I applied (or tried to) better transitions, examples, and analysis" (\#22), and "I decided to write my essay on the target audience of two different talk shows ... because I wanted to demonstrate how a particular target audience influenced a show's content" (\#12). The relatively small number of logical appeals present can indicate students' inability or lack of interest in constructing arguments, a lack of depth in cognitive operations, or an understanding of the cover letter as non-logically based.

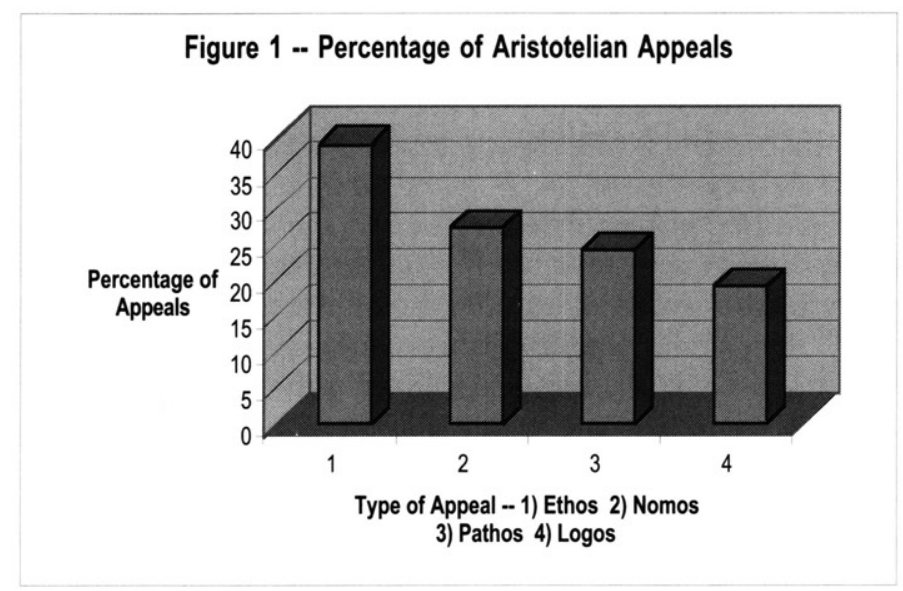

Figure 1 summarizes the frequency of appeals in the 88 cover letters I analyzed. The total is $108 \%$ as a result of cross-listed statements.

The use of Aristotle's appellate theory illustrates how students address and convince teachers of the importance of what they have 
learned as writers and students. Sometimes they connect their learning to the portfolios, although often not in specific ways. This rhetorical goal is followed by instances where students appeal to the teacher and/or reiterate classroom values. When discussing learning, students often do not cite particular passages or techniques in specific writings to illustrate their appellate statements; thus, as we will see in the next discussion about arguments, this lack of specificity results in arguments that are often not well supported.

\section{Stephen Toulmin}

Stephen Toulmin posits that there are three parts to an argument. After the initial assertion is made, a claim or statement where something is put forth that is debatable, it is supported with foundational and evidential backing for the claim, the data. Simply presenting the data, however, without connecting the support to the claim, does not assure the reader of the validity of the argument. Underlying the pertinent data is an assumption, perhaps culturally based, that allows for the logical connection between the assertion and data, also known as a warrant. Warrants can be inferred from the stated assertion and data, and this process allows the reader to see how the conclusion is reached (97-98). In applying Toulmin's theory, ten areas emerge in which students concentrate their assertions.

1. Assertions about how and why certain pieces were chosen for the portfolio. An example is "With each paper I had a specific point I wanted carried out and I believe after the many revisions, my point was made" (\#38). The student uses as data that he/she is proud of the ideas in these papers and that the writing flows. While the points made in each paper are not addressed in the student's letter, he/she does mention that revision involves adding more details and asking readers for input. The warrant, or underlying assumption, is that successful writing (writing that is worth working on) makes readers think or gets across a meaningful point with specific detail.

2. Assertions about the skills, strategies, and knowledge that students gained. While these assertions specify particular skills, they are usually not backed by actual assignments and students' experiences with those assignments. For example, one student asserts that the two essays he chose show examples of better transitions, examples, and analysis, techniques he states he learned from the teacher. The data do not support the claim as well as they might. This student does not provide examples from the portfolio or explain what better transitions might be or how examples and analysis are utilized in these essays. The warrant is that better transitions, examples, and analysis make for better writing or writing that is worthy of being evaluated, and a secondary warrant is that teachers have valuable knowledge to offer students in making them better writers. 
The example above is not the only instance where data are lacking specificity. For example, in Letter \#34 the student asserts that her writing has grown in many ways. As her data, she claims that writing in different genres helped that growth. There is no specific support, however, from the portfolio for exactly where or how her writing has grown. A specific warrant is difficult to determine since the reader is not privy to how writing in different genres helped this student. In most of the letters, asserting writing growth is more important than proving it.

3. Assertions about the writing process on particular portfolio essays. Students often mention something easy about the assignment and something difficult that they have overcome. For example, one student asserts that one of his papers was easy to write, because he freewrote and "barfed" onto the paper. He also asserts that he had a hard time organizing that same paper and hopes he has improved in that area. The warrant is that awareness of positive and negative aspects of the writing process is an important demonstration in a cover letter.

4. Assertions of ability and writing strength. The data provided by students illustrate the strong points of their writing and their abilities as students. The data, however, are often not tied directly to the students' portfolios. One student iterates all the items that cause her to give herself a $90 \%$ in the class - class participation, good class discussion leading, and $\mathrm{B}+$ on all writing assignments, with all requirements turned in on time. In this example and many others, there is no mention of how the portfolio essays justify a grade based upon the quality of writing or learning during the writing and compilation of the portfolio. The warrant is that other factors besides the writing quality should weigh heavily in a student's evaluation. Perhaps the student wishes to draw the teacher's attention away from the quality of the writing, or perhaps he/she does not understand the importance of or know how to talk about the quality of the writing and learning.

5. Assertions about work that still needs improvement. Students who make these claims state that, while they still recognize areas of weakness in the writing, they are certain these papers exhibit their learning in the class. One student claims that he is a better writer and researcher because he knows how to ask for help and how to interview people. He can sit for hours and hours at the computer now without becoming frustrated and can analyze his own writing weaknesses. However, there is no specificity about how he achieved this new ability or about actual changes in his writing process because of this analysis. The warrant is that asserting improvement in writing and claiming awareness of writing processes and weaknesses are the measures of assessment. 


\section{Assertions about how the teacher should read and grade the}

portfolio. Mostly, either all students in a particular class section explain how the portfolio should be graded, or none do. This suggests that students are responding to a specific prompt when they discuss how their work should be graded. When students offer a method of evaluation, they make assertions like the following:

I would like this portfolio to be graded by a fair yet critical eye. If I were to judge this portfolio I would make sure that it fulfills the requirements placed on it. I would look to see that essays have been revised and that time had been spent researching, writing, and revising. However, I would think about the time restraints placed on the person and I would realize that they are not even close to being a perfect writer. (\#32)

In this typical example, while the student acknowledges the teacher's requirements, he/she also provides criteria for evaluation, desiring that the teacher assign a grade based on the level of effort, and not consider the papers only as finished products. The student wants to be graded as a "good student," not necessarily as a writer. One warrant is that the completion of class requirements is not a sufficient criterion for evaluating this portfolio, that the amount of time spent and the level of improvement should also be considered. Another warrant is that the quality of writing alone should not be the primary consideration for a good grade.

7. Assertions regarding the student, teacher, and class. These claims often center on positive aspects of the class and rarely focus on anything negative. Comments include "This was a thought-provoking class" (\#64), or "Your feedback makes me a better writer" (\#41). There are often no particular data given, although occasionally a student mentions a certain assignment or teaching technique as contributing to the assertion. These claims seem to be overall impressions, possibly designed to have a positive influence on the teacher's affective state while reading the letter. Because of a lack of specific data, such warrants are impossible to determine in most cases.

8. Assertions about how "service learning" stimulates outside learning. Many classes contain a service learning component, which requires students to participate in some kind of community service related to the class theme. Students typically emphasize that they took more away from this kind of class than how to write better. The data include understanding concepts like "ethics" and "community" and seeing the need for getting involved in a community. One person states, "Although I only learned the ethics (some) involved in one specific field, it made me realize (also while reading my colleagues essays) that everything we do has an ethical code that is applied and followed in a 
community" (\#16). This student's data support what she learned about ethics and how that knowledge might affect her behavior in her future career, genetic engineering. The warrant is that, as a result of community service, one can understand the application of ethical principles.

9. Assertions about how various curricular choices, other than service learning projects, influence learning. A recurring discussion of marginalia (writing comments and questions in the margins of a reading assignment) is often present. Students claim that utilizing marginalia makes them more reflective, more engaged, and more aware of deeper meanings in their reading. Students support this claim by explaining how they approach reading differently and with a different attitude. Their warrant is that using marginalia improves reading and thinking about reading. For example, one student asserts that marginalia help her/him to be more reflective (\#18). The data are that she/he can now analyze the concept and structure of a story, being able to depict what is being said and why, while reading. The warrant: anything that helps one read more thoroughly also helps writing as well.

10. Assertions about outside factors that cause poor student performance. Students often assert that their less-than-A work is due to circumstances beyond their control. Their data include heavy workloads and other high-level classes. The warrant here is that whenever work and other classes interfere with English homework, teachers should make allowances.

\section{Kenneth Burke}

In A Grammar of Motives, Burke states that every act is motivated and performed in a variety of ways, including the act itself, the purpose, the agency, the agent, and the scene (xv). The act is what took place, in thought or deed (xv), and in this case, also includes the writing, the class, and the assignment of the portfolio cover letter. The purpose is why this particular thing was accomplished (xv), in other words, why this letter was produced. The agency is the means or instruments used to accomplish the act, how it was done (276). From what students mention in these letters, the agency also includes how the portfolio itself was accomplished. The agent is the person who performed the act $(\mathrm{xv})$. In this study, the primary agent is the student, although the teacher may also exert secondary agency as the instigator of the assignment. Finally, the scene is the material situation in which the act took place (128). Because the reader of the cover letter (often the teacher) has inside information and cultural knowledge of the class and student, which an outside reader may not be privy to, the scene may be difficult for a researcher to determine and subject to multiple interpretations. 
Using a Burkean analysis, the primary rhetorical purpose of a cover letter, for most of these students, was to exhibit growth or improvement and changes in their writing processes. The act of the cover letter was an opportunity for students to explain their reactions to writing, to the portfolio, and to particular curricular choices. For the most part, students situated themselves in such a way as to appeal to the teacher by iterating the value system of their particular environment, perhaps telling the teacher what she/he might want to hear. If agency with regard to a cover letter is viewed as the ability to assert oneself and one's ideals, then these cover letters encourage students to assert their learning. For the most part, however, students seem more concerned with pleasing the teacher and appealing to his/her set of values than analyzing their priorities and thinking. For example, while one student states that he/she views the portfolio as a celebration of learning, the entire letter is a discussion of positive aspects of the class such as research techniques, marginalia, and service learning without applying this information to the student's learning as demonstrated by the portfolio (\#17).

When looking at letters from single class sections to analyze scene, if the curriculum appears to prioritize grammatical issues, then the cover letters from that section seek to mention how students have improved in that area. If the curriculum focuses on ethics and community, students center their letters on these areas. If students feel they can be effective in appealing to their teacher's compassion, then the letters contain emotional appeals that explain the circumstances behind a lack of performance.

It is also evident that students attempt to attach their new learning onto the old, saying, for example, "I used to think revision was a waste of time, but now I think it is valuable" (\#33). This is a conjoining of the past with the present, but often students make such statements without reconstructing the basic assumptions under which their writing operates. Why did this student think revision was a waste of time? How and in what ways did the student's ideas of revision change, and why does he/she feel it is now a valuable tool? Without such reconstruction, little critical thinking can transpire. This may mean that most students have not gained control over their thinking but are merely paying lip service to the classroom's values, a move that does not alter thinking about writing on a long-term basis. According to John Barell, students who lack metacognitive knowledge are unable to "transfer knowledge or skills from one situation to another" (259).

\section{Summary of Aristotelian, Toulminian, and Burkean Perspectives on Portfolio Cover Letters}

Many students' assertions and appeals are tied to evaluation, rather than to a depth of thinking about learning or writing. They 
primarily seek to argue for a satisfactory grade. In addition, students often reject the finished portfolios as their primary means of evaluation. This assertion can indicate a lack of confidence on the student's part about the quality of the writing or her/his performance in the classroom. Students are aware of their audience (the teacher, in most cases) and argue and appeal in such a way as to validate their teacher's efforts and values.

The data in students' assertions are often scanty and unspecific, particularly in supporting assertions about writing decisions and choices. For example, one student claims to have done as much as possible for the portfolio. The data for this "outstanding" portfolio are that he/she made it look "as neat and proper as possible" (\#2). Since the terms "neat and proper" are not explained, it is difficult to deduce the warrant. Rarely do students argue that their portfolio achieves personal writing goals, so the learning often seems not as personally meaningful as it might be.

The specificity exhibited by many students in discussing curricular elements points out that, when students understand how some aspect of the class influences their writing, they can support their assertions well with data, unlike their assertions about writing choices. For example, one student claims, "This entire class has really brought together the ideas of 'community' and 'ethics' for me." The data are "At first, I failed to see the connection. Through the Service Learning Project and the many in-class discussions I realize how I am a part of a community. I can choose to become involved and make a difference in my community or I can sit back and let things happen" (\#17). One warrant is that service learning and class discussions connect ethics and community. Another warrant is that service learning helps one understand one's role as a citizen of a community.

Since students almost universally claim to have learned something in class, they argue for the pertinence of the teacher/class in achieving that learning. Comments about peer feedback and teacher input as contributing to the quality of writing are very common. Rarely do students analyze their own part in improving their writing skills and processes. In general, students are reluctant or unable to talk about writing processes in detail. Often writing growth is claimed but not supported, as in this example, ". . I I have grown as a writer and researcher throughout the semester" (\#10). Warrants cannot be determined from such assertions.

In the evaluation of writing, warrants generally reveal elements that are privileged by the student and teacher. A lack of detailed discussion, however, often brings the value-changing adoption of those elements into question. An example is the student who states, "I now know how to effectively revise" (\#33). The student does not explain his/her definition of effective revision or what has been specifically learned that contributes to this understanding. 
All in all, instead of focusing on portfolios, students view the primary rhetorical purpose of these letters as reviewing their learning rather than providing a detailed analysis of goals and thinking. Students' arguments primarily assert changes in writing and learning, but they are often poorly supported with evidence from the portfolio. The majority of these cover letters are inadequate in providing insight about what the students learned and information about how they might apply that learning in the future.

In looking at these 88 letters using the three theoretical lenses, I surmise that while students often review their processes in these documents, they do not actually exhibit metacognition. When students state, "I've learned how to be a better writer," there should be sufficient support for this kind of assertion. But beyond that, the students should be able to articulate how their thinking about and approach to writing have changed to make them better writers. One student claims, "I feel I have made progress in my work from the beginning of the semester and my writing shows that. I know that I look at things in a different perspective and analyze the stuff I feel to be important and crucial. My introductory survey shows how I have progressed, because it shows my new knowledge about research. My service learning project shows my ability to use theory and praxis" (\#18). This student attempts to articulate how he/she has changed when approaching writing and thinking. To demonstrate true metacognition, however, the student needs not only to indicate places where change has happened but also to specify how his/her perspectives have changed. How does the student decide what is important "stuff," and how does he/she analyze that stuff? Exactly how does this student's project conjoin theory and praxis, and what is the student's new knowledge about research?

\section{PROBLEMS WITH THE GENRE OF THE COVER LETTER}

As a result of this study, I believe there may be previously unexplored reasons why portfolio cover letters sometimes lack an articulation of cognitive analysis. It is my contention that the expectations for a cover letter and the student's perceptions of those expectations may be at fault for not fostering a deeper assessment of writing and thinking. First of all, the cover letter is usually addressed to the teacher, as it was in $72 \%$ of these letters. This immediately prescribes an evaluative audience and influences the letter's rhetorical purpose. While students may attempt to articulate changes in their writing and thinking because of the assignment and the teacher's expectations, students may still perceive of the cover letter as another means of assessment or as a way of achieving a dialogue with the teacher. On the other hand, when the teacher is not the audience, as in several letters addressed "To whom," the rhetorical purpose of the cover letter may have nothing to 
do with writing or thinking processes, as in the case of a student who spent the entire letter complaining about English or another case in which the student used the letter to comment on his/her college experience thus far. Perhaps a neutral yet familiar audience (the self?) would encourage self-examination.

Because of the students' impressions of the evaluative nature of the cover letter, they often justify or argue for a particular grade based upon the number of times that they assert growth and learning. Additionally, they comment upon their performance as students, compliment the teacher or the curriculum, complain about circumstances beyond their control, or describe and defend a particular topic. Ironically, students neglect what should be a primary purpose for a reflective document, to probe thinking and writing to integrate growth and change. Reflection becomes a lesser concern when the cover letter is viewed as an occasion to argue for a particular grade or to justify choices made in the portfolio. When evaluation takes precedence over reflection, students may also resort to description and explanation, techniques they are more comfortable with and more experienced at, rather than analysis, which is a more abstract and complex process.

Another problem with the genre of the cover letter may be its length. Most of the letters in this group of 88 letters were one page. A one-page cover letter is often a sweeping review of what has been done without a great deal of detail. Teachers, through conferencing with students about cover documents, can encourage students to include more specific examples of changes in their writing and thinking processes, perhaps encouraging a paper that is the length of an average reflective essay, say three to five pages, rather than a one-page, singlespaced letter.

Finally, a problem with the portfolio cover letter is its point in time. The end of the semester may not allow sufficient time for students to reflect as well or as deeply as they might if more time were allowed for thinking about how writing and thinking have changed. Usually there is a time crunch because students are studying for exams and finishing large projects for different classes. This can make a reflective letter a rushed or incomplete document without sufficient thought behind it. There can also be an advantage, however, in writing a cover document right after the portfolio is completed in that particulars about how papers were accomplished are still fresh in the student's mind. J. P. Powell contends that the reason why reflection works better at an end point in writing is because "it is extraordinarily difficult to identify what one is learning when engaged in a learning task..." (45). That's why "stepping back" or "turning back around" through reflection can help students better describe their feelings and thoughts about what happened when they aren't in the middle of learning (Verene 51-52). A plausible solution to overcoming the end-of-se- 
mester crunch might be to include the portfolio cover essay as another writing assignment, cycled through with drafts, peer workshopping, and teacher conferencing.

\section{CONCLUSION}

Like writing, reflective metacognition is a process with components such as review, reflexivity, and cognitive analysis, which require practice throughout the semester in order to maximize a learner's potential for growth and change. To be effective, reflective thinking should be bound up in the philosophy of writing as a whole, recognizing that the development of reflective ability is highly individualized and creatively cognitive. Students may progress through reflective stages at different rates, but all should be encouraged to attempt deeper reflection. Because metacognition is a complex skill, it is usually not intuitively understood, and students must be guided and be able to attain sufficient practice with it. Sources that can help teachers develop plans for increasing students' reflective abilities include Barell, Kay Burke, Calfee and Perfumo, Cranton, Foster, Hewitt, Johnston et al., Murphy and Smith, and Smyser.

While a great deal of research has proposed what students should do in portfolio cover letters, the reality may be different because of varying levels of cognitive maturity, lack of reflective practice, and/or the requirements of the assignments. While encouraging self-awareness, a cover letter alone may not give students sufficient practice to understand metacognition. By setting individual writing goals and progressing from simple to more complex reflective problem-solving questions that culminate in a deeply reflective essay at semester's end, basic writers and indeed all first-year college writers can become more reflective thinkers who are learning to be proficient at self-analysis and assessment. Along with writing, reflective analysis can become a lifelong habit that leads to better decision-making, more skilled writing, and continued intellectual growth.

\section{Works Cited}

Aristotle. Rhetoric. W. Rhys Roberts, trans. New York: Modern Library, 1984.

Barell, John. Teaching for Thoughtfulness: Classroom Strategies to Enhance Intellectual Development. White Plains: Longman, 1995.

Bartholomae, David. "Inventing the University." In When a Writer Can't Write. Ed. Mike Rose. New York: Guilford, 1985.

Berthoff, Ann E., Ed. Reclaiming the Imagination: Philosophical Perspectives for Writers and Teachers of Writing. Portsmouth, NH: Boynton/ Cook, 1984. 
Bizzell, Patricia, and Bruce Herzberg. The Rhetorical Tradition: Reading from Classical Times to the Present. Boston: Bedford Books, 1990.

Britton, James. "The Composing Processes and the Functions of Writing." In Research on Composing: Points of Departure. Ed. Charles R. Cooper and Lee Odell. Urbana, IL: NCTE, 1978.

"Language in the British Primary School." In Prospect and Retrospect: Selected Essays of James Britton. Ed. Gordon M. Pradl. Montclair, NJ: Boynton/Cook, 1982.

Bruner, Jerome S. On Knowing: Essays for the Left Hand. Cambridge: Harvard UP, 1979.

Burke, Kay. The Mindful School: How to Assess Authentic Learning. Rev. Ed. ERIC ED425196, 1994.

Burke, Kenneth. A Grammar of Motives. New York: Prentice-Hall, 1945. Calfee, Robert C., and Pamela Perfumo, Eds. Writing Portfolios in the Classroom: Policy and Practice, Promise and Peril. Mahwah, NJ: Lawrence Erlbaum, 1996.

Cranton, Patricia. Understanding and Promoting Transformative Learning: A Guide for Educators of Adults. San Francisco: Jossey-Bass, 1994.

Crosswhite, James. The Rhetoric of Reason: Writing and the Attractions of Argument. Madison: U of Wisconsin P, 1996.

Dewey, John. Experience and Education. New York: Macmillan, 1938.

Dowst, Kenneth. "The Epistemic Approach: Writing, Knowing, and Learning." In Eight Approaches to Teaching Composition. Ed. Timothy R. Donovan and Ben W. McClelland. Urbana, IL: NCTE, 1980.

Foster, Graham. Student Self-Assessment: A Powerful Process for Helping Students Revise Their Writing. Markham, ON: Pembroke, 1996.

Hacker, Douglas J., John Dunlosky, and Arthur C. Graesser, Eds. Metacognition in Educational Theory and Practice. Mahwah, NJ: Lawrence Erlbaum, 1998.

Hewitt, Geoffrey. A Portfolio Primer: Teaching, Collecting and Assessing Student Writing. Portsmouth, NH: Heinemann, 1995.

Johnston, Brian, Stephen Dowdy, Margaret Cain, Sr., Marion Richardson, and Helen Richardson. Assessing English: Helping Students to Reflect on Their Work. Philadelphia: Open UP, 1987.

McNeill, Barry, and Lynn Bellamy. "A Guide to Self-Evaluation and Documentation of Educational States." U.S. Arizona. ERIC ED386468, 1995.

Murphy, Sandra, and Mary Ann Smith. Writing Portfolios: A Bridge from Teaching to Assessment. Scarborough, ON: Pippin, 1992.

Powell, J. P. "Autobiographical Learning." In Reflection: Turning Experience into Learning. Ed. David Boud, Rosemary Keogh, and David Walker. New York: Nichols, 1985.

Qualley, Donna. Turns of Thought: Teaching Composition as Reflexive Inquiry. Portsmouth, NH: Boynton/Cook, 1997.

Smyser, Sheryl O'Sullivan. "Encouraging Reflection through Portfo- 
lios." Proceedings of the National Conference on Linking Liberal Arts and Teacher Education. U.S. California. ERIC ED390817, 1994. Toulmin, Stephen Edelston. The Uses of Argument. Cambridge: Cambridge UP, 1958.

Verene, Donald Phillip. Philosophy and the Return to Self-Knowledge. London: Yale UP, 1997.

Wolfe, Edward W. "Student Reflection in Portfolio Assessment." U.S. Iowa. ERIC ED396004, 1996.

Yancey, Kathleen Blake. "Dialogue, Interplay, and Discovery: Mapping the Role and the Rhetoric and Reflection in Portfolio Assessment." In Writing Portfolios in the Classroom: Policy and Practice, Promise and Peril. Ed. Robert C. Calfee and Pamela Perfumo. Mahwah, NJ: Lawrence Erlbaum, 1996.

Reflection in the Writing Classroom. Logan: Utah State UP, 1998. 


\title{
Paul Kei Matsuda
}

\section{Basic Writing and Second Language Writers: Toward an Inclusive Definition}

\begin{abstract}
Defining basic writers is becoming increasingly complex as the linguistic and cultural diversity of the college student population continues to intensify. Because the definition of basic writers influences whose needs are considered and whose needs are not, it is important to examine how basic writers are conceptualized in the disciplinary practices of basic writing. This historical article documents how the presence of second language writers has been reflected - or not reflected - in the definition of basic writers over the last four decades and highlights the importance of defining basic writers in ways that include all students who are subject to the disciplinary and instructional practices of basic writing.
\end{abstract}

Defining basic writers has always been a tricky business. Almost three decades ago, Mina P. Shaughnessy pointed out that "[o]ne school's remedial student may be another's regular or even advanced freshman" ("Basic"137). Similarly, a student who would be placed in a basic writing class at one institution might be enrolled in an English-asa-second language (ESL) writing class at another. In some cases, the same students who were identified as exemplary students in high school find themselves labeled "remedial" in college (Harklau "'Good Kids"). As Lynn Quitman Troyka has pointed out, describing writers as "basic," "remedial," or "developmental" tends to mask the diversity of the student population such terms are supposed to represent ("Defining"). Linda Adler-Kassner and Gregory R. Glau have also pointed out that "[q]uestions about what basic writing is, who basic writers are, and how to work with students in basic writing courses are some of the field's most compelling issues"(1). As the student population in institutions of higher education grows increasingly diverse both linguistically and culturally, the definition of the term "basic writer" is becoming even more complex.

Paul Kei Matsuda is Assistant Professor of English and Associate Director of Composition at the University of New Hampshire, where he teaches various writing courses as well as graduate courses in composition studies and applied linguistics. He has founded and chairs the Symposium on Second Language Writing, and co-edited several books, including Landmark Essays on ESL Writing (Erlbaum, 2001) and On Second Language Writing (Erlbaum, 2001). His work appears in such journals as Academic Writing, College Composition and Communication, Composition Studies, Computers and Composition, Journal of Second Language Writing, and Written Communication. 
In practice, most basic writing specialists recognize the difficulty of defining basic writers. In the professional literature of basic writing, however, the generalized term "basic writer" has often been used in referring to diverse groups of students without regard to their backgrounds-linguistic, cultural, or educational. Although it is important to avoid essentializing student populations by providing a detailed description of the particular group in question (Troyka "Defining" 13), generalized terms are sometimes necessary and useful because they enable scholars to talk about issues that cut across different institutional contexts. Yet, in teaching-related fields such as basic writing, those generalized terms - and the image of the "basic writer" reinscribed by the use of those terms - also implicitly define basic writing teachers and scholars as well as the scope of the field of basic writing. In other words, the conception of the basic writer in the professional literature has a significant bearing on who is included and who is excluded in the discussion of student needs and of pedagogical and administrative solutions.

One group of students who have traditionally been excluded from the conception of basic writers in the professional literature are the socalled Generation 1.5 ESL students - active learners of the English language who have received at least several years of U.S. high school education. ${ }^{1}$ They are often recent immigrants or refugees, although some international ESL students also fit this description. They come to basic writing courses for various reasons. In many cases, they are placed in basic writing courses rather than ESL writing courses because they are not clearly identifiable as ESL writers from their student records or from their spoken and written language features. Sometimes students are required to take basic writing courses after completing ESL writing courses because writing placement exams - many of which are not designed with nonnative speakers in mind -indicate that they are still unprepared for required first-year composition courses. In some cases, Generation 1.5 students are placed in basic writing courses rather than ESL writing courses because, for historical reasons, many ESL writing courses are designed for international ESL students (Matsuda "Reexamining"), whose needs are at least partially different from those of Generation 1.5 ESL students. ${ }^{2}$ In other cases, institutions have no choice but to place all ESL writers - both Generation 1.5 students and international students - into basic writing courses because they have not been able to obtain the resources or the expertise to develop and maintain separate ESL writing courses.

Despite the presence of Generation 1.5 students in basic writing classrooms, the amount of attention given to them in the field of basic writing has been, as I will show, rather scant. My goal in this historical essay is to examine how ESL writers - especially Generation 1.5 students - have fared in the conception of basic writers in the disciplinary 
practices of basic writing since the 1960s. In so doing, I hope to highlight the importance of defining basic writers in ways that include all students who are subject to the disciplinary and instructional practices of basic writing.

In constructing my historical narrative, I refer frequently to specific institutional practices that played an important role in the development of basic writing as a field of inquiry. Yet, my goal here is not to critique the work of basic writing specialists at the institutions mentioned or to examine the development of those programs in the larger political contexts. While I recognize the need for a more politically interested historiography, my primary focus here is to document how ESL issues have been positioned in relation to the disciplinary practices of basic writing. What I hope to accomplish with this article is to provide a description of the disciplinary context that shaped and was shaped by specific institutional and pedagogical practices, thereby laying the groundwork for the examination of the larger political context as well as more situated inquiry into specific institutional practices.

\section{The Increase of Generation 1.5 ESL Writers in the 1960s}

Although Generation 1.5 ESL writers have gained significant recognition only in the last decade or so, especially as a result of the publication of Generation 1.5 Meets College Composition (Harklau, Losey, and Siegal), their presence in U.S. higher education - and basic writing classrooms - is not a new phenomenon. As early as 1956, William Slager of the University of Utah noted the presence of a "large number of immigrants who have serious difficulties with English." As he explained, "Many of these students have lived in the community for years; they may even have graduated from local high schools and have served in the armed forces. Yet their scores in the English language tests are often as weak as, or weaker than, those of the newly arrived foreign students" (24-25).

Because of the language difficulties that were, in some ways, reminiscent of those faced by international ESL students, who had been part of U.S. higher education from earlier on (see Matsuda "Composition"), immigrant ESL students were often placed into existing ESL courses or "the Remedial English course for the regular American students" (Slager 25) based on the availability of courses rather than the students' needs. However, neither ESL writing courses nor remedial writing courses were able to provide adequate instructional support for immigrant ESL writers. Remedial English courses were inappropriate for obvious reasons: They were designed with monolingual native speakers of English in mind and did not include components that addressed specific difficulties that immigrant ESL students had, which "overlap[ped those] of the newly arrived foreign student's and the 
native-born American's" but were "the same as neither." In short, Slager emphasized that immigrant ESL students needed special assistance in learning English "for they cannot pass the regular freshman course" (26-27).

To many teachers and administrators at institutions where ESL programs or courses were already available, "an obvious solution" was "to put the immigrant and the foreign student in the same class, since their test scores prove to be comparable" (Slager 25). Slager argued, however, that this practice was "unwise" because, "although both groups need special work in English as a foreign language, the kind of work they need is often very different" (25). In most cases, existing intensive ESL programs - many of which were originally developed at internationally known research institutions, such as the University of Michigan - were designed specifically to address the needs of international ESL students, who, unlike immigrant ESL students, had rather limited previous exposure to the linguistic, cultural, and educational practices in the United States. As Slager, a former staff member of Michigan's English Language Institute, pointed out, "the same materials and techniques" developed at Michigan "do not work ideally with the immigrant":

Even though they have serious problems in English as a foreign language, the immigrants do not profit from classes that are specifically devised for the newly arrived foreign students. They need special work on grammar of usage. But they often need no help at all in aural comprehension; and since they have lived for some time in this country, they need very little orientation. (28-29)

Drawing on the habit-formation model of language acquisition, which was the most popular theory of language learning at the time, Slager explained the language difficulties encountered by immigrant ESL students as the unlearning of previously acquired language habits influenced by features of their native langauge. ${ }^{3}$ Based on this assumption, he further argued that the task for immigrant ESL students - and for their teachers - was "more complicated" than for international ESL students (28). For this reason, he argued the need to develop courses and materials designed specifically for immigrant ESL students in U.S. higher education. He wrote:

As yet, the best that can be said is that no linguistically sound materials have appeared specifically aimed at preparing the immigrant (who is in many ways already part of our community) for work in English on the college level. That there is a need for such specialized materials, there can be no doubt. (29) 
However, the issue of providing linguistic support for immigrant ESL students did not attract significant attention until much later because the increase in this group of students was, at least initially, a gradual process. Although, as Slager suggested, some institutions had already enrolled a large number of immigrant ESL students by the mid 1950s, other institutions did not begin to admit immigrant students with severe language difficulties until much later. At Hunter College of the City University of New York, for example, "immigrant groups" prior to the 1970s "had evidently mastered English before applying for admission" (Decker, Jody, and Brings 88), and ESL students were placed into "regular credit courses with native speakers" (Martino 22). In fact, the ESL student population before the 1970s consisted largely of international students who came to the United States on student or exchange visas; the immigrant ESL population remained relatively small until the late 1960s and early 1970s.

One of the reasons that relatively few immigrant ESL students had made their way into higher education was the admission requirements. Immigrant ESL students, because they were residents of the United States rather than "international" or "foreign" students, were expected to meet the same admission criteria as other U.S. students who were native English speakers. However, immigrant ESL students were often unsuccessful in gaining admission because few elementary and secondary schools were able to provide adequate linguistic support for them to succeed academically. Furthermore, as Guadalupe Valdés and Richard A. Figueroa have shown in Bilingualism and Testing: A Special Case of Bias, standardized tests, which are often designed only with monolingual speakers of English in mind, tend to disadvantage bilingual minority students. (For further discussion of how writing exams may disadvantage second language writers, see Benesch; Johns "Interpreting.")

In contrast, most international students, who went through different application processes, did not face this particular institutional barrier. Before English language proficiency tests such as the Michigan Test of English Language Proficiency (MTELP) and the Test of English as a Foreign Language (TOEFL) were developed in the 1960s, institutions did not have adequate means of assessing students' English language proficiency prior to their arrival in the United States. As Steven G. Darian, citing Edward Cieslak, wrote:

In a 1952 survey of 257 foreign students, Cieslak reports that under half ( 47 per cent) had to submit evidence of English proficiency prior to admission. Most frequently the evidence of proficiency consisted of statements by consular officials, cultural attachés, English teachers overseas, or an officer from a 
school the student attended. The second most used evidence was a statement that English had been studied in secondary school. Twenty-three percent of the foreign students surveyed listed screening of English by individuals who had returned home from the United States. Thirty-five percent stated that no proficiency in English was required. (107-8)

Although standardized college admission tests had been around since the beginning of the twentieth century, institutions were not able to use them as part of the admission requirement for international students because these tests were not readily available outside North America. Instead, international students were required to demonstrate their English language proficiency by successfully completing coursework in intensive English programs or, since the 1960s, by taking English language proficiency tests for nonnative speakers such as MTELP and TOEFL that were administered in various parts of the world (Spolsky).

Even when immigrant ESL students made it into college, institutional responses to their unique needs were negligible because their presence was often not officially recognized by institutions of higher education. Immigrant ESL students were virtually invisible to administrators - though certainly not to teachers who encountered them in the classroom. As Linda Harklau, Meryl Siegal, and Kay M. Losey have pointed out, institutions have not typically collected records of students' linguistic backgrounds ("Linguistically" 2). Although some attempts to adjust existing ESL or basic writing courses to the needs of immigrant ESL students were made locally, in most cases these efforts were left to the individual teacher's discretion. All in all, the immigrant ESL student population did not reach a critical mass until the 1970s, and composition specialists and second language specialists in general were slow to respond to Slager's early call for specialized materials and courses for immigrant ESL students.

\section{Open Admissions and the Rise of Basic Writing}

One of the most important forces for institutional change came around 1970 with the advent of the open-admissions policy that took effect at many urban institutions. Open admissions brought an influx of students who had traditionally been excluded from higher education, including a large number of citizens and permanent residents of the United States who spoke languages other than English at home. The most widely publicized and well-documented case of open admissions took place in the spring of 1970 at the City University of New York (CUNY).

Although the majority of the open-admissions students at CUNY 
during the first few years were U.S. citizens of European descent, there also was a growing number of "ethnic minorities," many of whom were speakers of so-called standard English as a second dialect (SESD) as well as English as a second language (Cross). The open-admissions students also included a large number of "foreign-born" students. By 1980 , at least $21.4 \%$ of newly entering students and $18.5 \%$ of transfer students at CUNY were born outside the United States (City University of New York). Referring to the diversity of the student population, Anne Folger Decker, Ruth Jody, and Felicia Brings, in A Handbook on Open Admissions, characterized CUNY as "a funnel into which people of all classes, races, religions, nationalities, and experiences were poured and out of which 'college students' emerged" (10).

The influx of students from a wide variety of backgrounds prompted some important institutional changes because it became clear to many that existing college curricula, which had traditionally served native speakers of English from relatively homogeneous upbringings, were not able to provide instructional support appropriate for the openadmissions students. The difficulties faced by open-admissions students were multiple-including cultural differences as well as a fundamental lack of preparation in math and English, especially reading and writing. Many institutions across the nation followed CUNY's lead in developing support programs for the new population of college students. By 1974, 71\% of all accredited colleges and universities in the United States had or were in the process of creating a basic skills program (Smith et al., cited in Lunsford Historical 45). In a survey of 58 U.S. colleges, Andrea Lunsford also found that $90 \%$ of these institutions "either already had or were planning to institute remedial English programs for their students" (cited in Lunsford Historical 45).

At CUNY, the differing needs of ESL students were recognized from the outset, and separate tracks of basic skills courses for basic writers and ESL students were created. Open-admissions students were generally categorized into "foreign-born" students - including recent immigrants and international students - and "native-born" U.S. students, some of whom also might have been second language writers. For instance, Hunter College, one of CUNY's four-year institutions, created "a parallel...sequence of courses" (Shaughnessy "Introduction" 3) "to help the [ESL] student acquire greater facility in written and spoken English" (Lavin, Alba, and Silberstein 261). Decker, Jody, and Brings also reported: "The English department [at Hunter College]...proposed that reading and writing be dealt with separately and that writing remediation be further specialized into non-ESL and ESL programs" (95). Additional support for ESL students was provided through tutoring programs, although they were not originally intended for ESL writers (88).

Efforts were also made to distinguish ESL students from basic 
writers through placement exams. Hunter College administered tests "in English structure and mechanics, reading comprehension, and second-language problems, as well as an essay exam to be scored by the English faculty" (Decker, Jody, and Brings 54). While the testing procedure was generally effective, it was time consuming for faculty members in the English department, and attempts were made to simplify it. As Decker, Jody, and Brings wrote:

In the summer of 1972...the English department tried eliminating the essay for these students in order to shorten the testing time and to see if placements could be made solely on the basis of an objective test. The department found that the objective test was fine for gross sorting - "needs remediation" or "does not" - but only a writing sample can indicate the fine distinctions between levels of remediation or the need for ESL (English as a Second Language) placement. In fact, the objective test originally adopted to select for ESL problems could not discriminate ESL from among a variety of other nonstandard English problems such as dialect and black English; when used without a writing sample, the test often indicated ESL placement for students who spoke only English. (56-57)

Realizing the complexity of identifying students who needed ESL support, Hunter College resolved to use multiple testing instruments, including an essay and the second language test as well as "objective" tests in reading, written English, and mathematics (Decker, Jody, and Brings 57).

CUNY's effort to distinguish basic writers from ESL students systematically and to provide separate instruction was an exception rather than the rule. At many other institutions, where the number of ESL students was relatively small or the commitment to providing instruction in basic skills was not as strong, resources were not allocated to develop separate programs for basic writers and ESL writers. In those situations, ESL students were often placed with native English-speaking students into basic writing courses or non-ESL sections of composition courses. For example, James R. Nattinger wrote in 1978 that "Portland State University, like any public urban university, has many second dialect and second language speakers, and like most, assigns these students to composition classes without regard for linguistic background" (79). In an article published in the 1987 issue of the Journal of Basic Writing, Jean Sanborn also wrote: "At many colleges, advanced English as a Second Language students enroll in regular basic writing courses or visit the Writing Center, particularly at small schools like Colby College that do not have an ESL program or faculty trained in ESL" (60). 
Although some composition teachers with additional expertise in second language teaching argued that basic writers and ESL writers can profitably be taught together (Roy "Alliance"; "ESL"), the vast majority of composition teachers continued to be unprepared to work with ESL writers in their classrooms. For this reason, the placement of basic writers and ESL writers in the same class was considered inappropriate by many second language specialists, who argued for separate courses for ESL writers on the basis of linguistic differences. ${ }^{4}$ For example, James Nattinger argued that basic writing courses may be appropriate for speakers of so-called "Standard English as a Second Dialect (SESD)" students but not for ESL writers "who...should study English composition apart, with a teacher trained in ESL methods" (79). In "ESL/Remedial English: Are They Different?" Sandra Lee McKay also warned that placing basic and ESL writers together to preserve financial resources without consideration for the special needs of ESL students was unwise.

\section{ESL Issues in the Work of Mina Shaughnessy}

Partly due to second language specialists' arguments for separate courses as well as the institutional separation at influential programs such as CUNY's, the field of basic writing did not fully integrate issues related to ESL writers within its scope. Although there were some notable exceptions (e.g., Lay "Chinese"; Rizzo and Villafane; Davidson; Bruder and Furey), the place of ESL issues in the field of basic writing in the 1970s was at best marginal. Perhaps one of the best ways to understand the relationship between ESL writing and basic writing is to examine how basic writing and writers have been defined by prominent figures in the field. In this section, I want to focus on the definitions of basic writing and writers by Mina P. Shaughnessy (19241978), undoubtedly one of the most influential leaders - both intellectually and morally - in the development of the field of basic writing in the 1970s. In a series of highly influential publications, she called for an increased attention to the writing needs of open-admissions students, thus contributing to the emergence of basic writing as a respectable subfield of composition studies.

Although Shaughnessy was genuinely committed to helping all open-admissions students and was also aware of the presence of ESL students, the place of ESL writing issues in her view of basic writing was rather tenuous. In "Basic Writing," a 31-page bibliographic essay, for instance, reference to ESL appears in only one paragraph. Her focus in this brief paragraph is not so much on the needs of ESL writers in basic writing classrooms but on the relevance of ESL pedagogy to basic writing. Shaughnessy seems to include immigrant ESL writers in her definition of basic writers when she refers to students who "have 
come from families and neighborhoods where people speak other languages" (139). Later in the same essay, however, she states: "Because of the quasi-foreign nature of the difficulties basic writing students have with formal English, many of the techniques developed in foreign-language teaching seem to be applicable to basic writing" (162; emphasis added). The use of the prefix "quasi-" suggests that basic writers' difficulties are not of "foreign" nature. That is, the definition of basic writers implicit in this sentence is distinct from ESL students who came from other countries, although it may include speakers of a "contact variety" of English (Valdés 103) - i.e., native speakers of non-dominant varieties of English whose speech and writing may exhibit linguistic features that resemble those of ESL writers.

That Shaughnessy was concerned almost exclusively with nativeborn U.S. citizens is also apparent in Errors and Expectations. In her introduction, Shaughnessy classified open-admissions students into three types, including: "(1) those who met the traditional requirements for college work"; "(2) those who had survived their secondary schooling but not thrived on it, whose reading was seldom voluntary and whose writing reflected a flat competence"; and "(3) those who had been left so far behind the others in their formal education that they appeared to have little chance of catching up" (2). Describing the third group of students, whom she characterized as "the true outsiders" (2), she wrote that their "difficulties with the written language" made them seem "as if they had come from a different country" (2; emphasis added), implying that they are not actually from other countries. Later, she noted that the student population she considers in Errors and Expectations is, for the most part, those who are "native to the United States, where they have had from twelve to thirteen years of public schooling, mostly in New York City" (7).

Although ESL was not Shaughnessy's utmost concern, she was not oblivious to the presence of ESL writers, either. In fact, her editorial in the inaugural issue of the Journal of Basic Writing (1975) refers to the presence of "foreign-born students, who make up about 10 percent of each freshman class" at City College ("Introduction" 3). However, she also recognized that "native-born" basic writers and "foreign-born" ESL students had differing needs, as she wrote in Errors and Expectations:

The native-born students differ from the second-language students in significant ways: they [native-born students] have usually experienced little or no success with written English in school, which is often not so of foreign-born students in relation to their native languages; they have not identified the real reason for their lack of success in writing, having usually perceived themselves (and having been perceived by their 
teachers as well) as native speakers of English who for some reason use "bad" English; and...they have been functioning in English for years, understanding the English of people in their communities and being understood by them in the full range of situations that give rise to speech, and managing...to hold jobs, get diplomas, and talk with a variety of "outsiders." (92)

In short, Shaughnessy considered basic writing to be a site of institutional practices that was distinct from ESL in terms of the population served. The needs of foreign-born ESL students with limited experience in English-speaking environments were to be addressed separately in courses that were specifically designed to prepare ESL students for work in required composition courses. ${ }^{5}$

\section{ESL Issues in the Journal of Basic Writing}

Although the field of basic writing has focused its attention on the needs of native-born students for the most part, basic writing specialists, who were motivated by their concern for all open-admissions students, did not ignore ESL students entirely. In fact, the Journal of Basic Writing, established in 1975 by Shaughnessy and her colleagues at City College of New York, CUNY, provided a site of interaction between basic writing and ESL writing teachers and researchers; during the first few years, JBW included several articles related to ESL issues. The first issue of the journal included two such articles (Lay "Chinese"; Rizzo and Villafane). In 1977, an article by David M. Davidson considered the application of sentence combining in an ESL writing program, and, in 1979, Mary Newton Bruder and Patricia R. Furey's article "The Writing Segment of an Intensive Program for Students of English as a Second Language" also appeared. Shortly after Shaughnessy's death in 1978, however, ESL issues disappeared from the pages of JBW for several years.

The status of ESL issues in JBW changed again in the latter half of the 1980s, when Lynn Quitman Troyka became the editor. Troyka, who served between 1986 and 1988, made several important institutional changes that contributed significantly to the increase of ESL discussions in JBW. First, she helped to broaden the scope of the journal. The new editorial policy, which was announced in the 1985 issue, reflected her inclusive definition of basic writers:

The term "basic writer" is used with wide diversity today, in some cases referring to a student from a highly oral tradition with little experience in writing academic discourse, and in other cases referring to a student whose academic writing is 
fluent but otherwise deficient. To help readers, therefore, authors should describe clearly the student population to which they are referring. (Call for Articles)

Whereas previous issues of $J B W$ called for articles on specific topics, the new policy stated that "Authors need not limit themselves to topics previously announced for the $J B W$ because issues will no longer be devoted to single topics" (Call for Articles). In addition, the call for articles included the term "English as a second language" in the list of possible topics.

The second change Troyka introduced was to make JBW a refereed journal. While the direct impact of the blind-review system on the scope of $J B W$ is difficult to assess, it is worth noting that the introduction of the system was followed by a substantial increase in the number of ESL-related articles. In fact, during Troyka's three-year tenure as editor, $J B W$ published at least six articles that dealt with issues related to ESL writing (i.e., Herendeen; Jie and Lederman; Johns "ESL"; Liebman; Purves; Sanborn). ${ }^{6}$ In other words, JBW published more articles on ESL during the three years under Troyka's editorship than it had in the first eleven years of its existence.

As the visibility of ESL-related articles in the Journal of Basic Writing increased in the mid 1980s, ESL issues finally came to be recognized as a legitimate concern for basic writing specialists. In an update to Shaughnessy's bibliographical essay on basic writing, Andrea Lunsford mentioned the changing definition of basic writing:

Defining the population of student writers we refer to as "basic" also presents difficult problems, which were first clearly elucidated in Shaughnessy's work in the sources she cites in the preceding essay in this book.... The growing foreign student population and the even faster growing number of students whose native language is not English greatly complicate definitions both of basic writing and of literacy. As Richard Lanham of UCLA notes, this shift in population will surely present one of the greatest challenges our discipline has had to face. (“Update" 211-12)

Later in the same essay, Lunsford referred to articles on language transfer (Lay "Chinese"; Rizzo and Villafane) and on the mixed placement of ESL students and basic writers (Nattinger; Roy "Alliance").

After Troyka stepped down as editor and Bill Bernhardt and Peter Miller took over as co-editors in 1989, submissions to JBW on issues related to ESL did not slow down, and names of authors who were also well-known in second language studies frequently appeared in the journal. In 1989, two articles addressed ESL issues in significant 
ways. The first one was "The Other Side of the Looking Glass" by Carlos Yorio and the second, "The Need for Conceptualizing at All Levels of Writing Instruction" by Marilyn Sternglass. In the following year, the journal published four ESL-related articles, including "Promoting Literacy Through Literature: Reading and Writing in ESL Composition" by Jacqueline Costello; "The Rhetoric/Syntax Split: Designing a Curriculum for ESL Students" by Barbara Kroll; "Writing: A Holistic or Atomistic Entity?" by Kyle Perkins and Sheila R. Brutten; and "Through Students' Eyes: The Experiences of Three ESL Writers" by Vivian Zamel.

Submissions of ESL-related articles were so numerous that, in a 1990 JBW editorial (vol. 9, no. 2), Bernhardt and Miller lamented that "...there continues to be at least one area in which we have an overabundance of submissions (ESL) and another in which there is virtually none (computers in basic writing)" (2; emphasis added). Although no article on ESL was published in 1991, in 1992 three articles related to ESL appeared in the journal (Benson, Deming, Denzer, and Valeri-Gold; Patthey-Chavez and Gergen; Lay "Learning”).

The intensity of interest in ESL issues prompted CUNY to host a special conference on ESL and, in 1991, to establish College ESL, a journal which identified itself as "a unique forum for exploring questions and concerns regarding the education of English as a second language (ESL) students, specifically urban immigrant and refugee adults in college and pre-college settings" (College ESL Editorial Policy). Anticipating the creation of a new journal focusing on ESL issues, Bernhardt and Miller made the following announcement in their $1990 \mathrm{JBW}$ editorial (vol. 9, no. 1):

Topics related to the teaching of writing to non-native speakers of English appear to be particularly popular, so much so that we welcome the advent of a new journal -also published by The City University of New York - focused on this area. An announcement and call for papers for College ESL appears elsewhere in this issue. (1)

The creation of College ESL was a significant step in the history of ESL because it marked the recognition of the increase of immigrant and refugee students in higher education during the 1980s and the 1990s. As Gay Brookes, editor of College ESL, wrote in the inaugural issue of the journal:

Our experience is defined in part by our ESL students - college-age and adult, living in urban centers, by and large permanent residents of the United States who have come as immigrants and refugees. As is true in many urban colleges across the country, ESL students are growing in numbers in the City 
University of New York. Nearly one of every two students in CUNY speaks English as a second language. They differ in many ways from foreign students who come for education only and plan to return to their countries, and who are traditionally educated and middle-class. Most significantly, the ESL population is vastly heterogeneous. They have in common that English is not their first language, but that may be all. They form a common part of the overall student body, and teaching them, responding to their educational needs, is complex.

We wanted a journal to talk about these students in the classroom, the university, the workplace, society, and the family and community, about how we teach them and meet their educational needs and about a host of issues related to them and their language development. (Brookes i)

The establishment of College ESL, however, may also have reinforced the disciplinary division of labor between composition studies and second language studies - just as the creation of the TESOL (Teachers of English to Speakers of Other Languages) organization did in the 1960s (see Matsuda "Composition"). In effect, it institutionalized the separation of ESL and basic writing as academic specialties. The immediate impact of the division was apparent in the changes in $J B W^{\prime} s$ acceptance patterns; the number of ESL-related articles published in $J B W$ dropped noticeably after 1992. During the remainder of Bernhardt and Miller's tenure as editors, the journal published only two articles that focused on ESL issues (i.e., Cochran; Severino).

ESL concerns were not completely removed from the scope of $J B W$, however, especially because Trudy Smoke of Hunter College, who is also well known for her work in ESL (see, e.g., Smoke Adult ESL), became a co-editor in 1995-first with Karen Greenberg (1995-1996) and then with George Otte (1996-2002). In addition, Tony Silva, a second language writing specialist and co-editor of the Journal of Second Language Writing, joined the editorial advisory board in the same year. Under the editorship of Smoke and Otte, a few articles addressed ESL issues in a central way (e.g., Clark and Haviland; Mlynarczyk).

With the fall 2001 issue of the Journal of Basic Writing, Trudy Smoke stepped down as editor and was replaced by Bonne August, Chair of the English Department of Kingsborough Community College. At about the same time, another change occurred that prompted a shift in $J B W^{\prime} s$ editorial policy; the editors' column for spring 2002 announced that College ESL would soon cease publication:

We have indeed considered and published ESL-focused work in the past (and "English as a second language" is indeed an 
interest mentioned in our call for articles), but now we found ourselves wanting to highlight and not just acknowledge this interest.... [W] e want to stress our interest in accounts of ESL research and instruction that seem especially relevant to work in BW because of the overlap and interface between the fields, ever less distinct, ever more embroiled with the difficulties of definition and (often related) vulnerabilities of their special populations. (Otte and August 1)

The spring 2002 issue of $J B W$ included two articles that focused primarily on ESL students (Mlynarczyk and Babbitt; Pally, Katznelson, Perpignan, and Rubin). The fall 2002 issue included another article centered on concerns of second language writers (Williams).

Beginning with the spring 2003 issue, Rebecca Mlynarczyk, CoDirector of the ESL Program at Kingsborough Community College and a frequent writer about ESL issues, became co-editor of the Journal of Basic Writing. In addition, several ESL specialists joined JBW's editorial board: Gay Brookes, Martha Clark Cummings, Elizabeth Rorschach, Ruth Spack, and Vivian Zamel. While the effects of recent changes in the editorial policy of the Journal of Basic Writing remain to be seen, it seems significant that the journal has reemphasized its recognition of the need to consider issues related to second language writers in basic writing programs as well as the interdisciplinary relationship between basic writing and ESL.

\section{ESL Within the Field of Basic Writing}

A disciplinary divide between the fields of basic writing and ESL still seems to prevail in the general conception of basic writers. By the mid 1990s, the field of basic writing had come to focus almost exclusively on basic writers who were native speakers of English, although second language writers continued to be present in many basic writing courses. In a 1995 article published in JBW, J. Milton Clark and Carol Peterson Haviland pointed out the limitation of inclusiveness in basic writing classes for ESL writers:

As we considered our philosophical and theoretical commitments to inclusiveness and collaboration, we began to recognize how limited that inclusiveness and collaboration was, particularly with the non-native speakers we have in our fairly typical Southern California basic writing classes: a mix of white, African American, Latino, Asian, and American Indian native speakers as well as Latino and Asian non-native speakers who have scored in the lower half on California State University's English Placement Test and are enrolled for one, two, or three 
Some basic writing specialists continued to acknowledge the presence of ESL writers in basic writing programs. In her discussion of basic writing in the Encyclopedia of Rhetoric and Composition (1996), Troyka writes: "For a small but rapidly growing subset of BW [Basic Writing] students, English is not their first language. Some, though not all, have completed courses in English as a second language (ESL) by the time they take BW" (69). In contrast, Bill Bolin's essay on "basic writing/ writers" published in Keywords in Composition Studies (1996) makes no mention of the presence of ESL writers in the basic writing classroom at many institutions. While Paul Heilker and Peter Vandenberg, the editors of Keywords, provide a disclaimer that essays in this volume do not "attempt to capture the established knowledge of a unified discipline," the fact that Bolin did not discuss the presence of ESL writers in a project that sought to explore "the multiple layers of meaning inhabiting" the term (Heilker and Vandenberg 1) seems to suggest that ESL is often overlooked as a significant constitutent in basic writing classrooms. The omission of ESL from this critical examination of key terms in composition studies has an important implication because, as Heilker and Vandenberg suggest, "in the very process of rendering the fluid, actively contested meanings of these terms we [contributors to the volume] risk reifying them" (4-5).

\section{Towards a More Inclusive Definition of Basic Writing}

As I have tried to show, ESL writers, despite their significant presence in basic writing classrooms, have remained peripheral in the disciplinary practices and academic scholarship of basic writing during the last four decades. In the formative years of basic writing, certain institutions such as Hunter College, where the particular institutional arrangement made the separation between ESL and basic writing appropriate as well as feasible, influenced the view of basic writing as distinct from the field of ESL in the population served. Although the Journal of Basic Writing provided a viable forum for the discussion of ESL issues for a while, the creation of College ESL, a separate forum for the discussion of second language issues, was followed by a decline in the number of ESL-related articles in JBW. While there continue to be some basic writing specialists who acknowledge the presence of ESL writers, the dominant conception of basic writers in the professional literature does not seem adequately to reflect the presence of ESL writers.

It would have been more appropriate for basic writing to focus exclusively on the needs of native English speakers if native Englishspeaking basic writers and ESL writers could be identified clearly and 
accurately and if all institutions were able to offer appropriate placement options for all types of writers. ${ }^{7}$ Unfortunately, neither is the case at the present time. The distinction between basic writers and second language writers is becoming increasingly untenable because of the increasing diversity among second language writers and basic writers. Furthermore, creating all possible placement options is often not feasible in today's institutional and political climate, in which many institutions are seeking ways to preserve resources by eliminating what are perceived as remedial programs and by consolidating related programs (Smoke "Instructional"). In order to address the needs of ESL writers who will continue to be enrolled in basic writing courses, all basic writing teachers - or, better yet, all writing teachers - need to be prepared to work with ESL writers.

It is important to stress the need for additional professional preparation for all writing teachers who are likely to encounter ESL writers in their classrooms at some point in their careers. Yet, it would not be fair to place the responsibility solely on individual writing teachers because, as I have tried to demonstrate, the lack of attention to ESL writers in basic writing is more systemic in nature. Underlying the marginalization of ESL writers in the field of basic writing - as well as in composition studies in general - is the persistence of the disciplinary division of labor as a metaphor in conceptualizing the interdisciplinary relationship between composition studies and second language studies. Underlying the disciplinary division of labor is the notion that faculty in composition studies work with native English speakers and those in TESOL with nonnative speakers - a notion that came into being during the formative years of composition studies and TESOL and continued to be influential until fairly recently (Matsuda "Composition"; "Situating").

In order to address the needs of ESL writers in basic writing classrooms, then, it is important to recognize the problem of the disciplinary division and make conscious efforts to include ESL issues in the discussion of basic writers and basic writing, as Linda Adler-Kassner and Gregory Glau did when they made the effort to include a section on "Teaching English as a Second Language" in The Bedford Bibliography for Teachers of Basic Writing. In order to develop scholarship on ESL writers and writing that is relevant to basic writing teachers, it is important to increase interdisciplinary cooperation between basic writing specialists and second language specialists. ${ }^{8}$ As we continue to use the term "basic writing," we must also constantly remind ourselves of the practical difficulty and ethical complexity of defining basic writers, as many basic writing specialists have suggested (see, e.g., Hull, Rose, Fraser, and Castellano; Troyka "Defining"). Given the increasing diversity of students who come to basic writing classrooms, it is no longer possible to define basic writers in terms of abstract and ulti- 
mately unreliable criteria such as their writing placement test scores, language backgrounds, or immigration status. Rather, the general definition of basic writers needs to include all students who are subject to the disciplinary and pedagogical practices of basic writing.

\section{Notes}

1. Linda Harklau provides a succinct review of research on Generation 1.5 students in "Changing Currents in Second Language Writing Research: A Colloquium" (Matsuda, Canagarajah, Harklau, Hyland, and Warschauer 153-56).

2. With the recognition of the presence of Generation 1.5 students, many ESL writing programs are beginning to make the necessary adjustments to accommodate all types of ESL writers. For a discussion of how ESL specialists have begun to address the needs of Generation 1.5 ESL writers, see Harklau, Losey, and Siegal.

3. The behavioral view of language learning as habit formation and the contrastive view of the problem of language learning as negative transfer have been discredited and replaced by other theories of second language acquisition. For an overview, see Silva, Leki, and Carson.

4. See Matsuda ("Composition") for a review of similar arguments that were raised in the 1950s and the 1960s.

5. In arguing that Shaughnessy's intention was not to address the needs of ESL students, I do not intend to deny the usefulness or relevance of her work for ESL writers. Sandra Lee McKay, in her review of Shaughnessy's Errors and Expectations, points out that "many of the errors delineated by Shaughnessy are prevalent in the essays of ESL students" (McKay "Errors" 416). McKay also argues that Shaughnessy's book is "quite relevant to ESL" because both basic writing teachers and ESL teachers are concerned about "the growth of the student and the need for accuracy in language use" (McKay 417). Shaughnessy and others were also aware of the growing body of knowledge in second language studies and sought to apply insights from ESL pedagogy in order to help native English-speaking basic writers (Matsuda and Jablonski).

6. I have intentionally omitted "Krashen's Second-Language Acquisition Theory and the Teaching of Edited American English" by Elizabeth Tricomi from consideration because her article is concerned with the application of Krashen's work to the teaching of native English- 
speaking basic writers and has little to do with ESL writers.

7. For a discussion of various placement options for ESL writers, see Silva "Examination"; Matsuda and Silva.

8. Opportunities for such interdisciplinary cooperation are increasing slowly but steadily. At the 2004 meeting of the Conference on College Composition and Communication, for example, the Special Interest Group on Second Language Writing, organized by Kevin Eric De Pew and Susan K. Miller, will focus on the relationship between ESL writing and basic writing.

\section{Works Cited}

Adler-Kassner, Linda, and Gregory R. Glau, eds. The Bedford Bibliography for Teachers of Basic Writing. Boston: Bedford/St. Martin's, 2002.

Benesch, Sarah. "ESL on Campus: Questioning Testing and Tracking Policies." ESL in America: Myths and Possibilities. Ed. Sarah Benesch. Portsmouth, NH: Boynton/Cook, 1991, 59-74.

Benson, Beverly, Mary P. Deming, Debra Denzer, and Maria ValeriGold. "A Combined Basic Writing/English as a Second Language Class: Melting Pot or Mishmash?" Journal of Basic Writing 11.1 (1992): 58-74.

Bernhardt, Bill, and Peter Miller. Editors' Column. Journal of Basic Writing 9.1 (1990): 1-2.

. Editors' Column. Journal of Basic Writing 9.2 (1990): 1-2.

Bolin, Bill. "Basic Writing/Writers." Keywords in Composition Studies. Ed. Paul Heilker and Peter Vandenberg. Portsmouth, NH: Boynton/ Cook, 1996, 26-9.

Brookes, Gay. Introduction. College ESL 1.1 (1991): i-ii.

Bruder, Mary Newton, and Patricia R. Furey. "The Writing Segment of an Intensive Program for Students of English as a Second Language." Journal of Basic Writing 2.2 (1979): 67-84.

Call for Articles. Journal of Basic Writing 4.1 (1985).

Cieslak, Edward. The Foreign Student in American Colleges. Detroit: Wayne State University Press, 1955.

City University of New York. Immigration/Migration and the CUNY Student of the Future. New York: City University of New York, 1995.

Clark, J. Milton, and Carol Peterson Haviland. "Language and Authority: Shifting the Privilege." Journal of Basic Writing 14.1 (1995): 5766.

Cochran, Effie Papatzikou. "Giving Voice to Women in the Basic Writing and Language Minority Classroom." Journal of Basic Writing"13.1 
(1994): 78-90.

Costello, Jacqueline. "Promoting Literacy Through Literature: Reading and Writing in ESL Composition." Journal of Basic Writing 9.1 (1990): 20-30.

Cross, Kathryn Patricia. Beyond the Open Door: New Students to Higher Education. San Francisco: Jossey-Bass, 1971.

Darian, Stephen G. English as a Foreign Language: History, Development and Methods of Teaching. Norman, OK: University of Oklahoma Press, 1972.

Davidson, David M. "Sentence Combining in an ESL Writing Program." Journal of Basic Writing 1.3 (1977): 49-62.

Decker, Anne Folger, Ruth Jody, and Felicia Brings. A Handbook on Open Admissions: Success, Failure, Potential. Boulder, CO: Westview Press, 1976.

Editorial Policy. College ESL 1.1 (1991).

Harklau, Linda. "From the 'Good Kids' to the 'Worst': Representations of English Language Learners across Educational Settings." TESOL Quarterly 34.1 (2000): 35-67.

Kay M. Losey, and Meryl Siegal, eds. Generation 1.5 Meets College Composition: Issues in the Teaching of Writing to U.S.-Educated Learners of ESL. Mahwah, NJ: Erlbaum, 1999.

Meryl Siegal, and Kay M. Losey. "Linguistically Diverse Students and College Writing: What is Equitable and Appropriate?"Generation 1.5 Meets College Composition: Issues in the Teaching of Writing to U.S.-Educated Learners of ESL. Ed. Linda Harklau, Kay M. Losey, and Meryl Siegal. Mahwah, NJ: Erlbaum, 1999. 1-14.

Heilker, Paul, and Peter Vandenberg. Introduction. Keywords in Composition Studies. Ed. Paul Heilker and Peter Vandenberg. Portsmouth, NH: Boynton/Cook, 1996. 1-8.

Herendeen, Warren. "Of Tricksters and Dilemmas in ESL Writing Classes: An Epistolary Account." Journal of Basic Writing 5.2 (1986): 49-58.

Hull, Glynda, Mike Rose, Kay Losey Fraser, and Marisa Castellano. "Remediation as Social Construct: Perspectives from an Analysis of Classroom Discourse." College Composition and Communication 42.3 (1991): 299-329.

Jie, Gao, and Marie Jean Lederman. "Instruction and Assessment of Writing in China: The National Unified Entrance Examination for Institutions of Higher Education." Journal of Basic Writing" 7.1 (1988): 47-60.

Johns, Ann M. "The ESL Student and the Revision Process: Some Insights from Schema Theory." Journal of Basic Writing 5.2 (1986): 7080 .

"Interpreting an English Competency Examination: The Frustra- 
tions of an ESL Science Student."Written Communication 8 (1991): 379-401

Kroll, Barbara. "The Rhetoric/Syntax Split: Designing a Curriculum for ESL Students." Journal of Basic Writing 9.1 (1990): 40-55.

Lavin, David E., Richard D. Alba, and Richard A. Silberstein. Right Versus Privilege: The Open-Admissions Experiment at the City University of New York. New York: The Free Press, 1981.

Lay, Nancy Duke S. "Chinese Language Interference in Written English." Journal of Basic Writing 1.1 (1975): 50-61.

"Learning from Natural Language Labs." Journal of Basic Writing 11.2 (1992): 74-81.

Lunsford, Andrea A. An Historical, Descriptive, and Evaluative Study of Remedial English in American Colleges and Universities. Unpublished doctoral dissertation, Ohio State University, 1977.

. "An Update of the Bibliography on Basic Writing." Teaching Composition: 12 Bibliographical Essays. Ed. Gary Tate. Fort Worth, TX: Texas Christian University Press, 1987. 207-26.

Martino, Martha. "Give Credit Where Credit Is Due." College ESL 2.1 (1992): 20-22.

Matsuda, Paul Kei. "Composition Studies and ESL Writing: A Disciplinary Division of Labor." College Composition and Communication 50.4 (1999): 699-721.

. "Reexamining Audiolingualism: On the Genesis of Reading and Writing in L2 Studies." Linking Literacies: Perspectives on L2 Reading-Writing Connections. Ed. Diane Belcher and Alan Hirvela. Ann Arbor: U of Michigan P 2001. 84-105.

"Situating ESL Writing in a Cross-Disciplinary Context."Written Communication 15.1 (1998): 99-121.

and Jeffrey Jablonski. "Beyond the L2 Metaphor: Towards a Mutually Transformative Model of ESL/WAC Collaboration." Academic.Writing 1 (2000). <http://wac.colostate.edu/aw/articles/ matsuda_jablonski2000.htm>.

A. Suresh Canagarajah, Linda Harklau, Ken Hyland, and Mark Warschauer. "Changing Currents in Second Language Writing Research: A Colloquium." Journal of Second Language Writing 12 (2003): 151-79.

and Tony Silva. "Cross-Cultural Composition: Mediated Integration of US and International Students." Composition Studies 27.1 (1999): 15-30.

McKay, Sandra. “ESL/Remedial English: Are They Different?" English Language Teaching Journal 35.3 (1981): 310-15.

. Review of Errors and Expectations: A Guide for the Teacher of Basic Writing. TESOL Quarterly 13.3 (1979): 415-17.

Mlynarczyk, Rebecca Williams. "Finding Grandma's Words: A Case Study in the Art of Revising." Journal of Basic Writing" 15.1 (1996): 
3-22.

and Marcia Babbitt. "The Power of Academic Learning Communities." Journal of Basic Writing 21.1 (2002): 71-89.

Nattinger, James R. "Second Dialect and Second Language in the Composition Class." TESOL Quarterly 12 (1978): 77-84.

Otte, George, and Bonne August. Editors' Column. Journal of Basic Writing 21.1 (2002): 1-2.

Pally, Marcia, Helen Katznelson, Hadara Perpignan, and Bella Rubin. "What Is Learned in Sustained-Content Writing Classes along with Writing?" Journal of Basic Writing 21.1 (2002): 90-108.

Patthey-Chavez, G. Genevieve and Constance Gergen. "Culture as an Instructional Resource in the Multiethnic Composition Classroom." Journal of Basic Writing 11.1 (1992): 75-96.

Perkins, Kyle, and Sheila Brutten. "Writing: A Holistic or Atomistic Entity." Journal of Basic Writing 9.1 (1990): 75-84.

Purves, Alan C. "Rhetorical Communities, the International Student, and Basic Writing." Journal of Basic Writing 5.1 (1986): 38-51.

Rizzo, Betty, and Santiago Villafane. "Spanish Language Influences on Written English." Journal of Basic Writing 1.1 (1975): 62-71.

Roy, Alice M. "Alliance for Literacy: Teaching Non-Native Speakers and Speakers of Nonstandard English Together." College Composition and Communication 35 (1984): 439-448.

"ESL Concerns for Writing Program Administrators: Problems and Policies." Writing Program Administration 11 (1988): 17-28.

Sanborn, Jean. "Obstacles and Opportunities: Sentence Combining in Advanced ESL." Journal of Basic Writing 6.2 (1987): 60-71.

Severino, Carol. "Inadvertently and Intentionally Poetic ESL Writing." Journal of Basic Writing 13.2 (1994): 18-32.

Shaughnessy, Mina P. "Basic Writing." Teaching Composition: 10 Bibliographical Essays. Ed. Gary Tate. Fort Worth, TX: Texas Christian University Press, 1976. 137-67.

. Errors and Expectations: A Guide for the Teacher of Basic Writing. New York: Oxford University Press, 1977.

Introduction. Journal of Basic Writing 1.1 (1975): 1-4.

Silva, Tony. "An Examination of Writing Program Administrators' Options for the Placement of ESL Students in First Year Writing Classes."Writing Program Administration 18.1/2 (1994): 37-43.

---, Ilona Leki, and Joan Carson. "Broadening the Perspective of Mainstream Composition Studies: Some Thoughts from the Disciplinary Margins." Written Communication 14 (1997): 398-428.

Slager, William. "The Foreign Student and the Immigrant: Their Different Problems as Students of English." Language Learning 6 (1956): 24-29.

Smoke, Trudy, ed. Adult ESL: Politics, Pedagogy, and Participation in Classroom and Community Programs. Mahwah, NJ: Erlbaum, 1998. 
_. "Instructional Strategies for Making ESL Students Integral to the University." On Second Language Writing. Ed. Tony Silva and Paul Kei Matsuda. Mahwah, NJ: Erlbaum, 2001. 129-141.

Spolsky, Bernard. Measured Words. Oxford, UK: Oxford University Press, 1995.

Sternglass, Marilyn S. "The Need for Conceptualizing at All Levels of Writing Instruction." Journal of Basic Writing 8.2 (1989): 87-98.

Troyka, Lynn Quitman. "Basic Writing." Encyclopedia of Rhetoric and Composition: Communication from Ancient Times to the Information Age. Ed. Theresa Enos. New York: Garland, 1996. 69-70.

"Defining Basic Writing in Context." A Sourcebook for Basic Writing Teachers. Ed. Theresa Enos. New York: Random House, 1987. 215.

Tricomi, Elizabeth Taylor. "Krashen's Second Language Acquisition Theory and the Teaching of Edited American English." Journal of Basic Writing 5.2 (1986): 59-69.

Valdés, Guadalupe. "Bilingual Minorities and Language Issues in Writing: Toward Professionwide Responses to a New Challenge." Written Communication 9 (1992): 85-136. and Richard A. Figueroa. Bilingualism and Testing: A Special Case of Bias. Norwood, NJ: Ablex, 1994.

Williams, Jessica. "Undergraduate Second Language Writers in the Writing Center." Journal of Basic Writing 21.2 (2002): 73-91.

Yorio, Carlos. "The Other Side of the Looking Glass." Journal of Basic Writing 8.1 (1989): 32-45.

Zamel, Vivian. "Through Students' Eyes: The Experiences of Three ESL Writers." Journal of Basic Writing 9.2 (1990): 83-98. 


\section{Sugie Goen and Helen Gillotte-Tropp}

\section{Integrating Reading and Writing: A Response to the Basic Writing "Crisis"}

ABSTRACT: This article describes a FIPSE-funded integrated reading/writing program developed at San Francisco State University in response to the latest basic writing "crisis." After noting the theoretical and practical necessity for integrating reading and writing, the authors provide a detailed account of the program and report on its first year of implementation. They conclude by offering some valuable lessons learned from this experience.

\section{THE BASIC WRITING "CRISIS"}

As Ira Shor wryly observes, basic writing is in a perpetual state of crisis (91). Of late, the crisis has gained momentum from widely publicized attempts in various states to eliminate or strictly limit remediation. These efforts are expected to have a profound impact on racial diversity, educational opportunity, enrollment, and retention at a number of postsecondary institutions. In their January 1998 report on college remediation, the Institute for Higher Education Policy warned that with over $80 \%$ of today's sustainable jobs requiring education beyond high school and $65 \%$ requiring skills in advanced writing and critical thinking, the social and economic consequences of not providing remedial instruction are "high" (viii), and abandoning remedial efforts in higher education would be "unwise public policy" (ix).

At the 23-campus California State University (CSU), with its enrollment of 440,000 students, nearly half of all first-time freshmen place into basic writing. On our San Francisco State University (SFSU) campus, more than $80 \%$ of these basic writers speak native languages or dialects other than standard English, half are immigrants, $89 \%$ are stu-

Sugie Goen is Associate Professor of English and Basic Writing Coordinator at San Francisco State University. She teaches basic writing courses as well as graduate courses on basic writing pedagogy and composition theory and research methods. Helen Gillotte-Tropp is Professor of English and Reading Coordinator at San Francisco State University. She also directs the graduate certificate program in Teaching Post-Secondary Reading. She is recognized locally and nationally as a leader in the field of postsecondary reading instruction and teacher education and currently directs a partnership program with a local alternative elementary school that places student interns inside reading classrooms. Professors Goen and Gillotte-Tropp co-direct the FIPSEfunded integrated reading/writing program at San Francisco State. 
dents of color, slightly over half are the first in their families to go to college, and a third grew up in families where the primary breadwinner had less than the equivalent of a high school education (Goen 25157). Despite obvious threats to equity and diversity, the CSU Board of Trustees mandated a plan in 1997 to reduce the number of incoming students in remedial courses to no more than $10 \%$ by 2007 . This plan immediately limited remedial instruction to one year and instituted the hefty penalty of "disenrollment" from the university for any student failing to complete the remedial requirement during his or her first year. ${ }^{1}$

Contributing to the basic writing crisis is an historical and persistent trend in literacy education to treat reading and writing as distinct and separate processes, with reading being considered the more elementary of the two (McCormick 6; Nelson and Calfee 1). Those of us who teach reading and writing know, and have known for a long time, that the acquisition of academic literacy is a slow, protracted process. Unfortunately, those of us working in higher education in the United States also know that postsecondary institutions have historically operated as though learning to read should be accomplished by the third grade and learning to write by the twelfth. Accordingly, any postsecondary instruction in reading and writing is de-facto remedial and, as such, vulnerable to political and educational forces aimed at its removal.

\section{A RESPONSE TO THE “CRISIS"}

Fortunately, basic writing's perpetual state of crisis is attended by an equally perpetual search for new and better ways to meet the needs of basic writing students. At SFSU, our search led to the design of an innovative program in which instruction in reading and writing is fully integrated, and students' movement from the margins of the university to its academic center can be appreciably hastened.

For a number of years preceding the implementation of the 1997 remedial policy, we had tried to persuade our institution of the critical importance of linking instruction in reading with instruction in writing. Convinced by empirical findings indicating that the processes of reading and writing are closely linked (see, e.g., Ackerman; Salvatori; Spivey and King; Nelson and Calfee), we had become increasingly frustrated with our system of separate reading and writing courses. Meanwhile, accumulated data from more than twenty years of CSU English Placement Test administrations provide mounting evidence that students' performance on the reading portion of the test disproportionately accounts for their placement in basic writing classes, suggesting that students' difficulty constructing meaning from texts may be a significant source of their difficulty constructing meaning in texts. 
Initially, our efforts outside the English department to advocate for the interconnectedness of reading and writing were strongly resisted, at least until the advent of the one-year remediation policy. About the time the policy went into effect, it was not unusual for as many as $30 \%$ of the SFSU students who placed into basic writing to still be taking basic writing courses well into their second year of enrollment (Goen 167). The Board of Trustees mandate was greeted with a new willingness at all levels of the SFSU administration to consider changes to its remedial programs. Meanwhile, the opportunity afforded by the Board of Trustees mandate inspired us to convene a small team of faculty to put our thinking to the test. We reasoned that if the link between instruction in reading and writing is as crucial as we hypothesized, then it follows that basic writing students would reap demonstrably greater benefits from an approach that integrates the two. And if this hypothesis proved true, we wondered whether our students could achieve these benefits effectively (and swiftly) enough to enable them to move into the academic mainstream well within the confines of the one-year remediation rule.

Between 1999 and 2000, we refined our thinking about these questions, experimented inside classrooms, and ultimately designed a fully integrated reading/writing program. In the fall of 2001, we received a three-year grant from the U.S. Department of Education's Fund for the Improvement of Postsecondary Education (FIPSE) to implement our program and assess its outcomes. That same fall, we received administrative approval to offer ten sections of the integrated reading/writing course. In the discussion that follows, we describe the new reading/ writing program, placing it within the context of SFSU's "remedial" English requirement, and report on its first year of implementation.

\section{SFSU's “Remedial" English Requirement}

The essential components of SFSU's "remedial" English requirement have been in place for more than two decades. Students who score in the lowest quartile on the English Placement Test (a placement instrument contracted through the Educational Testing Service and used throughout the CSU system) must complete a full year of developmental-level course work in reading and writing. In their first semester, they take a 3-unit basic writing course (English 48) concurrently with a 1-unit reading course (English 118). In their second semester, they take another 3-unit basic writing course (English 51) concurrently with a 1-unit reading course (English 121). Students who score above the lowest quartile, but below the cutoff score for freshman-level composition, take a single semester of English 51 concurrently with English 121 while those who score above the cutoff go directly into English 114, SFSU's 3-unit first-year composition course. Whether stu- 
dents place into one or two semesters of developmental-level course work, they must successfully complete the remediation requirement in their first year at SFSU or risk disenrollment from the university. Students most at-risk for disenrollment, and/or dropping out of college altogether, are typically those who score in the lowest quartile on the English Placement Test.

Because the curriculum and pedagogy of the basic writing and reading courses have traditionally been separate, students have not been encouraged to make the connections between themselves as readers and writers. Teachers, too, have been unprepared to see the connections. With few exceptions, SFSU's reading and writing instructors have received graduate education in teaching either college composition or reading. ${ }^{2}$ Despite recent efforts to encourage our new graduate students to pursue both courses of study, the vast majority of basic writing teachers have little or no knowledge of the curriculum of the reading course, its theoretical underpinnings, and its potential connection to the writing curriculum. And although the reading teachers are more likely to have had some experience in and preparation for teaching writing, few curricular opportunities have been available to exploit fully the connections between reading and writing within the confines of a one-unit reading course.

\section{The Integrated Reading/Writing Program}

Rather than requiring students who score in the lowest quartile on the English Placement Test to complete two basic writing classes, two reading classes, and yet another first-year composition class (for a total of up to five different teachers and five different groups of classmates), our integrated reading/writing program places these "at-risk" students into a single year-long course in which instruction in reading and writing are explicitly interconnected. In the first semester of the integrated course, students complete developmental-level course work equivalent to our basic writing courses (English 48 and 51) integrated with our reading courses (English 118 and 121); in the second semester, students accomplish an integrated version of work equivalent to first-year written composition (English 114). Students who successfully complete the new year-long course have thereby met not only the CSU remediation requirement, but also SFSU's first-year written composition requirement, in effect completing in one year what would ordinarily take three semesters to accomplish (see Table 1$).^{3}$ 
Comparison of SFSU's Integrated Reading/Writing Program and Conventional Program

\begin{tabular}{|c|c|c|}
\hline & Semester One (4 units) & Semester Two (3 units) \\
\hline Integrated $\mathbf{R} / \mathbf{W}$ & Integrated coursework & Integrated course work \\
\hline Program (8 units total, & equivalent to basic writing and & equivalent to first-year \\
\hline 1 teacher, 1 group of & reading: English 48, English & written composition: \\
\hline \multirow[t]{3}{*}{ classmates) } & 118, English 51, English 121 & English 114 \\
\hline & Remediation Requirement & \\
\hline & Complete & \\
\hline SFSU's Conventional & Basic writing and reading: & Basic writing and \\
\hline Program ( 8 units total, & English $48+$ English 118 & reading: English $51+$ \\
\hline 4 te achers, 4 groups of & & English 121 \\
\hline \multirow[t]{2}{*}{ classmates) } & & Remediation \\
\hline & & Requirement Complete \\
\hline
\end{tabular}

We began developing our integrated curriculum with a small group of teachers whose graduate training and professional experience include both reading and writing. During our deliberations and planning, we realized that in order for our course to be truly integrated, it could not be a course in which reading always precedes writing. Taking such an approach reduces writing to something that is done after the reading is complete as a way to check comprehension rather than a way to work through, analyze, and arrive at an understanding of a text. Neither could it be a course that reduces reading to a supporting role, providing information and lending authority to bolster the writing. Vivian Zamel criticizes courses that purport to connect reading and writing in such unidirectional terms (468): writing courses with assignments based upon readings (reading-to-write) or reading courses with writing assignments tacked on at the end (writing-to-read).

As a counterpoint, we imagined an integrated course in which the similarities and connections between reading and writing would be made explicit, a course where students would see how the structures, practices, and language of each process can enhance understanding of the other. The aim of the course we envisioned would be to engage students in an exploratory study of texts (including their own) produced by members of various social, cultural, and academic com- 
munities, to achieve a range of authentic authorial purposes, and to facilitate student analysis of their own writings and those of their classmates. This aim was grounded in the following six principles distilled from over thirty years of research on basic writing and reading.

Principle 1: Integration. In summarizing research on the connections between reading and writing, Sandra Stotsky found some consistent correlations, namely that "better writers tend to be better readers" that "better writers tend to read more than poorer writers," and that "better readers tend to produce more syntactically mature writing than poorer readers" (16). Robert Tierney and Margie Leys agree that "selective reading experiences definitely contribute to writing performance" (25) while Mariolina Salvatori contends that introspective reading, or reading as "an analogue for thinking about one's own and other's thinking, about how one's thinking is ignited by the thoughts of others," has a stimulative and generative effect on students' writing (446). Anthony Petrosky notes that writing can also contribute to the development of reading, that "the only way to demonstrate comprehension is through extended discourse where readers become writers who articulate their understandings of and connections to the text in their responses" (24). Vivian Zamel detects some "profound ways" in which writing teaches reading, for "the process of writing shares much in common with the process of learning. ... [W]riting allows one to discover and consider one's stance, one's interpretation, one's immediate reactions to a text. ... [I]t makes these responses to text overt, concrete, and tangible" (470). Meanwhile, Kathleen McCormick found that when students are taught reading and writing as separate subjects, these beneficial effects are lost. Students commonly write essays that basically summarize a reading with some personal observations thrown in; the two activities they typically find most difficult are "integrating one's own ideas and knowledge into the written conversation with one's sources" and "interpreting source texts for a purpose of one's own" (99).

While we began designing our integrated reading/writing course with the primary goal to create an integrated curriculum, we soon gave equal attention to developing an integrated instructional approach. In this regard, we take our cue from James Flood and Diane Lapp, who urge us to devote as much thought and study to understanding integrated instruction as we have to understanding the conceptual links between reading and writing (21-22). We are also aware that while some of the basic research findings on the reading-writing connection have informed instructional practices (most notably in justifying the use of readings in the composition classroom), instruction in reading and writing is far from integrated, in part because of the nature of the English discipline. Literacy educators are still identified as either reading teachers or writing teachers. Nelson and Calfee notice that university 
English departments are still populated by literature (reading) and composition (writing) faculty who have experienced "different kinds of graduate education, who cite different authors, who use different terminology, and who publish in different journals, and turf wars still rage. Attempts to create a more integrated discipline are often resisted" (35-36). McCormick complicates the picture, noting a further division between teaching reading on the one hand, and literature on the other: "reading as an academic subject is traditionally separate from literature instruction. ... [M]any teachers of English and almost all in the colleges and universities do not regard themselves as involved in teaching reading" (6).

Principle 2: Time. Learning and improvement in reading and writing develop gradually and are directly related to the notion of writing and reading as situated within communities of discourse. Most successful basic writing programs cite time as a factor crucial to their program's success, time for learning to develop and for communities to form. Shaughnessy's program at the City University of New York was three semesters; Bartholomae and Petrosky's at the University of Pittsburgh is an intensive six-unit, six-hour course. UC Berkeley's recently reconceptualized alternative to its Subject A requirement ${ }^{4}$ is an intensive six-unit course that meets five hours a week; Arizona State University's Stretch Program for at-risk students "stretches" the freshman writing course over two semesters; and Soliday and Gleason's alternative to remedial writing at City College of New York is a oneyear course. In designing their "Enrichment" program, Soliday and Gleason note that "forming communities is vitally important" for underprepared students, especially on urban, commuter campuses (66). Like our SFSU students enrolled in basic writing, many of the students enrolled in the CUNY program work part or full time, come from families with low incomes, and/or have family responsibilities, caring for younger siblings or their own children. They concluded: "It is all too easy for such students to be pulled away from the college campus by adult concerns. This project's two-semester writing course creates a space for students to become grounded in college life during the crucial first year" (66). Moreover, as Emig and other researchers have noted, writing can be enhanced by working in, and with, a group of other writers in an enabling community environment.

Principle 3: Development. Literacy is predominantly learned rather than taught and at a pace that can be very slow, especially if the reading and writing represent significant learning. According to Emig, attempting to teach certain reading/writing structures explicitly and expecting students to learn them is "magical thinking" (135). A yearlong structure allows development to proceed, however slowly, by introducing students to certain thinking/reading/writing strategies that they can then apply in increasingly more complex contexts. This struc- 
ture simultaneously allows teachers to move the class at a pace more conducive to learning, as opposed to teaching.

In SFSU's conventional approach, teachers and students meet three hours a week for writing and two hours for reading over the course of a sixteen-week semester. As anyone who regularly teaches either the basic writing or reading course knows, it can easily be the fifth week of the semester before even the most alert teacher is able to identify some of the complex reading or writing difficulties that vex individual students. By the time the teacher can start working regularly with the student in individual conferences or get the student plugged into the various adjunct learning assistance resources on campus - and for the student to start showing signs of response - the semester is nearing its end. Then, when the student joins two new basic writing and reading classes the following semester, the process has to begin anew.

Because students and teachers in our integrated reading/writing program stay together for the full year, teachers have plenty of time to put our learning assistance resources in place. As early in the first semester as possible, they identify students who need small group and/ or individual tutoring or other learning assistance and help direct these students to appropriate resources to enhance their learning over the entire rest of the year.

Principle 4: Academic Membership. For decades, institutional rules and regulations have marginalized and stigmatized remedial programs and their students. By putting into place a one-year course that satisfies two requirements at once (the CSU remediation requirement and SFSU's first-year written composition requirement), we have dismantled the remedial sequence that frequently holds students back for several semesters and, under the one-year time limit, subjects them to disenrollment from the university. With few exceptions, students who do not pass the one-year integrated reading/writing course are not required to repeat it; rather, they are required to take and pass English 114, the first-year written composition course (see endnote 3 ).

The integrated reading/writing program promises to move students as quickly and humanely as possible into the university mainstream, and keep them there, breaking what, for many students, has been a dismal cycle of failure at the remedial level. The program has removed another punitive remnant of remediation: the lack of baccalaureate credit (which carries with it the stigma of not being perceived as "real" college work). SFSU's basic writing courses, English 48 and 51 , carry workload credit but do not count towards graduation. The integrated course carries partial credit towards graduation, but more importantly, it satisfies the freshman composition requirement for graduation.

The credit-bearing aspect of the program provides an added ben- 
efit: should the trend continue in higher education in the direction of complete elimination of remedial programs, we can potentially "protect" the integrated reading/writing course on the basis that it carries non-remedial credit and satisfies a university requirement for graduation.

Principle 5: Sophistication. A fundamental tenet from recent scholarship on basic writing is that the nature of the reading and writing activities in a basic-level course should be virtually indistinguishable from that in a college-level or advanced course. With a full year at their disposal, teachers of the integrated reading/writing course can offer support and scaffold assignments in ways that are simply not feasible in a 16-week semester. They can also help students become adept at sophisticated literate activities required for success at the university, such as reading book length works, engaging in original research, and participating in collaborative and/or co-authored projects.

Principle 6: Purposeful Communication. In college-level basic writing classrooms, attention is too often paid to modeling correct grammatical and essayist forms instead of providing opportunities for students to interact with language actively for authentic communicative purposes. We know that meaning is what drives linguistic competence; yet in many basic writing classrooms, the focus is on language itself, on teaching its parts abstracted from meaningful contexts, in a prearranged order of skills development (Kutz, Groden, and Zamel 18-19). To assure that our program provides students with opportunities for active interaction with texts in meaningful contexts, we designed the curriculum to meet the following objectives:

Objective 1: To understand the ways that readers read and writers write in and beyond the university, across a range of tasks. To accomplish this goal we require students to read a wide range of materials (expository, fiction, poetry, and hypertext) written from different points of view. This objective is crucial in helping our students become members of the academy. Our students are enrolled full time and take courses in other disciplines such as math, business, psychology, physical and social sciences. The majority also work full or part time outside of school. Our integrated course provides instruction that will help students set purposes and goals for their reading and writing in school and beyond, as well as learn to apply and internalize a variety of effective strategies for reading rapidly enough to comprehend text and generate ideas for writing.

Objective 2: To develop a metacognitive understanding of the processes of reading and writing. Metacognition is typically revealed in a student's conscious strategies for selecting and recalling main ideas, summarizing another's text, or producing conscious, elaborate "think aloud" protocols during composing tasks. Helping students attain awareness and knowledge of their own mental processes such that they 
can monitor, regulate, and direct themselves to a desired end are key components in our curriculum. We achieve this goal by providing many opportunities for students to experience a variety of idea-generating tools (clustering, freewriting, previewing, prereading and coding [PPC], and questioning).

One useful example of a composing strategy that we use extensively throughout our curriculum is $\mathrm{K}-\mathrm{W}-\mathrm{L}+$, a four-step procedure intended to help teachers become more responsive to helping students access appropriate knowledge when reading texts. While $\mathrm{K}-\mathrm{W}-\mathrm{L}+$ is traditionally considered to be a reading strategy only, it is an excellent idea-generating tool in which students brainstorm and generate categories for ideas $(\mathrm{K})$, develop interests and curiosities by asking questions $(\mathrm{W})$, write on what has been learned and use the new learning as a set of reading notes (L), to see which questions still need to be answered, discuss any additional questions, and determine what further ideas need to be researched $(+)$. More importantly, $\mathrm{K}-\mathrm{W}-\mathrm{L}+$ is a strategy that students can use to comprehend a text, then use to shape and organize ideas for a written product, and finally use in peer response groups to give or receive feedback on their thinking and understanding of a topic as well as on the content and organization of their written responses. More specifically, through instruction and experience in using composing strategies like $\mathrm{K}-\mathrm{W}-\mathrm{L}+$, students come to read as writers and write as readers, knowing that there is only one process composing meaning - whether it comes from their transactions with existing texts or their production of new ones.

Objective 3: To understand the rhetorical properties of reading and writing, including purpose, audience, and stance. Our curriculum is designed to engage students in many reading and writing tasks. Writing tasks include freewriting, planning, developing rough drafts, making revisions, practicing sentence combining, and, of course, producing essays. Reading tasks include practice in methods of increasing reading rate and improving comprehension, developing recall and interpretation skills, employing efficient study techniques, and experiencing the reading-writing relationship across all disciplines. Overall, students learn to organize their essays to support their points of view in ways that are appropriate to the topic, audience, and purpose; write cohesive paragraphs; and write sentences that are both well-focused and employ a range of sentence combining options. They learn to write informal reading journals and double-entry journals that encourage dialectical thinking, use a variety of graphic organizers, participate in small group discussions, and learn question-asking techniques. Ultimately our curriculum is designed to help students understand that we "draft" a first reading and revise or elaborate on it in subsequent readings, just as we do in writing. We want our students to learn that readers construct the meaning of texts they read by degrees in the same 
way writers gradually construct meaning in the texts they write.

Objective 4: To understand and engage in reading and writing as a way to make sense of the world, to experience literacy as problem solving, reasoning, and reflecting. Our curriculum accomplishes this objective in two ways: First, the topics students read and write about prepare them to join current conversations on important social issues and help them critically engage with a variety of texts: popular print and visual media (newspapers, magazines, films, television); statistics in both tabular and prose forms; fiction; and exposition. Students can then enter into the conversations of our world by writing essays that are based on their thinking about the issues they are reading about-essays that use writing and reading to learn and that help students understand the kinds of writing frequently used in public discourse such as taking a position, reporting, evaluating, speculating, and interpreting. Secondly, we know that students must have some stake in what they are reading and writing about, that for literacy to be a genuine act of meaning-making, students must have an investment of some kind in order to take the intellectual risks that meaning-making requires. Therefore, each unit of our course has incorporated community building activities that not only satisfy inexperienced readers' and writers' needs for structure and content, but that also offer them the freedom to develop their style, repertoire, and voice, to locate themselves in these texts. Community- building exercises also help students learn relationship-building, class-building, and team-building skills and provide a vehicle through which they become stakeholders in creating a caring environment as the foundation for growth and learning. Over the course of the year that students spend together in this program, they learn essential collaborative skills through carefully designed and scaffolded interactive learning experiences. The course is designed so that the community-building strategies are "top-loaded" in the first semester, providing a variety of tools for students to draw upon, and allowing enough time for students to internalize them with repeated practice throughout the year.

Objective 5: To develop enjoyment, satisfaction, and confidence in reading and writing. To help achieve this objective, student selfassessment is an important component of the new course. For reasons similar to those cited by Soliday and Gleason (referring to Astin's research on the undergraduate experience), we include self-assessment because it has been shown to be a valid measure of student performance when compared to actual pre-test/post-test measures (72) and because we believe it to be a valuable tool in helping students articulate for themselves what they have learned and to derive satisfaction from that learning. At the end of each semester, teachers ask students to write a self-reflection essay to assess their "Reading and Writing Process." In these essays, students evaluate what they learned, what 
changed in their reading and writing, and what they still need to work on. They conclude by setting some reasonable learning goals for the future. Teachers also periodically ask students to write self-reflections on their process of completing a given essay assignment and on how they integrated reading and writing strategies to complete the task.

In our years of teaching novice readers and writers, we have also discovered that our students do not do much, if any, reading for pleasure. Therefore we have built fictional reading requirements into our curriculum, supplemented by a variety of activities to stimulate collaborative learning, discussion, and personal and analytical writing.

\section{PROGRAM ASSESSMENT}

In fall 2001, we enrolled 169 students in the new integrated reading/writing program. ${ }^{5}$ Enrollment in the new course followed already established procedures for placement and course registration. Students who scored in the lowest quartile on the placement test received their results by mail along with a letter describing the integrated reading/ writing program and giving specific instructions about how to register for the course. Information about eligibility and registration in the program was also made available through other campus venues, including the summer freshman orientation sessions. The majority of students enrolled in the new course at freshman orientation; others enrolled in the course during the regular registration period. When students registered, they were informed in writing of the experimental nature of the course and the specific data collection, analysis, and dissemination procedures involved. We also asked all the students who scored in the lowest quartile enrolled in our conventional program (English 48 and 118 in fall and English 51 and 121 in spring) to serve as a comparable control group. Both groups signed consent forms indicating their agreement to participate in the evaluation study.

\section{Procedures}

We measured the extent to which the course is realizing its objectives using a variety of data sources: end-of-year grade comparisons; comparative gains on standardized reading tests; comparisons of holistically scored portfolios of student writing; self-assessments of students completing the integrated program; and second-year written composition pass rates of students who arrived via the three-semester conventional sequence compared to those who arrived from the oneyear integrated program.

End-of-Year Grade Comparisons. Throughout the fall and spring semesters, we collected enrollment census figures (fourth-week class lists) and final grade sheets from all ten sections of the integrated read- 
ing/writing course and from the control sections. We compared endof-year retention in the new program to retention in the conventional sequence of remedial classes. We also compared CSU remedial policy compliance of students in the new program to those in the conventional course sequence. Finally, we determined each group's readiness for the next level composition course: either first-year written composition (English 114) for students completing the conventional sequence or second-year written composition (English 214) for students completing the integrated course.

Reading Outcomes. We measured students' gains in reading proficiency at two junctures: Using the Descriptive Test of Language Skills ${ }^{6}$ (DTLS), we assessed their proficiency as they completed the developmental portion of the curriculum, and we assessed their proficiency as they completed the first-year written composition-level curriculum using the Gates-MacGinitie Reading Test. ${ }^{7}$

We administered a pre-DTLS to students in both the integrated and control classes during the first week of the fall 2001 semester. Since students in the integrated course complete the developmental-level curriculum by the end of the fall semester, they took a post-DTLS in December. Students in the control group took a post-DTLS at the end of spring 2002 while they were enrolled in English 121. The DTLS measures both reading comprehension and critical reasoning. It calculates reading comprehension as a total score on three submeasures: 1 ) identifying word or phrase meaning through context, 2) understanding literal and interpretive meaning, and 3) understanding writer's assumptions, opinions, and tone. Similarly, it calculates critical reasoning as the sum of scores on three submeasures: 1) interpreting information, 2) using information appropriately, and 3) evaluating information.

We administered a pre-Gates-MacGinitie test to students in the integrated program at the beginning of spring 2002, when they were just beginning to do work equivalent to first-year written composition (English 114). They took a post-Gates-MacGinitie at the end of spring. Since students in the control group did not enroll in English 114 until fall 2002 (their third semester), they took a pre-test in the beginning of the fall 2002 semester and a post-test at the end. The Gates-MacGinitie measures both reading comprehension and vocabulary and assigns students a total score as a sum of the two measures.

Writing Portfolios. We collected six sample essays from students in both groups, which we assembled into two separate portfolios. The first portfolio represents students' work early, near the middle, and as they completed the developmental-level portion of the curriculum. We collected the first portfolio during the fall 2002 semester from students in the integrated program, and over the fall 2001 and spring 2002 semesters for students in the control group. The second portfolio represents students' work from the first-year written composition-level of 
the curriculum. We collected the second portfolio during the spring 2002 semester for students in the integrated course and during the fall 2002 semester while control group students were enrolled in English 114 , the regular first-year composition course.

Using a four-point rubric, experienced external readers scored the portfolios across five categories: 1) the integration of reading and writing; 2) formulating and supporting a thesis; 3 ) organization; 4) sentence structure; and 5) grammar and mechanics. The readers were then asked to use the same four-point rubric to assign the portfolio an overall evaluation. ${ }^{8}$ We began the reading with a norming session using anchor portfolios to arrive at consensus for scoring across the categories.

Student Self-Assessments. At the end of each semester, teachers asked students in the integrated course to write a self-reflection essay to assess their "Reading and Writing Process." In addition to the portfolio assessments by outside readers, we also collected these written self-assessments of students' learning experiences in the integrated course. Since these self-reflection essays were specifically intended to assess what students thought of the new integrated program, we did not ask students in the control sections to write self-reflection essays.

Second-Year Composition Pass Rates. After students left the integrated reading/writing program, we followed their progress in second-year written composition, English 214. As they completed English 214, we accessed their final grades in SFSU's student database and then compared their pass rates to aggregate pass rates in English 214.

\section{Outcomes}

Across all categories of data, students in the integrated reading/ writing program outperformed their counterparts in SFSU's conventional sequence of basic reading and writing courses.

End-of-Year Grade Comparisons. As Table 2 shows, of the 169 students enrolled in the integrated reading/writing course, 136 were retained to the end of the first year, for a retention rate of $81 \%$. The 33 students who left the program did so early in the first semester, either because they withdrew entirely from the university or because of a scheduling conflict that caused them to withdraw from the course. Of the 136 students who remained, $97 \%$ successfully completed the CSU remediation requirement, compared to $84 \%$ of students in the control group. More importantly, $71 \%$ of those students who passed the integrated course did so with a grade of B- or better and have also met SFSU's first-year written composition requirement and are now ready for the next level course, second-year written composition. Thirty-eight students $(28 \%)$ completed the integrated course with a $C$ grade and have yet to complete the first-year written composition requirement; by comparison, all of the $84 \%$ who passed the conventional sequence of basic writing and reading courses have yet to complete the firstyear written composition requirement. 
Comparison of Final Grades (by percent), Spring 2002

\begin{tabular}{|c|c|c|c|}
\hline Grades & $\begin{array}{c}\text { Integrated Group } \\
(\mathrm{N}=136)^{\mathrm{a}} \\
\end{array}$ & $\begin{array}{c}\text { Control Group } \\
(n=204)^{b}\end{array}$ & Percent Difference \\
\hline A & $14 \% \quad(n=19)$ & $15 \% \quad(n=31)$ & $-1 \%$ \\
\hline B & $55 \% \quad(\mathrm{n}=75)$ & $48 \% \quad(n=99)$ & $+7 \%$ \\
\hline C & $28 \% \quad(\mathrm{n}=38)$ & $21 \% \quad(n=43)$ & $-7 \%$ \\
\hline Total Pass & $97 \% \quad(n=132)$ & $84 \% \quad(n=173)$ & \\
\hline $\mathrm{NC}$ & $3 \% \quad(n=4)$ & $15 \% \quad(\mathrm{n}=31)$ & $-12 \%$ \\
\hline
\end{tabular}

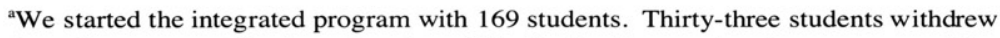
from the course and/or the university within the first few weeks of semester one. The remaining 136 students were retained for the full year, for a first-year retention rate of $81 \%$.

${ }^{\text {b }}$ The conventional sequence began in Fall 2001 with 246 students. Forty students withdrew from the course and/or the university during the first weeks of the first semester. Another two students withdrew during the second semester, for a retention rate of $83 \%$.

Reading Outcomes. As indicated in Table 3, students in the integrated program scored higher than the control group on all of the individual subscales of the DTLS. The total differences in scores on reading comprehension and critical reasoning are very significant $(p<0.01)$ in favor of students in the integrated program. The only insignificant difference between the two groups was on the reading comprehension submeasure, "understanding writer's assumptions, opinions, and tone."

Table 3

Post-Test Results of Descriptive Test of Language Skills, Spring 2002

\begin{tabular}{|c|c|c|c|c|c|c|c|c|c|}
\hline \multirow{2}{*}{\multicolumn{2}{|c|}{ Submeasures }} & \multicolumn{4}{|c|}{ Reading Comprehension } & \multicolumn{4}{|c|}{ Critical Reasoning } \\
\hline & & $1^{\mathrm{a}}$ & $2^{b}$ & $3^{\mathrm{c}}$ & total & $1^{\mathrm{d}}$ & $2^{e}$ & $2^{f}$ & total \\
\hline Integrated & $\begin{array}{r}\text { Mean } \\
\mathrm{SD}^{\mathrm{g}} \\
\end{array}$ & $\begin{array}{c}8.3 \\
2.02 \\
\end{array}$ & $\begin{array}{l}11.8 \\
2.72 \\
\end{array}$ & $\begin{array}{l}8.69 \\
2.51 \\
\end{array}$ & $\begin{array}{l}28.7 \\
5.59 \\
\end{array}$ & $\begin{array}{c}6.1 \\
1.17 \\
\end{array}$ & $\begin{array}{c}7.2 \\
1.94 \\
\end{array}$ & $\begin{array}{c}6.8 \\
1.82 \\
\end{array}$ & $\begin{array}{l}20.1 \\
3.71 \\
\end{array}$ \\
\hline Control & $\begin{array}{r}\text { Mean } \\
\text { SD }\end{array}$ & $\begin{array}{c}7.6 \\
2.08 \\
\end{array}$ & $\begin{array}{c}11 \\
3.14 \\
\end{array}$ & $\begin{array}{c}8.5 \\
2.44 \\
\end{array}$ & $\begin{array}{c}27 \\
6.27 \\
\end{array}$ & $\begin{array}{c}5.6 \\
1.39 \\
\end{array}$ & $\begin{array}{c}6.7 \\
1.93 \\
\end{array}$ & $\begin{array}{c}6.3 \\
2.01 \\
\end{array}$ & $\begin{array}{l}18.6 \\
4.24 \\
\end{array}$ \\
\hline \multicolumn{2}{|c|}{ Difference } & 0.7 & 0.8 & 0.19 & 1.7 & 0.5 & 0.5 & 0.5 & 1.5 \\
\hline \multicolumn{2}{|c|}{ Signifcance } & 0.002 & 0.009 & ns & 0.007 & 0.0003 & 0.014 & 0.012 & 0.0005 \\
\hline
\end{tabular}

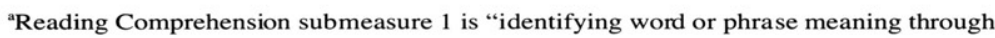
context."

${ }^{b}$ Reading Comprehension submeasure 2 is "understanding literal and interpretive meaning."

${ }^{\mathrm{c}}$ Reading Comprehension submeasure 3 is "understanding writer's assumptions, opinions and tone."

"Critical Reasoning submeasure 1 is "interpreting information."

"Critical Reasoning submeasure 2 is "using information appropriately."

${ }^{f}$ Critical Reasoning submeasure 3 is "evaluating information."

${ }^{\mathrm{g}} \mathrm{SD}$ means the standard deviation 
Students in the integrated program also scored significantly higher $(p \leq 0.05)$ than the control group on the Gates-MacGinitie total score for vocabulary and reading comprehension (see Table 4).

Table 4

Results of Gates-Maginitie Reading Test, Fall 2002

\begin{tabular}{|c|c|c|c|c|}
\hline & & Vocabulary & Comprehension & Total \\
\hline Integrated & $\begin{array}{r}\text { Mean } \\
\text { SD }^{\mathrm{a}} \\
\end{array}$ & $\begin{array}{c}27.1 \\
6.3 \\
\end{array}$ & $\begin{array}{c}33.1 \\
5.9 \\
\end{array}$ & $\begin{array}{l}60.2 \\
10.6 \\
\end{array}$ \\
\hline Control & $\begin{array}{c}\text { Mean } \\
\text { SD } \\
\end{array}$ & $\begin{array}{c}23.8 \\
5.3 \\
\end{array}$ & $\begin{array}{c}30.3 \\
5.0 \\
\end{array}$ & $\begin{array}{c}54.1 \\
8.5 \\
\end{array}$ \\
\hline \multicolumn{2}{|c|}{ Difference } & 3.3 & 2.8 & 6.1 \\
\hline \multicolumn{2}{|c|}{ Significance } & 0.05 & 0.06 & 0.03 \\
\hline
\end{tabular}

${ }^{\text {a }} \mathrm{SD}$ means the standard deviation.

Writing Portfolios. As Table 5 displays, the first portfolios of students in the integrated course received higher scores than the control portfolios on all five individual categories and in the overall evaluation of the portfolio. In two of these categories, sentences and grammar/mechanics, the differences were statistically significant $(p \leq 0.05)$. The difference in the overall evaluation of the portfolios was very significant ( $p \leq 0.01)$ in favor of those written by students in the integrated reading/writing program.

Table 5

Results of Developmental-Level Portfolio Evaluation, Spring 2002

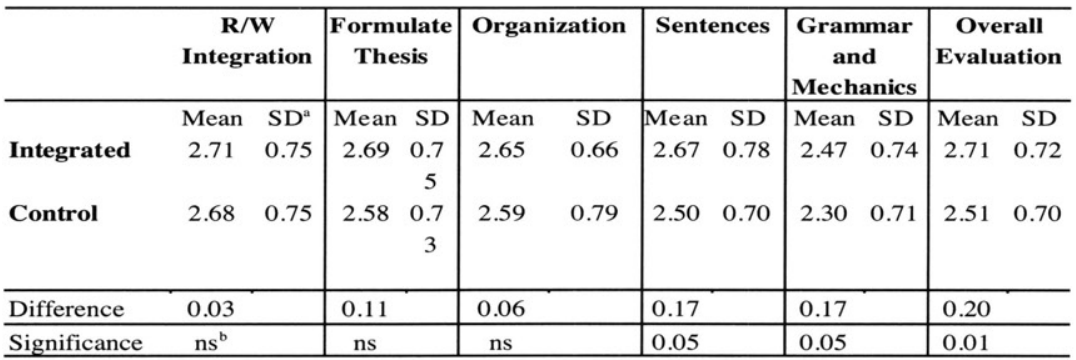

"SD means the standard deviation.

bns means "not significant." 
In spring 2002, the second semester of the integrated reading/ writing program, we collected a second set of portfolios from students in the integrated course and compared them to portfolios from students in the control group collected in fall 2002, while they were enrolled in English 114. The results of these comparisons are displayed in Table 6 . As with the first portfolio, the second portfolio from students in the integrated course received higher scores than those of the control group on all five categories and in the overall score. The score on "Reading/Writing Integration" and the overall score were significantly higher $(\mathrm{p} \leq 0.05)$ in favor of portfolios written by students in the integrated course.

Table 6

Results of First-Year Written Composition-Level Portfolio Evaluation, Fall 2002

\begin{tabular}{|c|c|c|c|c|c|c|c|c|c|}
\hline & \multicolumn{2}{|c|}{$\begin{array}{c}\mathbf{R} / \mathbf{W} \\
\text { integration }\end{array}$} & $\begin{array}{c}\text { Formulate } \\
\text { thesis }\end{array}$ & \multicolumn{2}{|c|}{ Organization } & \multicolumn{2}{|c|}{ Sentences } & $\begin{array}{c}\text { Grammar } \\
\text { and } \\
\text { mechanics }\end{array}$ & $\begin{array}{c}\text { Overall } \\
\text { Evaluation }\end{array}$ \\
\hline & Mean & SD & Mean SD & Mean & SD & Mean & SD & Mean SD & Mean SD \\
\hline Integrated & 3.05 & 0.55 & $2.82 \quad 0.54$ & 2.8 & 0.55 & 2.69 & 0.59 & $2.48 \quad 0.68$ & $2.83 \quad 0.602$ \\
\hline Control & 2.8 & 0.53 & $2.65 \quad 0.61$ & 2.76 & 0.54 & 2.57 & 0.57 & $2.50 \quad 0.65$ & 0.596 \\
\hline Difference & 0.03 & & 0.11 & 0.06 & & 0.17 & & 0.17 & 0.20 \\
\hline Significance & 0.025 & & $\mathrm{~ns}$ & ns & & $\mathrm{ns}$ & & 0.05 & 0.044 \\
\hline
\end{tabular}

Student Self-Assessments. Students enrolled in the integrated course corroborate that the course is meeting its stated objectives to make explicit the links between reading and writing and for students to gain satisfaction and confidence in their ability to make meaning. For example, a number of students wrote comments indicating they now had an "internalized reader" guiding their writing process:

I don't just think of myself when I write my essay. I think about who else is going to read my paper, so I take that into consideration and try to do my best to make the essay understandable. (Adrian)

During the [Integrated] English course, I have drastically improved on my essay in many aspects. First of all ... my essay's organization was not well-tuned, but in fact it mislead and confused my reader. Now my essay is well-oiled and guides the reader smoothly through the essay, with a general introduction that warns and prepares the reader of what's to come, 
body paragraphs that expound deeply upon the certain topic, and a conclusion that sums up what the reader read. (Sydney)

Other students made comments suggesting that the integrated course has taught them to "see" their own writing as they "see" the writing that they read:

As a writer, it is important to me to join "things" together because it shows the level the writer is at. For example, the sentences in a children's book are very short while the sentences in a novel, college level writing, are quite long in comparison. (Jason)

You learn that peer review is a process that helps you see things through the eyes of the reader. If the reader doesn't understand what you are talking about, then the paper needs some improvement. (Myeisha)

And still others commented on how the course had affected their self-perceptions as readers, writers, and learners:

It has been a long process for me to get to this point as a reader and writer. When entering this course, I really did not know anything that I have learned so far. I am glad that I did not know anything because I was able to actually LEARN in this class which is something I have not done for so long. Not only did I learn, but I learned it in different ways that seem exciting to me. (Melissa)

Every lesson taught in this course is developed to enhance your talents as a reader and writer; therefore, take advantage of every lesson. Indeed, there will be lessons that you may not appreciate at the very moment taught but believe me, these lessons will play major roles when reading and writing during this class and in future academic and non-academic experiences. I remember having little enthusiasm when first introduced to pre-reading tactics, skills like PPP, $\mathrm{KWL}+$, and notetaking, but I later found these skills to be extremely necessary when reading-duh! (Denise)

My confidence in expressing thoughts through writing was built by friends in class who have been of great support and my own improvement which made me dare for more.... While training to improve my reading skills, I've gained not only speed and accuracy with comprehension but also confidence in my learning abilities. (Tiffany) 
Second-Year Composition Pass Rates. As part of the assessment of the integrated reading/writing program, we were interested in how students progress when they leave the program and complete the next level course, second-year written composition. As Table 7 points out, students who arrived in English 214 via the integrated reading/writing program successfully completed the course at a higher rate $(97 \%)$ than those who arrived in English 214 by conventional routes (90\%).

Table 7

Second-Year Composition (English 214) Comparative Pass Rates, Fall 2002

\begin{tabular}{|c|c|c|c|}
\hline & Total Students & Total Pass & Total Not Passing \\
\hline Integrated & $76^{\mathrm{b}}$ & $74(97 \%)$ & $2(3 \%)$ \\
\hline Control $^{\mathrm{a}}$ & 967 & $869(90 \%)$ & $98(10 \%)$ \\
& & & \\
\hline
\end{tabular}

\footnotetext{
a The control group for this assessment was an aggregrate of grades from all sections of English 214, minus the grades of the 76 students from the integrated course.

${ }^{\text {b}} 94$ students were eligible to enroll in English 214 in Fall 2002 (see Table 2). Of the se 94 students, 76 enrolled in Fall 2002; two students enrolled in summer 2002, six students enrolled in Spring 2003 and ten students were no longer enrolled at the university. An unfortunate and unanticipated outcome of the one-year remediation rule: the vast majority of students who place in basic writing and reading also must also complete SFSU's math remediation requirement. We know that at least four of the ten students who were no longer at SFSU in Fall 2002 were disenrolled from the university because of failure to complete the math remediation requirement within their first year.
}

\section{Conclusions from the First-Year Assessment}

The data from the first year of the program offer compelling evidence that students in the integrated course can meet the cognitive challenges of learning to write as readers and read as writers, and that they can perform these tasks at a level of competence that places them fully into the mainstream of intellectual life at the university. At least as important from the standpoint of the one-year remediation rule, most can also meet these challenges well within their first year of enrollment.

The student self-assessments support the reading and portfolio findings that the integrated course is having a positive influence on students' literacy development and on their confidence and satisfaction as learners. Evidence in the portfolios and in students' self-assess- 
ments suggests that they are able to develop an authoritative and confident stance in their writing, that they have an "internalized reader" guiding their writing process, and that they are able to "see" their own writing the way they "see" the writing of the texts they read.

While these first-year findings paint a promising portrait of literacy development, the extent to which the integrated program can prove to be a viable response to SFSU's basic writing "crisis" will be more fully determined by corroborating data from the second and third years. We have already analyzed DTLS data from the second year, which replicates the findings from the first year. As we move forward, we reflect on a number of lessons we've learned from this first year. Given the likely effects of teacher preparation on students' achievement, we are convinced that instructors need to have extensive preparation in teaching both reading and writing. In the second year, we carefully selected three new teachers to join the initial seven, all of whom have a strong background in reading as well as composition. Meanwhile, in order to better prepare our staff of writing teachers who lack the requisite background in reading, we have conducted a number of in-service workshops on integrating reading and writing. A significant component of this ongoing teacher education has been videotaping class sessions from the first year of the program. These edited videotapes of exemplary integrated reading/writing lessons serve as a valuable resource for writing teachers who are unfamiliar with the reading curriculum and how to use reading to support writing development and for reading teachers interested in using writing to help students work through their understanding of texts. We have also made changes to our graduate program to ensure that new teachers are well prepared to teach reading and writing in a more fully integrated instructional approach. SFSU now offers a year-long graduate seminar, "Projects in Teaching Integrated Reading/Writing," a required course for students pursuing SFSU's Graduate Certificate in Teaching Postsecondary Reading and/or the Graduate Certificate in Teaching College Composition.

Without doubt, implementing the program presented here has required much collective will and effort. However, as Glynda Hull concluded in her unpublished report on Berkeley's effort to transform Subject A, "It is definitely possible to take an existing remedial program and to transform it into something different and better, for students and for instructors" (40). Recent efforts to address the basic writing crisis at such far-flung places as UC Berkeley and the City College of New York have much to teach us. Most notable among the lessons is that for the program presented here to succeed, the necessary changes must occur from the ground up, and from the top down. Far too often, concerns about curriculum, pedagogy, and composition theory are left out of administrative policy discussions about remediation. But just as 
often, we in basic writing and reading classrooms are content to ask questions only about curriculum and pedagogy and to ignore the complex ways that remediation interacts with vested institutional, economic, and political interests. For this new approach to succeed, we must be willing to consider curricular alternatives in the context of institutional change. In short, the program presented here requires change at the level of the classroom, the program, the university, and the CSU system. While executive mandates to curtail remediation may provide the impetus for change, the basic writing profession is in a position to do much more than simply respond to these directives. Rather, we can, and must, take an active role in transforming remediation in ways that are more thoroughly grounded in theories of learning and literacy and articulated assumptions about the complex institutional practice called "basic writing." By doing so, we will get closer to the root of what it takes to successfully educate the underprepared students who will inevitably continue to find their way to the university, and we will do so in a manner that proactively defends their right to higher education.

\section{Authors' Acknowledgement}

We want to express our gratitude for the thorough and helpful comments by the JBW editors on an earlier draft of this article and a special thanks to Barbara Ustanko for her invaluable editorial assistance. The Integrated Reading/Writing program described in this article is funded by the U.S. Department of Education's Fund for the Improvement of Postsecondary Education, Grant \#P116B011242-03.

\section{Notes}

1. Students who are "disenrolled" have a block placed on their registration. They can have their registration at SFSU reinstated if they show evidence that they have completed comparable course work at a community college within one semester of being disenrolled. After one semester, they must reapply for admission to the university. Seventeen percent of first-time freshmen admitted to SFSU in fall 2000 were disenrolled from the university in fall 2001 for failure to comply with the one-year remediation requirement. No accurate figures are currently available for how many of these students made their way back to the university.

2. SFSU offers an MA in Composition and a "Graduate Certificate in Teaching College Composition" as well as a "Graduate Certificate in Teaching Postsecondary Reading." 
3. Based on our pre-2001 experimentation, the course instructors recommended a change to our grading system for the integrated course. In order to meet SFSU's first-year written composition requirement, students must pass the integrated course with a B- or better. Students who get a C or lower need to enroll in English 114, SFSU's first-year written composition course. In rare cases, some students who don't pass the course will not be allowed to enroll in English 114 and will have failed to meet the CSU remediation requirement.

4. Subject A is the University of California's equivalent to the CSU English Placement Test. All students who enter the University of California as freshmen must demonstrate their command of the English language by taking the Subject A examination (with some exemptions allowed). Those who do not pass the Subject A exam can meet the requirement by taking a specially designated composition course.

5. Enrollment in all SFSU developmental reading and writing classes is limited to 18 students, and so we had room to accommodate 180 students in the program. In fall 2001, target enrollments were down campus-wide. All writing classes with a size limit of 18 averaged 16 students per class.

6. The DTLS (Princeton, NJ: Educational Testing Service [MAPS Division],1995) is a well established set of four tests designed to be used in a variety of situations ranging from large-scale screening and placement of entering students to identification of an individual's learning needs. The reading comprehension test consists of 45 questions, administered in 45 minutes; the critical reasoning test consists of 30 questions, administered in 45 minutes. We use Forms M-K-3KDT and M-K3LDT (pre- and post-test, respectively). Because this test has been used by all faculty teaching developmental reading classes on the SFSU campus for more than twenty years, and because the reading skills it assesses are equivalent to those measured on the CSU English Placement Test [EPT], we have found it to provide the necessary detailed information with which to counsel students on their reading strengths and needs that are not provided for by the EPT. Also, over the years, we have found a high correlation between students' scores on the DTLS with placements based on EPT scores. Lastly, the DTLS normative sample includes a student population from 11 two-year colleges and 24 four-year colleges, regionally drawn across the U.S. The sample includes an ethnically diverse group of students who have been enrolled in regular and remedial/developmental courses, and a proportionate number of ESL students - a population very like the student population attending SFSU. 
7. The Gates-MacGinitie Reading Test for adult readers (GatesMacGinitie Reading Tests, Fourth Edition, Level AR [Adult Reading], Forms S \& T, Itasco, IL: Riverside Publishing, 2000) is wide-ranging in difficulty, reflecting the great variation in reading competence in an adult population. We selected it for use in the integrated reading/writing program because it is appropriate for older readers entering college programs; its format is simple, clear, and familiar, and the content of Level AR is mature, reflecting the interests of older students. The Vocabulary Test (20 minutes) contains 45 questions, measuring word knowledge. The Comprehension Test (35 minutes) contains a total of 48 questions that probe students' understanding of passages. Some questions require the student to construct an understanding based on information that is explicitly stated in the passage; others require the student to construct an understanding based on information that is implicit in the passage. The Gates-MacGinitie Test provides important information to help teachers discover students' ineffective reading strategies and to answer representative questions such as: 1) As a group, how well do the students read? 2) Are the students, as a group, progressing in reading at about the rate one would expect? Are they catching up? 3) Has a new set of materials or procedures made any difference in how well the students read? 4) Which students may need special attention?

8. We used a modified portfolio checklist developed by Soliday and Gleason. A copy of this checklist is available from the authors.

\section{Works Cited}

Ackerman, John M. “Reading, Writing, and Knowing: The Role of Disciplinary Knowledge in Comprehension and Composing." Research in the Teaching of English 25.2 (1991): 133-78.

Astin, Alexander W. What Matters Most in College? Four Critical Years Revisited. San Francisco: Jossey-Bass, 1993.

Emig, Janet. The Web of Meaning: Essays on Writing, Teaching, Learning and Thinking. Portsmouth, NH: Boynton/Cook, 1983.

Flood, James, and Diane Lapp. "Reading and Writing Relations: Assumptions and Directions." The Dynamics of Language Learning. Ed. J. Squire. Urbana, IL: NCTE, 1987. 9-26.

Goen, Sugie. "Re-considering Remediation: A Case Study of Basic Writing in the California State University." Diss. Stanford U, 1997.

Hull, Glynda. "Alternatives to Remedial Writing: Lessons from Theory, from History, and a Case in Point." Unpublished manuscript, 1998. Institute for Higher Education Policy. College Remediation: What It Is, What It Costs, What's at Stake. Washington, DC, 1998.

Kutz, Eleanor, Suzy Groden, and Vivian Zamel. The Discovery of Com- 
petence: Teaching and Learning with Diverse Student Writers. Portsmouth, NH: Boynton/Cook, 1993.

McCormick, Kathleen. The Culture of Reading and the Teaching of English. New York: Manchester UP, 1994.

Nelson, Nancy, and Robert Calfee, eds. The Reading-Writing Connection. Chicago, IL: The National Society for the Study of Education, 1998.

Petrosky, Anthony. "From Story to Essay: Reading and Writing." College Composition and Communication 33 (1982): 19-36.

Salvatori, Mariolina. "Conversations with Texts." College English 55.4 (1996): 440-54.

Shor, Ira. "Our Apartheid: Writing Instruction and Inequality." Journal of Basic Writing 16.1 (1997): 91-104.

Soliday, Mary, and Barbara Gleason. "From Remediation to Enrichment: Evaluating a Mainstreaming Project." Journal of Basic Writing 16.1 (1997): 64-78.

Spivey, Nancy Nelson, and James King. "Readers as Writers Composing from Sources." Reading Research Quarterly 24.2 (1989): 7-26.

Stotsky, Sandra. "Research on Reading/Writing Relationships: A Synthesis and Suggested Directions." Composing and Comprehending. Ed. J. Jensen. Urbana, IL: ERIC Clearinghouse on Reading and Communication Skills and NCRE, 1984. 7-22.

Tierney, Robert J., and Margie Leys. "What Is the Value of Connecting Reading and Writing?" Convergences: Transactions in Reading and Writing. Ed. Bruce T. Peterson. Urbana, IL: NCTE, 1986. 15-29.

Troyka, Lynn. "Closeness to Text: A Delineation of Reading Processes as They Affect Composing." Only Connect: Uniting Reading and Writing. Ed. Thomas Newkirk. Portsmouth, NH: Boynton/Cook, 1986. 187-97.

Zamel, Vivian. "Writing One's Way into Reading." TESOL Quarterly 26.3 (1992): 463-85. 


\title{
News and Announcements
}

The Conference on Basic Writing (CBW) is pleased to announce the winners of its first annual AWARD FOR INNOVATION. Please join us in congratulating

\author{
San Francisco State University, Literacy Unleashed \\ An Integrated Approach to Reading and Writing. \\ Application submitted by Professor Helen P. \\ Gillotte-Tropp.
}

The University of Wyoming, The Synergy Project: A Learning Community for At-Risk and Basic Writing Students. Application submitted by Professor Kelly Belanger.

The application materials were judged on specific criteria: Originality - the creativity and uniqueness of the innovation; Portability - the extent to which the innovation lends itself to application in other institutions or contexts; Results and Benefits - specific details, data, and observations derived from the innovation, focusing on specific educational benefits to students. The winning schools will be presented with a plaque at the Special Interest Group (SIG) meeting at the 2004Conference of College Composition and Communication, in San Antonio. Winners also will be invited to give a brief presentation about their award-winning innovative program to SIG members. For more information on the Conference on Basic Writing, see: http://www.asu.edu/ clas/english/composition/cbw/

CONGRATULATIONS to both San Francisco State University and the University of Wyoming - and many thanks to everyone who submitted an award application.

\section{Conference Announcement and Call for Proposals Assembly for the} Teaching of English Grammar (ATEG) Fifteenth Annual Conference July 16-17, 2004, Seattle University, Seattle, Washington. Pre-Conference Mini-Course: July 14-15, 2004. We welcome proposals for the conference program on all grammar-related topics, both theory and classroom practice. Proposals may describe, analyze, and/or critique any and all aspects of the teaching of grammar in our schools, at all levels, from any perspective. Conference program proposals should be no more than one page, double-spaced, $12 \mathrm{pt}$. font. Send proposals by May 20, 2004 either electronically or by mail to: Kristin Denham, Dept. of English, 516 High St, Western Washington University, Bellingham, WA 
98225. Email: kristin.denham@wwu.edu. The Pre-Conference MiniCourse for K-12 and college teachers will focus on "Grammar in the Writing Classroom." Mini-course faculty will include grammarians, linguists, and teachers of writing and literature. Graduate credit through Central Washington University and clock hours will be available. The conference and pre-conference mini-course will be held on the campus of Seattle University, close to downtown Seattle. Seattle University dorm rooms will be available for $\$ 26$ per person (in a shared room; $\$ 39$ for a single room). Hotel space is reserved at the charming Inn at Virginia Mason, within walking distance of both Seattle University and downtown Seattle ( $\$ 85$ for a room with two twin-size beds; $\$ 105$ for one queen-size bed; hotel prices do not include $15.8 \%$ tax). For information on conference registration and on the pre-conference minicourse contact: Michael Kischner, North Seattle Community College, Seattle, WA 98103. Tel: 206 528-4540. Email: mkischner@sccd.ctc.edu

$3^{\text {th }}$ RELC International Seminar on Innovative Approaches to Reading \& Writing Instruction, Singapore - April 19-21, 2004. The Regional Language Centre (ELC), an educational project of of the Southeast Asia Ministers of Education Organization (SEAMO) will hold its annual International Seminar in Singapore from April 19-21. Plenary speakers include Dick Allwright, Anne Burns, Stephen Krashen, Paul Nation, Moses Samuel, and Ruth Wong. Registration deadline is March 27. Information at admn@relc.org.sg or www.relc.org.sg 


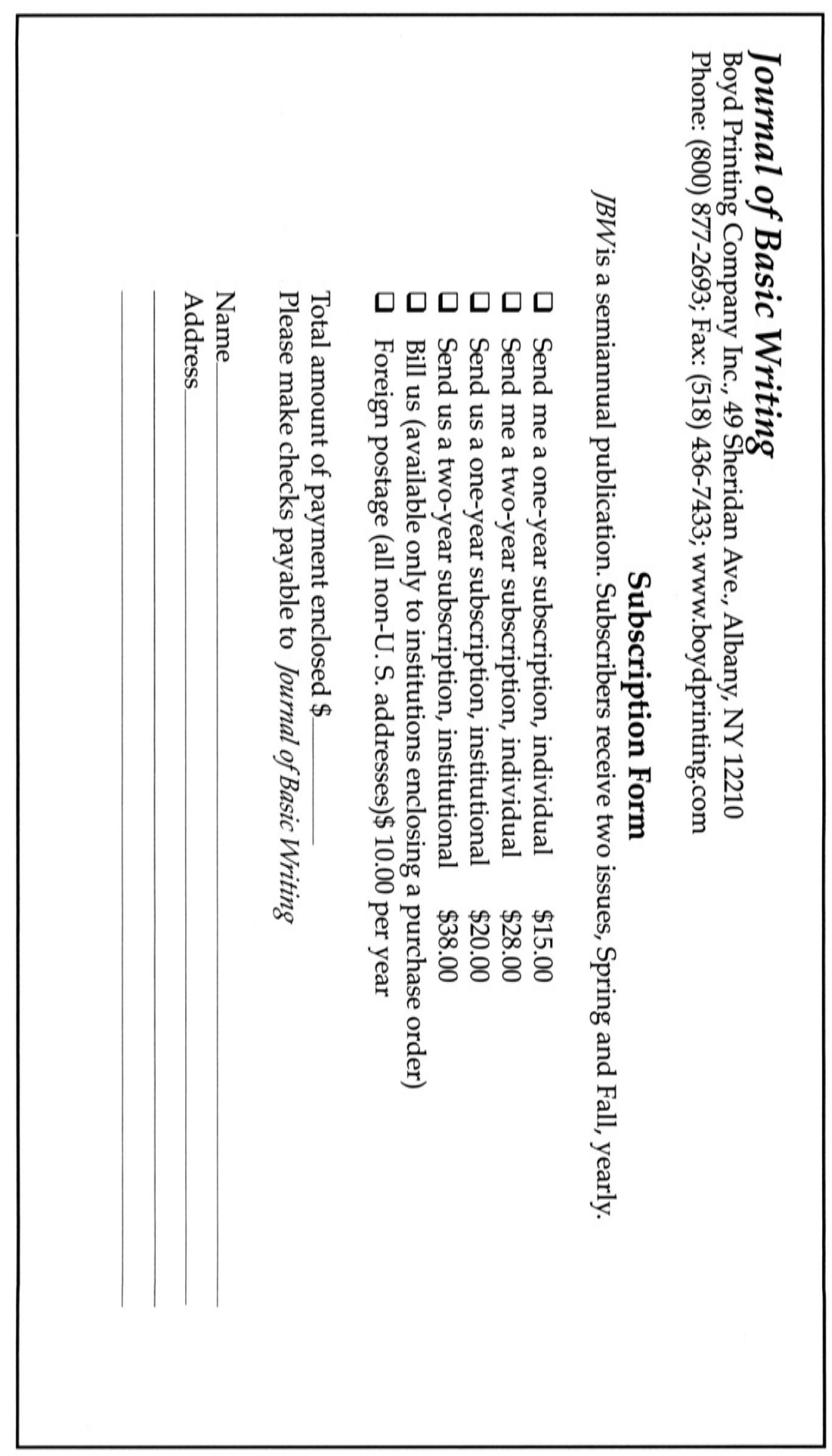




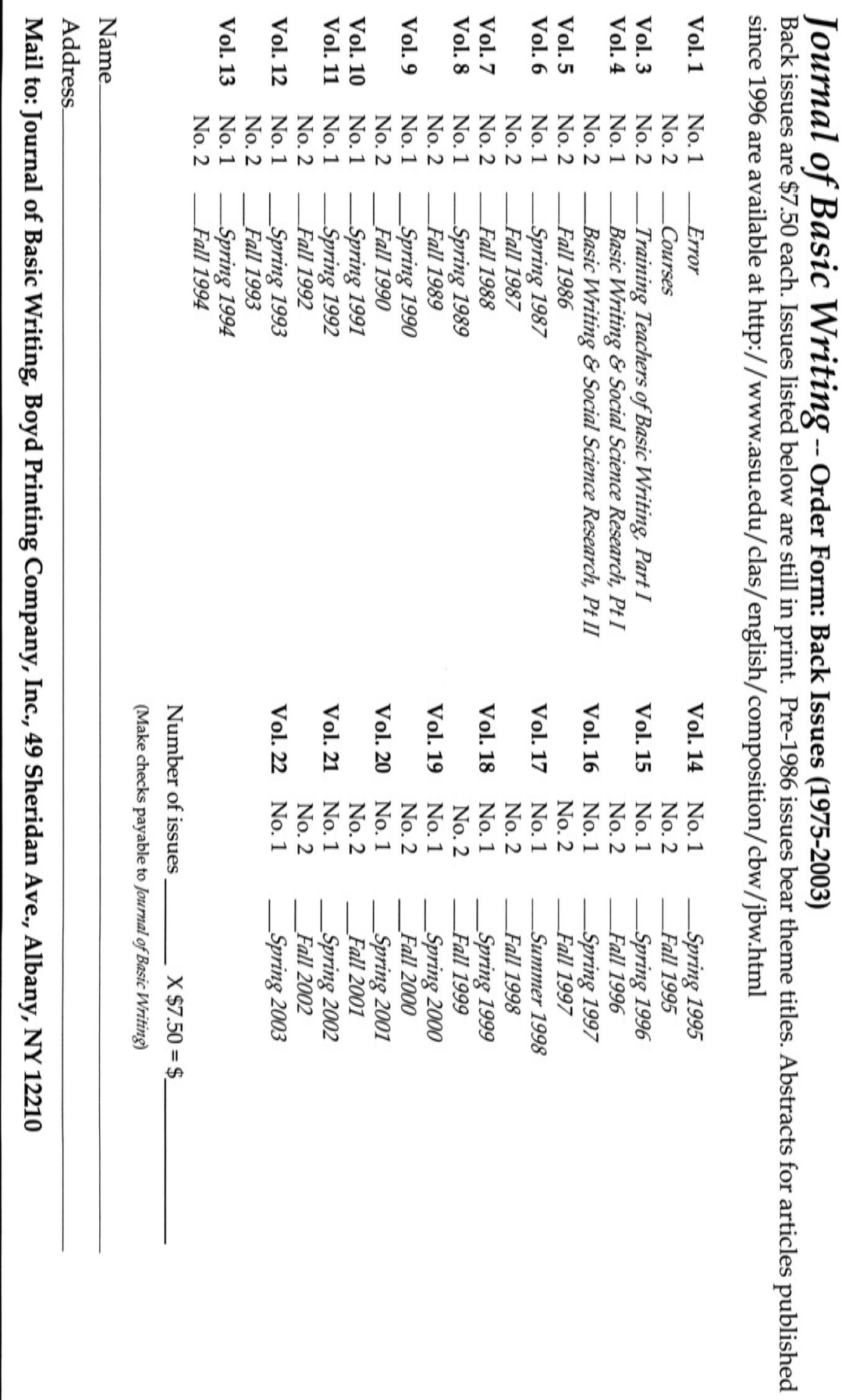








